\title{
Extensão da Ferramenta de Apoio à Programação Paralela (F.A.P.P.) para Ambientes Paralelos Virtuais
}

KALINKA REgINA LUCAS JAQUIE

Orientador: Prof. Dr. Marcos José Santana

Dissertação apresentada ao Instituto de Ciências Matemáticas e de Computação da Universidade de São Paulo - ICMC/USP, como parte dos requisitos para a obtenção do título de Mestre em Ciências - Área de Ciências de Computação e Matemática Computacional.

USP - São Carlos

Fevereiro/1999 
Ao Luiz Henrique, Rosa, Lubienska e Gustavo Henrique, pelo apoio e dedicação. 


\section{Agradecimentos}

Ao amigo, orientador e Professor Dr. Marcos José Santana, pela orientação, acompanhamento e paciência, amizade sempre sincera que dedicou a este trabalho e a mim.

À Professora Drª Regina Helena C. Santana, pelos "helps" e por ser a "mamãezona" de todos nós.

Ao Luiz Henrique (meu marido), cujo incentivo, dedicação, apoio e companheirismo foi essencial para a realização desse trabalho.

À minha família e principalmente minha mãe Rosa, que souberam compreender minha ausência e sempre me incentivam.

Ao amigo Professor Peron pelo incentivo e apoio.

Aos Professores Araújo e Dagoberto pela confiança demostrada.

À Beth, Laura e Marília, por sempre estarem dispostas a ajudar no que fosse preciso, na Secretaria da Pós-Graduação.

Aos companheiros e amigos de mestrado: Célia, Maria Helena, Sarita, Renata, Roberta, Flávio, Rita, Ana, Paulo, Simone, Adriana, Helder, Silmara, Aletéia, Renato, Rejane, Andrezza, Jorge, Daniel, Edmilson, Tatiana, Fernanda e muitos outros, que de uma maneira ou de outra contribuíram para a realização deste trabalho.

Às moças da biblioteca, sempre muito prestativas e atenciosas.

Ao Tio Zé, Da . Olga e Lú, pela simpatia no atendimento do "redondo".

À FAPESP pelo apoio financeiro.

A Deus, por estar sempre presente em minha vida.

A todos aqueles que contribuíram de forma direta e indireta para a realização deste trabalho. 


\section{Resumo}

Os sistemas computacionais distribuídos aplicados à computação paralela permitem uma melhor relação custo/benefício para a computação paralela. Esses sistemas oferecem a potência computacional adequada às aplicações que não necessitam de uma máquina maciçamente paralela, porém necessitam de uma potência computacional maior que uma máquina seqüencial pode oferecer.

P.V.M. (Parallel Virtual Machine) e M.P.I. (Message Passage Inteface) são exemplos de ambiente de paralelos virtuais amplamente discutido na literatura. Tendo em vista a grande utilização desses ambientes tanto em nível acadêmico quanto em níveis comerciais e industriais, torna-se interessante a criação de uma ferramenta que apoie o desenvolvimento de programas para esses ambientes. Poucas são as ferramentas desse tipo que aparecem na literatura; uma delas e que permite ser estendida para dar suporte a tais ambientes é a F.A.P.P. (Ferramenta de Apoio à Programação Paralela).

Dentro desse contexto, este trabalho apresenta a modelagem dos ambientes paralelos virtuais segundo a abordagem proposta na definição da F.A.P.P., para que arcabouços de programas P.V.M. e M.P.I possam ser gerados. Essa ferramenta permite a utilização da computação paralela a um maior número de usuários, ou seja, auxiliando os iniciante na confecção dos programa e os experientes na manutenção, além de permitir maior produtividade.

Foram realizados estudos visando a validação e a avaliação da ferramenta. Os resultados obtidos demonstram que a ferramenta possui comportamento estável e tem potencial para ser utilizada livremente em ambientes P.V.M. e M.P.I.. 


\begin{abstract}
Distributed computing systems applied to parallel computing allow the realisation of a better cost/benefit relation for parallel programming. These systems offer an adequate computing power to those applications which do not require a massively parallel architecture but need such a computer power not available from sequential computers.

P.V.M. (Parallel Virtual Machine) and M.P.I. (Message Passing Interface) are good examples of parallel virtual environments being widely discussed in the literature. These virtual environments are broadly used in both academic, commercial and industrial applications, making attractive the development of supporting tools for these parallel programming environments. There are few of such tools available in the literature. F.A.P.P. is one of these tools and it can be extended to support parallel virtual environments.
\end{abstract}

This work addresses the extension of the F.A.P.P. in order to produced P.V.M. and M.P.I. source code. This extension can help a large number of users to develop parallel programs either by giving support for the beginners or by increasing the productivity of the experienced parallel programmers, besides helping in the maintenance phase.

The tool produced is tested by means of several examples which show a stable behaviour and that the tool can be easily used in both P.V.M. and M.P.I. environments. 


\section{CONTEÚDO}

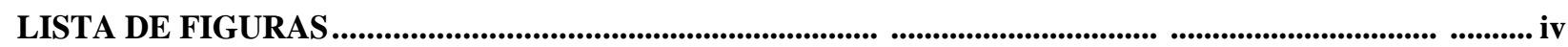

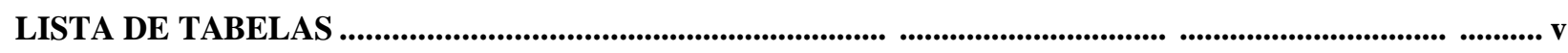

1. INTRODUÇÃ

2. PROGRAMAÇÃO CONCORRENTE/PARALELA.......................................................................... 16

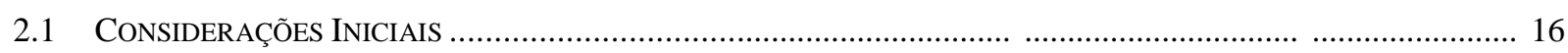

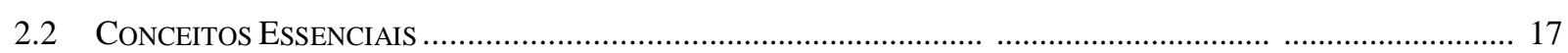

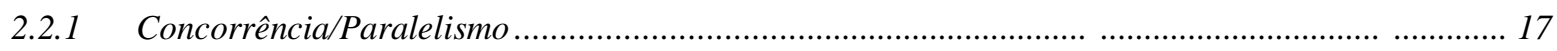

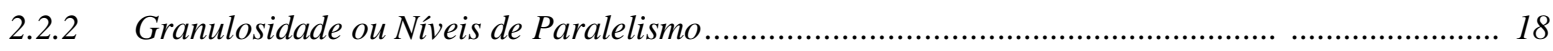

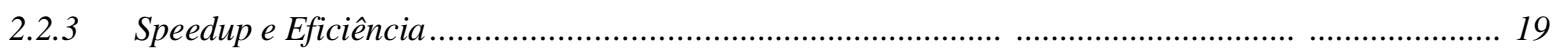

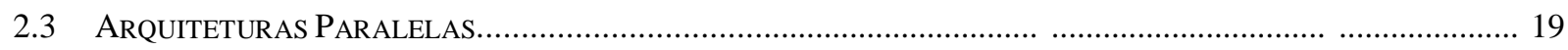

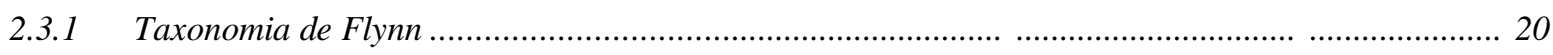

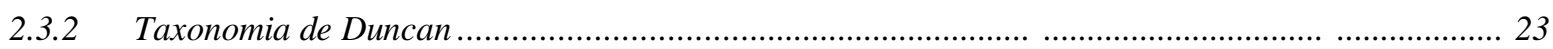

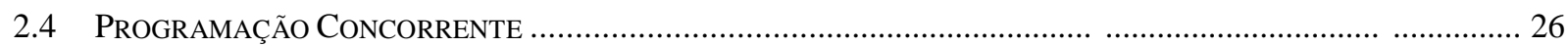

2.4.1 Especificação de Execução Concorrente ………........................................................................ 26

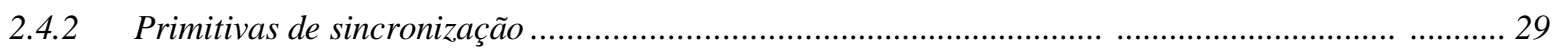

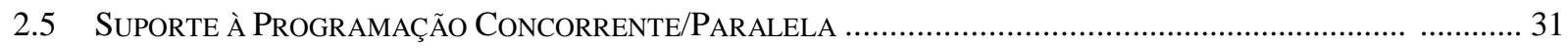

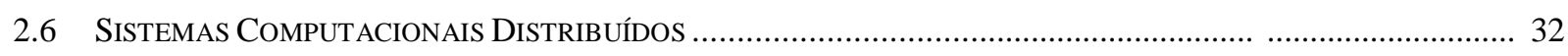

2.6.1 Características Essenciais de um Sistema Distribuído …………............................................... 33

2.6.2 Modelos Arquiteturais Clássicos, Compostos e Avançados .......................................................... 34

2.6.3 Comunicação

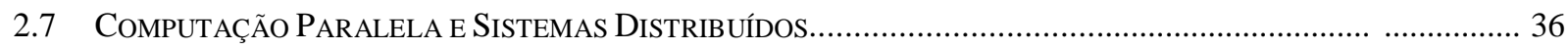

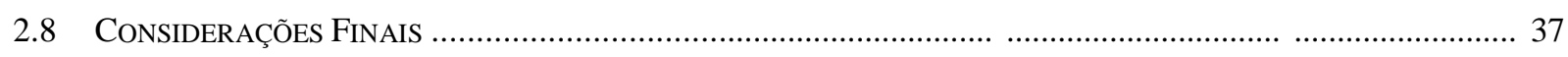

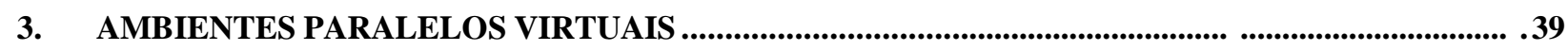

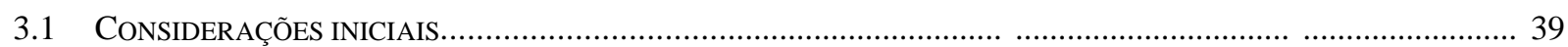




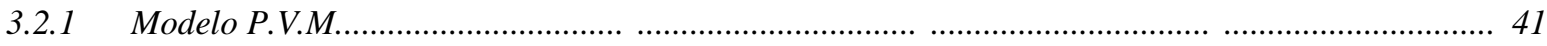

3.2.2 Componentes do P.V.M......................................................................................................42

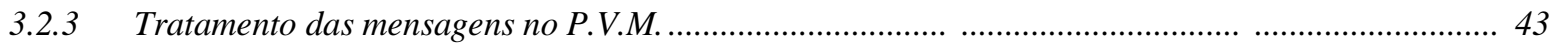

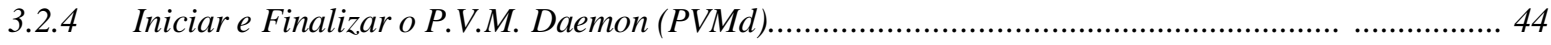

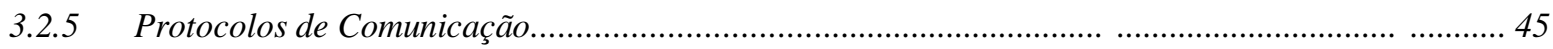

3.2.6 Tolerância a Falhas........................................................................................................ 45

3.2.7 P.V.M. em Sistemas com Multiprocessadores …............................................................... 46

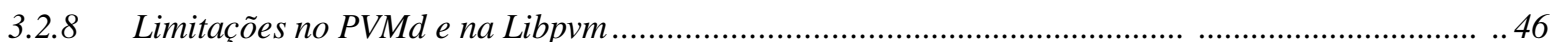

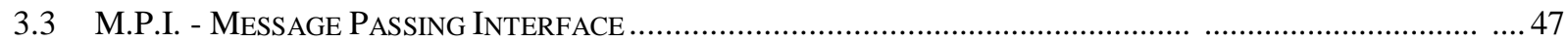

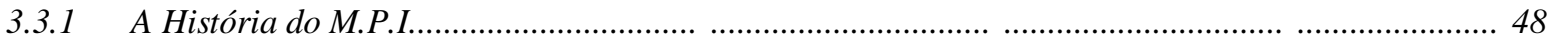

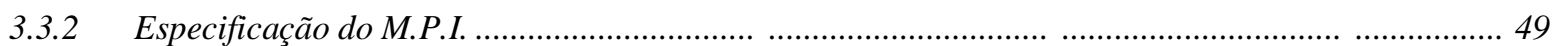

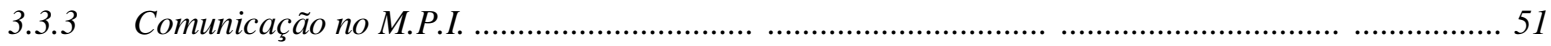

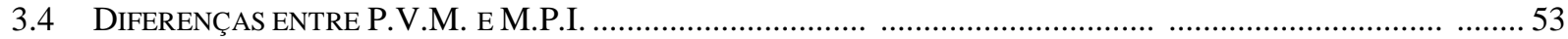

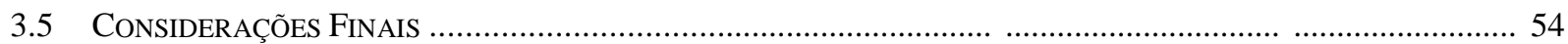

4. FERRAMENTAS PARA DESENVOLVIMENTO DE PROGRAMAS PARALELOS .......................57

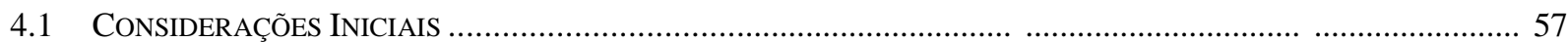

4.2 MotivaÇão Para o Uso de Ferramentas de Apoio À ProgramaÇão ............................................... 58

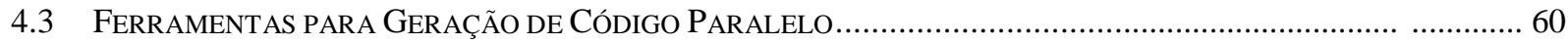

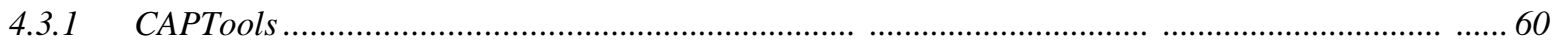

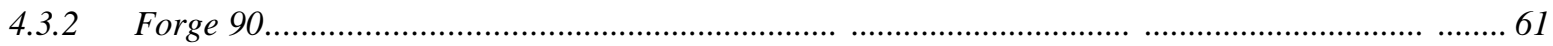

4.3.3 Sistema de Compilação Fortran Vienna (VFCS) .................................................................62

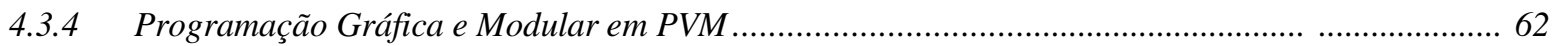

4.3.5 Ferramenta de Apoio à Programação Paralela (F.A.P.P.)...................................................64

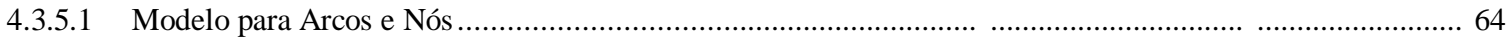




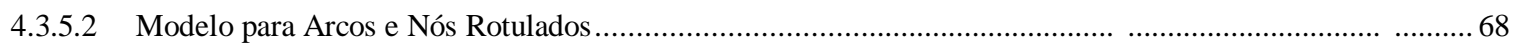

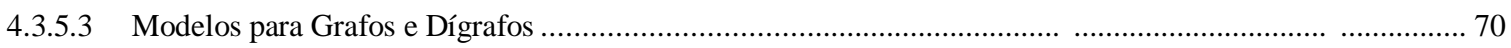

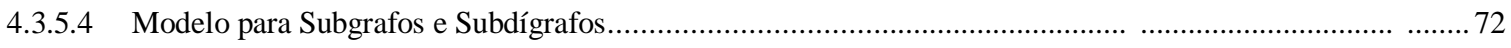

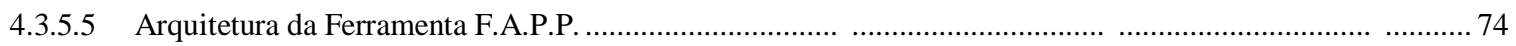

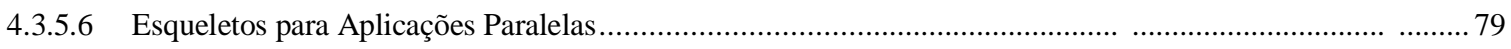

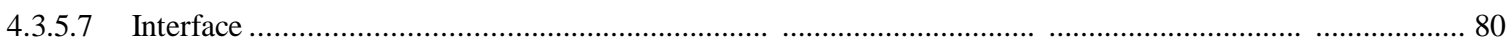

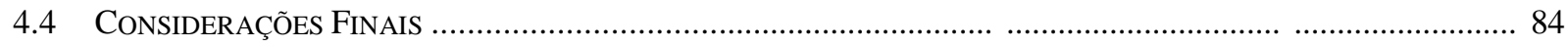

5. APLICANDO A ABORDAGEM DA F.A.P.P. PARA APLICAÇÕES PARALELAS VIRTUAIS .........87

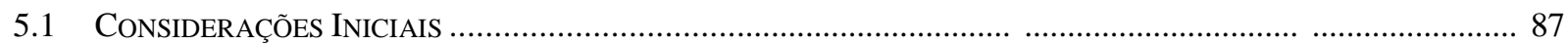

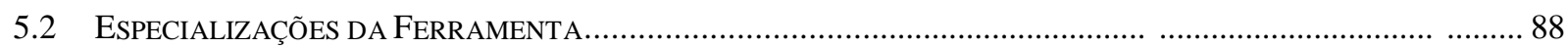

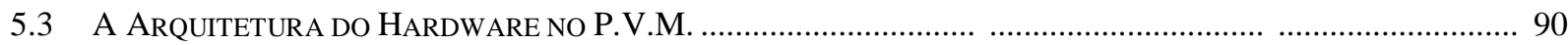

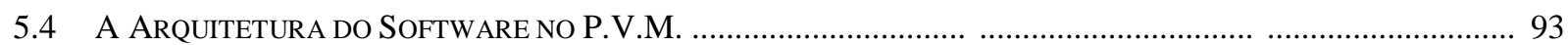

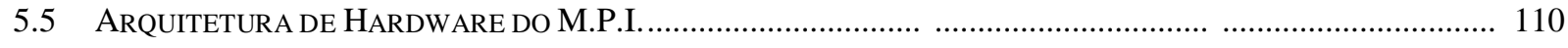

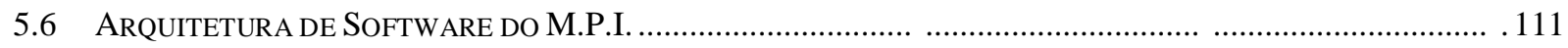

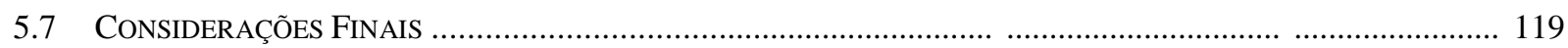

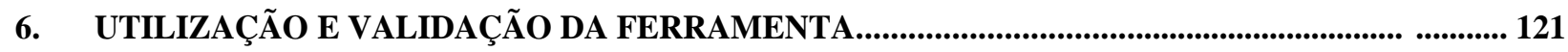

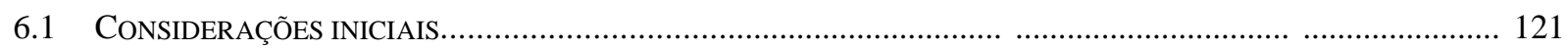

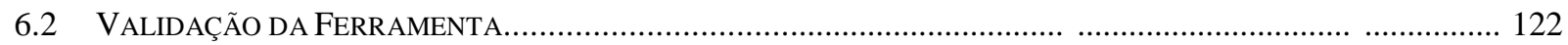

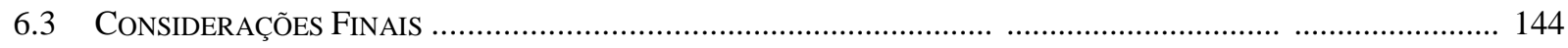

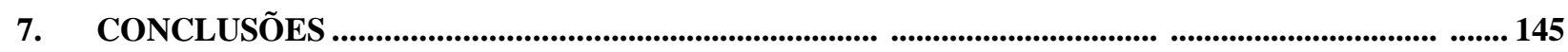

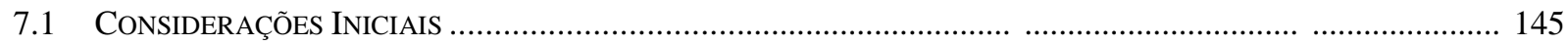

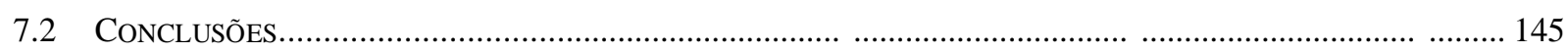

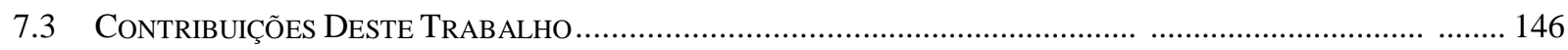

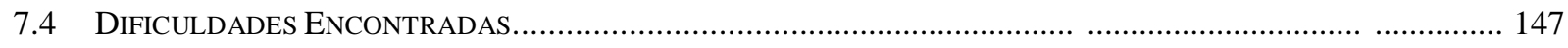

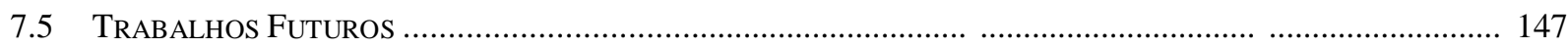




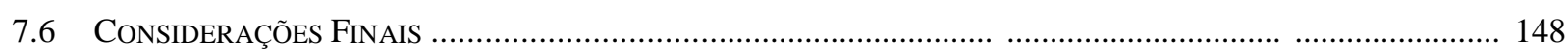

8. REFERÊNCIAS BIBLIOGRÁFICAS ................................................................................................... 149 


\section{LISTA DE FIGURAS}

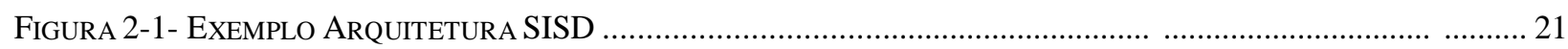

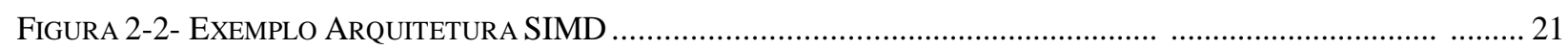

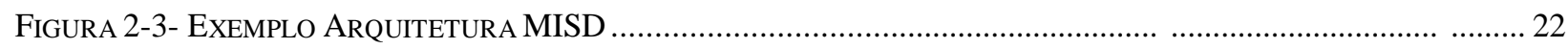

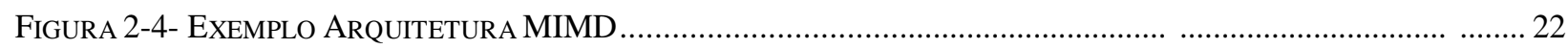

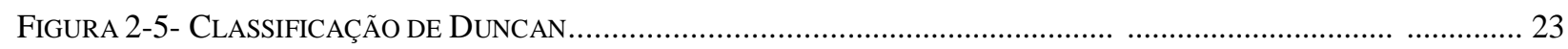

FIGURA 2-6- ESTRUTURA DE ARQUITETURA MIMD DE MEMÓRIA DISTRIBUÍDA..................................................... 24

FIGURA 2-7 - ESTRUTURA DE ARQUITETURA MIMD COM MEMÓRIA COMPARTILHADA............................................... 25

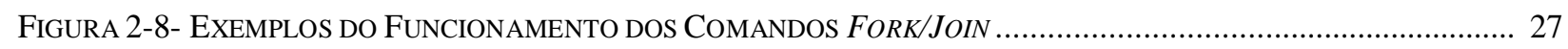

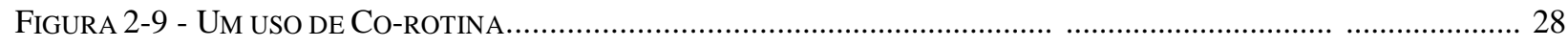

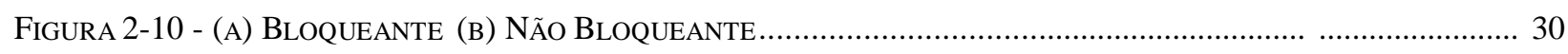

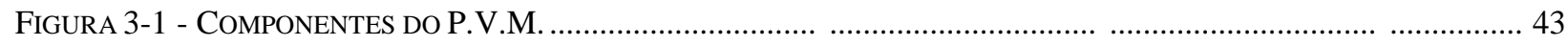

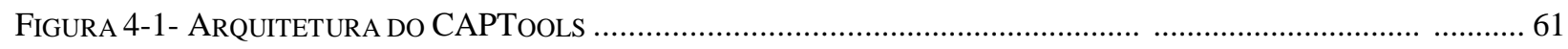

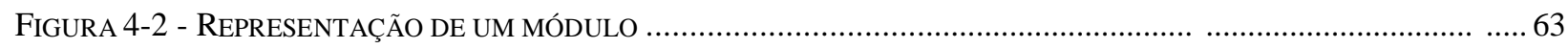

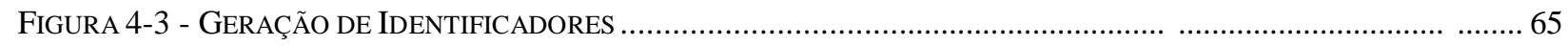

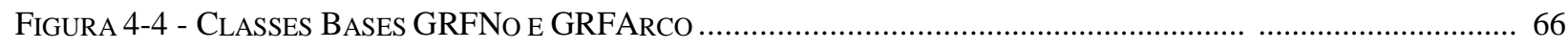

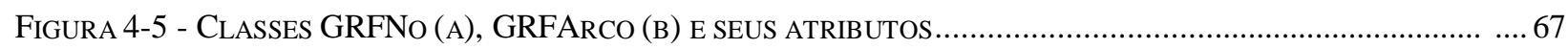

Figura 4-6 - Classe Para a Geração de ObJetos Persistentes ...................................................................... 67

Figura 4-7 - Classe Para a RePReSentaÇão de Nós Rotulados .................................................................. 68

FIGURA 4-8 - ClasSES DE GRFRotULO, GRFNoRotulAdo, GRFARCO .............................................................. 69

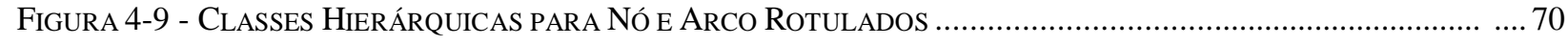

Figura 4-10 - ClasSe Para Gerenciamento dos Objetos do Sistema............................................................ 71

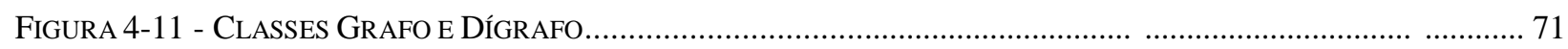

FIGURA 4-12 - ClaSSE SUPERNó E SUPER-ARCo ………........................................................................... 72

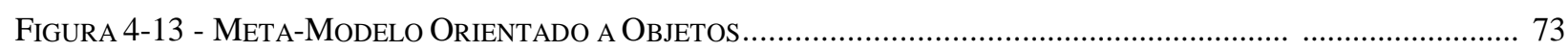




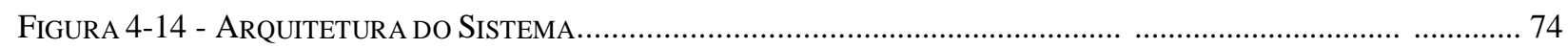

Figura 4-15 - Classes-Base Para o Modelo dos Componentes das ARQuiteturas ….................................... 76

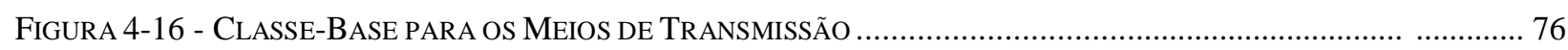

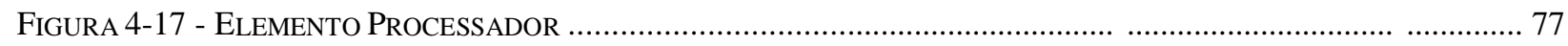

FIGURA 4-18 - REPRESENT AÇÃO GRÁFICA DOS GRAFO DE CONEXÃO DOS ELEMENTOS PROCESSADORES ......................77

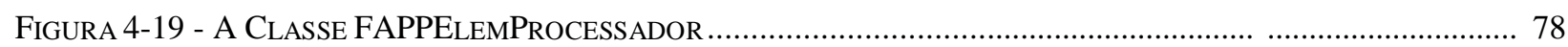

FIGURA 4-20 - HIERARQUIA DE CLASSES PARA A TAXONOMIA DE DUNCAN ……............................................. 78

Figura 4-21 - Um Modelo Para Programas Paralelos ................................................................................ 79

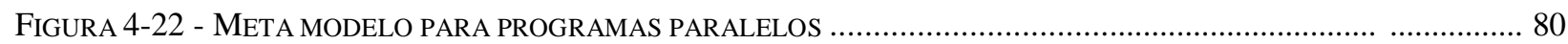

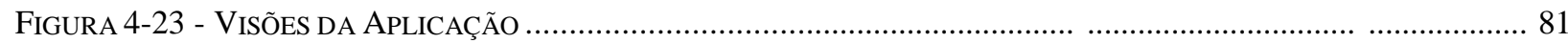

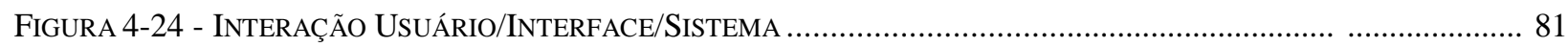

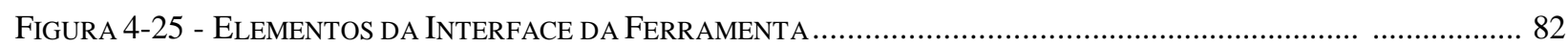

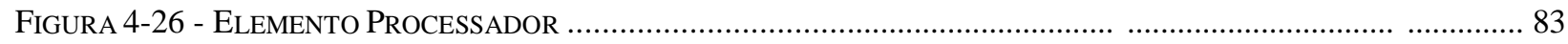

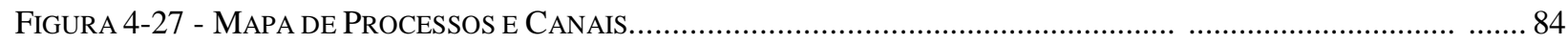

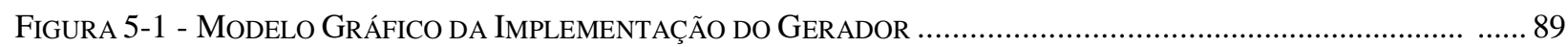

FIGURA 5-2 - CADASTRO DE PROCESSADORES ............................................................................................ 91

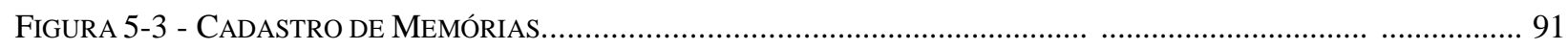

Figura 5-4 - Modelo de ObJetos - Componentes de Hardware ............................................................... 92

Figura 5-5 - Gerador de Protótipo de APlicações Para Ambientes Paralelos Virtuais............................ 94

Figura 5-6 - Modelo de ObJetos - Componentes de Software …………………........................................... 95

FIGURA 5-7 - GRAFO DAS TAREFAS E SUAS COMUNICAÇÕES S.P.M.D.......................................................... 96

FIGURA 5-8- GRAFO DAS TAREFAS E SUAS COMUNICAÇÕES M.P.M.D............................................................ 102

FIGURA 5-9- GRAFO DAS TAREFAS E SUAS COMUNICAÇÕES S.P.M.D. (M.P.I.) ................................................... 111

FIGURA 5-10- GRAFO DAS TAREFAS E SUAS COMUNICAÇÕES M.P.M.D........................................................... . 115 


\section{LISTA DE TABELAS}

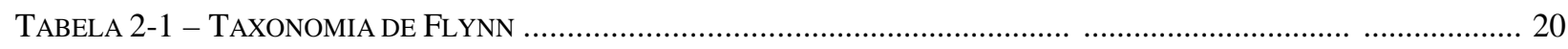

TABELA 3-1 - ALGUNS DOS PRINCIPAIS EQUIPAMENTOS QUE EXECUTAM O PVM................................................. 41

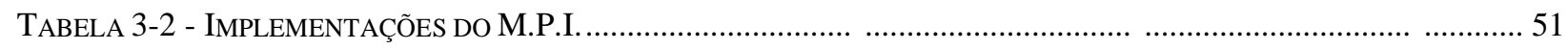

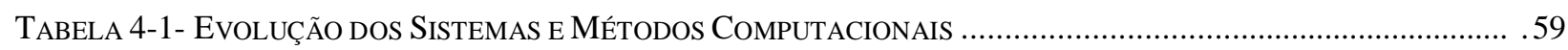




\section{Introdução}

A computação é, sem dúvida, uma área que experimentou um desenvolvimento sem comparação ao longo das últimas quatro décadas. O desenvolvimento do hardware sempre foi sustentado e motivado pelo desenvolvimento da eletrônica. O desenvolvimento do software, entretanto, não acompanha o do hardware na mesma velocidade [PRE95] e uma das maiores barreiras observadas é a dificuldade em se atingir portabilidade e a dificuldade em se migrar de um paradigma de programação para outro, em função do desenvolvimento das arquiteturas de computadores, por exemplo [ZAL91].

Um dos entraves que se encontra na área da programação paralela corresponde ao forte acoplamento existente entre o software em desenvolvimento e o hardware alvo, isto é, o software é, normalmente, fortemente dependente do hardware e o desenvolvimento visando bom desempenho (um dos objetivos fundamentais da computação paralela) leva à necessidade de se adequar, de modo coerente, o software ao hardware [FOS95, HOA85, AND83]. Outro fator preocupante nesta área ainda é o custo. Na tentativa de solucionar essa situação, apareceram os sistemas distribuídos, que tiveram como objetivo inicial o compartilhamento de recursos [COU94].

Com a necessidade do compartilhamento de recursos, sistemas, antes centralizados, sofreram mudanças em seus modelos arquiteturais e beneficiaram-se da utilização de computadores autônomos conectados por uma rede de comunicação.

O desenvolvimento de software seqüencial, destinado à execução em máquinas tradicionais, que seguem a arquitetura de von Neumann, é uma área bem estabelecida, contando com uma gama diversificada de ferramentas de apoio ao desenvolvimento, depuração e avaliação. Por outro lado, o desenvolvimento de software paralelo, destinado à execução em máquinas baseadas em arquiteturas paralelas, ainda não possui um elenco bem definido e bem estabelecido de ferramentas e metodologias de apoio ao desenvolvimento, depuração e avaliação [PRE95].

Algumas metodologias e ferramentas de apoio têm sido propostas e implementadas nos últimos anos, visando cobrir a lacuna existente na área de programação paralela/concorrente [ZIM92, JON96]. Uma contribuição nessa área corresponde à ferramenta denominada $\boldsymbol{F} . \boldsymbol{A} . \boldsymbol{P} . \boldsymbol{P}$. (Ferramenta de Apoio à Programação Paralela), proposta em um programa de doutorado desenvolvido dentro do Grupo de Sistemas Distribuídos e Programação Concorrente do ICMCUSP [CAL97]. O desenvolvimento da F.A.P.P. apresenta uma infra-estrutura de apoio para o desenvolvimento de programas paralelos. Porém, como já enfatizado nesta introdução, em se tratando de software paralelo, o seu desenvolvimento está intimamente ligado à arquitetura alvo.

A F.A.P.P. é uma ferramenta implementada com base em uma modelagem orientada a objetos, que considera o hardware (a taxonomia de Duncan foi considerada [GIL81, DUN90]) com seus elementos básicos (processadores, memória, canais de comunicação, etc.) e o software. 
Ambos são modelados a partir da teoria dos grafos [MAL74, BOA79] e segundo o paradigma da orientação a objetos [COL96 MAR96]. Assim, software e hardware são reduzidos a um grafo e o modelo global produzido é totalmente orientado a objetos. Isso permite o estabelecimento da ferramenta $\boldsymbol{F}$.A.P.P., que utiliza a metodologia de desenvolvimento de programas desenvolvida por Foster [FOS95], que propõe um desenvolvimento análogo ao utilizado em programas seqüenciais, seguindo a técnica de programação por esqueleto proposta por Zima e Chapman [ZIM92] .

A F.A.P.P. é baseada em uma técnica de modelagem, que permite a incorporação de novas tecnologias, tanto em nível de hardware como de software. Dessa forma, a primeira especialização da ferramenta, foi desenvolvida (por razões históricas) para programação baseada em Occam2 e transputers [JOH96, HOA78, INM90]. A ferramenta está operacional para esse ambiente de programação e o objetivo desta dissertação de mestrado é o desenvolvimento da modelagem necessária e da especialização da $\boldsymbol{F . A . P . P . ~ p a r a ~ a m b i e n t e s ~ p a r a l e l o s ~ v i r t u a i s . ~}$

A escolha de ambientes paralelos virtuais, que correspondem atualmente às plataformas de passagens de mensagens (ou plataformas de portabilidade) executando sobre sistemas computacionais distribuídos, está intimamente ligada à vasta utilização e difusão desses ambientes, nas mais diferentes áreas do conhecimento [BEG94, GEI94, GRO95].

A computação paralela em ambientes paralelos virtuais é bastante versátil, permitindo que a busca por alto desempenho possa ser exercitada a partir de plataformas computacionais distribuídas. Isso traz benefícios diversificados, incluindo uma possível queda na relação custo/benefício da computação paralela, uma vez que ambientes distribuídos (por exemplo redes de estações de trabalho ou computadores pessoais) podem ser utilizados para esse fim.

Os dois exemplos atuais mais discutidos na literatura e utilizados de fato são o PVM e o MPI [BEG94, GEI94, GRO95]. O PVM é considerado um padrão de fato, dado a sua vasta utilização e popularidade alcançadas não apenas no meio acadêmico, mas também em diversas aplicações na indústria e outros setores. O MPI, por sua vez, foi proposto para ser um padrão internacional de biblioteca de passagem de mensagens e vem, aos poucos, conquistando adeptos e demonstrando seu potencial. Ambos, PVM e MPI são alvos de estudos e considerações no desenvolvimento deste projeto.

O objetivo desta dissertação é a extensão da Ferramenta de Apoio à Programação Paralela para ambientes paralelos virtuais tais como o PVM (Paralell Virtual Machine) e o MPI (Message Passing Interface).

Devido a sua grande utilização e características como simplicidade, robustez e eficiência, o ambiente de passagem de mensagens PVM, desenvolvido por Geist, et al. [SUN94] [GEI94] [BEG94], é utilizado como base para teste e validação da Ferramenta em questão.

Embora o termo desempenho esteja diretamente relacionado com a computação paralela, o objetivo principal deste trabalho é permitir a utilização da computação paralela 
especificamente em ambientes paralelos de uma maneira mais fácil e direta, possibilitando assim a utilização desses ambientes até por usuários sem conhecimento dos mesmos.

Este trabalho está dividido em sete capítulos, sendo os de número 2, 3 e 4 capítulos de revisão bibliográfica. No capítulo 2 são discutidas a evolução das arquiteturas de computadores e a classificação dessas arquiteturas (Flynn e Duncan). Abordam-se também o conceito de sistemas distribuídos e o potencial da computação paralela utilizando-se dos conceitos dos sistemas distribuídos [ALM94] [TAN92].

No capítulo 3 é apresentada uma discussão dos ambientes paralelos virtuais P.V.M. e M.P.I., seus componentes, suas formas de comunicação, o tratamento das mensagens, entre outras características [SUN94] [GEI94] [BEG94].

A evolução das arquiteturas paralelas e a apresentação de ferramentas que auxiliam o desenvolvimento automático de programas paralelos, com destaque para a Ferramenta de Apoio à Programação Paralela (F.A.P.P.) que é a base para este trabalho, são apresentadas no capítulo 4 [CAL97] [AND83] [CAL94] [CAR94] [FOS95] [HOA85] [ZHO93].

No capítulo 5, serão apresentados os componentes da F.A.P.P. que serão utilizados na geração de código para ambientes paralelos virtuais, as extensões e adaptações necessárias para tornar possível a geração do protótipo de aplicações em P.V.M. e M.P.I..

No capítulo 6, exemplos da ferramenta serão apresentados, bem como os resultados.

Concluindo, o capítulo 7 apresenta uma análise final sobre o trabalho realizado, identificando as contribuições, as principais dificuldades encontradas e as sugestões para trabalhos futuros. 


\section{Programação Concorrente/Paralela}

O projeto e a implementação de supercomputadores com arquitetura paralela é um dos problemas que vêm desafiando a ciência e a engenharia neste fim de milênio. Apesar do surgimento da computação paralela e dos sistemas computacionais distribuídos ter sido marcado por objetivos distintos, observa-se uma rápida convergência de ambas as áreas, tendo como desfecho um forte inter-relacionamento caracterizado por características comuns.

Este capítulo aborda os conceitos essenciais pertinentes à área de computação concorrente/paralela, incluindo também classificações de arquiteturas paralelas, técnicas utilizadas na computação concorrente/paralela, no desenvolvimento de programas concorrentes/paralelos e na utilização de sistemas computacionais distribuídos na computação paralela.

\subsection{Considerações Iniciais}

A literatura apresenta várias definições para computação paralela, dentre as quais cabem citar a sugerida por Almasi [ALM94]: “computação paralela constitui-se de uma coleção de elementos de processamento que se comunicam e cooperam entre si e com isso resolvem um problema de maneira mais rápida", e a apresentada por Quinn [QUI87]: "computação paralela é o processamento de informações que enfatiza a manipulação concorrente dos dados, que pertencem a um ou mais processos que objetivam resolver um único problema".

Mesmo tendo as arquiteturas seqüenciais de von Neumann sido um grande avanço tecnológico, largamente aprimoradas ao longo dos anos, elas ainda demonstram deficiências quando utilizadas por aplicações que necessitam de grande potência computacional. A necessidade do aumento do poder de processamento provocou o surgimento da computação paralela, tendo como meta aumentar o poder de processamento em uma única máquina.

A computação paralela apresenta diversas vantagens em relação à seqüencial, tais como:

- alto desempenho para programas lentos;

- soluções mais naturais para programas intrinsecamente paralelos;

- maior tolerância a falhas; e

- modularidade [SOU96]. 
Algumas das desvantagens da utilização da computação paralela são:

- maior dificuldade na programação;

- necessidade de balanceamento de cargas;

- intensa sobrecarga de comunicação; e

- sincronismo.

Em adição, o paradigma de programação vinculado às arquiteturas seqüenciais (e amplamente conhecido pelos usuários em geral) constitui um obstáculo a ser transposto quando adotada a computação paralela.

O aumento da utilização de sistemas computacionais distribuídos, associado aos conceitos de computação paralela, permite que tarefas possam ser realizadas explorando maior potência computacional com relevante redução dos custos.

\subsection{Conceitos Essenciais}

Diversas características encontradas na computação paralela não estão presentes na computação seqüencial. No entanto, computadores paralelos têm se tornado comuns e por essa razão, e para que se tornem mais eficientes, têm empregado técnicas utilizadas pela programação concorrente, permitindo inúmeras formas de organização dos processadores, bem como um gerenciamento mais complexo dos elementos de processamento.

Os conceitos, concorrência/paralelismo, granulosidade, speedup e eficiência, serão descritos adiante para que este trabalho se torne mais claro e de fácil compreensão.

\subsubsection{Concorrência/Paralelismo}

Concorrência é uma idéia que existe há muito tempo, consistindo em diferentes tarefas serem executadas ao mesmo tempo, de forma a produzir um resultado particular mais rapidamente [SNO92].

Concorrência não implica em múltiplos elementos de processamento, pode ocorrer concorrência com um único processador ou com múltiplos processadores. Em contrapartida, 
paralelismo exige a execução de várias tarefas (ou processos ${ }^{1}$ ) simultaneamente, exigindo vários elementos de processamento.

A existência de um único elemento de processamento implica em que apenas uma tarefa seja executada a cada instante, tendo-se um pseudo-paralelismo, ou seja, a ilusão que se tem é a de que as tarefas estão sendo executadas ao mesmo tempo. Na verdade, o processador está sendo compartilhado pelas diversas tarefas em execução, e um possível ganho de velocidade depende do tipo de tarefa que é executado.

\subsubsection{Granulosidade ou Níveis de Paralelismo}

Granulosidade pode ser definida como o tamanho das unidades de trabalho submetidas aos processadores ou ainda como a quantidade de trabalho realizado entre iterações do processador [KIR91].

Uma divisão pouco objetiva, mas consagrada na literatura, é dada à granulosidade: Grossa, Média e Fina.

Por granulosidade grossa, entende-se como sendo aquela com paralelismo de alto nível, ou seja, poucos processos grandes e complexos, e tem-se como unidade de paralelismo processos e programas [NAV89] [KIR91]. Já a granulosidade fina é caracterizada pelo paralelismo de baixo nível, onde existe grande número de processos pequenos e simples e cujas unidades de paralelismo são instruções e operações, havendo centenas e milhares de processos. Por último, tem-se a granulosidade média, que é constituída de vários processos médios e cujas unidades de paralelismo são processos, instruções, e loops, havendo dezenas de processos, que são caracterizados pela execução de trechos ou sub-rotinas de programas de forma que o paralelismo é atingido entre os blocos ou subrotinas dos programas.

1 parte de um programa que é executada seqüencialmente, mas que pode ser executada concorrentemente ou com outros processos do mesmo programa [AXF90], ou ainda por um programa em execução composto pelo programa executável, seus dados, pilha, ponteiro para a pilha, contador de instruções, registradores e demais informações necessárias para sua execução [NAV89]. 


\subsubsection{Speedup e Eficiência}

Aumentar desempenho é uma das metas da computação paralela. Dois parâmetros são utilizados para medir as vantagens na utilização da computação paralela: speedup e eficiência [KIR91] [QUI87].

Speedup - medida que tem por objetivo determinar a relação existente entre o tempo dispensado para executar um algoritmo em um único processador (T1) e o tempo gasto para executá-lo em "p" processadores (Tp).

$$
\text { Speedup }=\mathrm{T} 1 / \mathrm{Tp}
$$

Quando o speedup se iguala a "p" indica que o caso ótimo foi atingido, significando que o aumento da capacidade de processamento é diretamente proporcional ao número de processadores, definindo o conceito de sistemas escalares [MCB94]. Casos onde o speedup é maior que o ótimo são possíveis, sendo conhecidos por anomalia do speedup ou speedup superlinear [FOS95]. A comunicação entre processos, granulosidades inadequadas e partes não paralelizáveis de programas, são fatores que afetam diretamente o resultado do speedup.

Eficiência, por sua vez, relaciona speedup e número de processadores, ou seja, identifica a utilização do processador. No caso ótimo (100\% de utilização) a eficiência deve eqüivaler a 1 e o speedup a "p"; já em casos reais a eficiência é menor que 1 e o speedup menor do que "p".

\subsection{Arquiteturas Paralelas}

Várias formas de arquiteturas de computadores são referenciadas como arquiteturas paralelas ou de multiprocessadores ${ }^{2}$. Toda arquitetura paralela possui como objetivo principal o aumento do poder computacional através do aumento do número de elementos de processamento.

Entende-se aqui por arquitetura paralela máquinas que são capazes de executar mais de uma tarefa ao mesmo tempo, excetuando-se o paralelismo de baixo nível.

Três questões essenciais devem ser consideradas para uma arquitetura paralela: a granulosidade dos elementos de processamento, a topologia de interconexão entre os elementos de processamento, e a distribuição do controle entre os elementos de processamento. Granulosidade refere-se ao poder de cada elemento de processamento na arquitetura. Topologia refere-se ao padrão e densidade das conexões existentes entre os elementos de processamento.

${ }^{2}$ Todas as arquiteturas de computadores com múltiplos processadores. 
Controle de distribuição está relacionado à alocação das tarefas aos elementos de processamento e sincronismo de suas interações [DES87].

Devido ao rápido desenvolvimento das arquiteturas de computadores e para que as características comuns possam ser agrupadas, algumas classificações têm sido propostas. Várias taxonomias estão disponíveis [GIL81], sendo duas delas fortemente diferenciadas na literatura [ALM94] [TAN92]: taxonomia de Flynn e taxonomia de Duncan.

A taxonomia de Flynn baseia-se na observação do conjunto de instruções e de dados que podem ser simples ou múltiplos [FLY72]. Uma classificação mais refinada, que tem por objetivo suprir as dificuldades de acomodação de novas arquiteturas dentro da taxonomia de Flynn é a taxonomia de Duncan [DUN90].

\subsubsection{Taxonomia de Flynn}

Essa taxonomia foi proposta em 1966 e apesar de ser antiga ainda é bastante usada e respeitada. Essa taxonomia tem sido muito utilizada pela abrangência de arquiteturas representadas, até mesmo permitindo representações de arquiteturas MISD (Multiple Instruction Single Data), apesar da não existência na literatura de máquinas com esse tipo de arquitetura [FLY72] [ALM94] [DUN90].

Nessa taxonomia as arquiteturas são distribuídas em quatro categorias de máquinas (Tabela 2-1).

Tabela 2-1 - Taxonomia de Flynn

\begin{tabular}{c|l}
\hline SISD & $\begin{array}{l}\text { "Single Instruction Single Data": nesse caso há apenas uma instrução atuando } \\
\text { sobre um dado. }\end{array}$ \\
\hline SIMD & $\begin{array}{l}\text { "Single Instruction Multiple Data": nesse caso uma única instrução atua sobre } \\
\text { dados diferentes e é caracterizado por unidades de controle síncronas, porém } \\
\text { distribuídas. }\end{array}$ \\
\hline MISD & $\begin{array}{l}\text { "Multiple Instruction Single Data" : nenhuma máquina construída até o } \\
\text { momento. Nesse caso múltiplas instruções atuariam sobre um dado. }\end{array}$ \\
\hline MIMD & $\begin{array}{l}\text { "Multiple Instruction Multiple Data": nesse caso existem cadeias não } \\
\text { formatadas de instruções atuando em paralelo sobre dados distintos. }\end{array}$
\end{tabular}


A maioria das máquinas convencionais hoje disponíveis, e que correspondem ao tradicional modelo de von Neumann, como por exemplo IBM PC, representa a categoria SISD. Nessa categoria a execução é sequiencial, podendo ser otimizada pelo uso de pipeline, no entanto utilizando uma única unidade de controle (Figura 2-1) [FLY72].

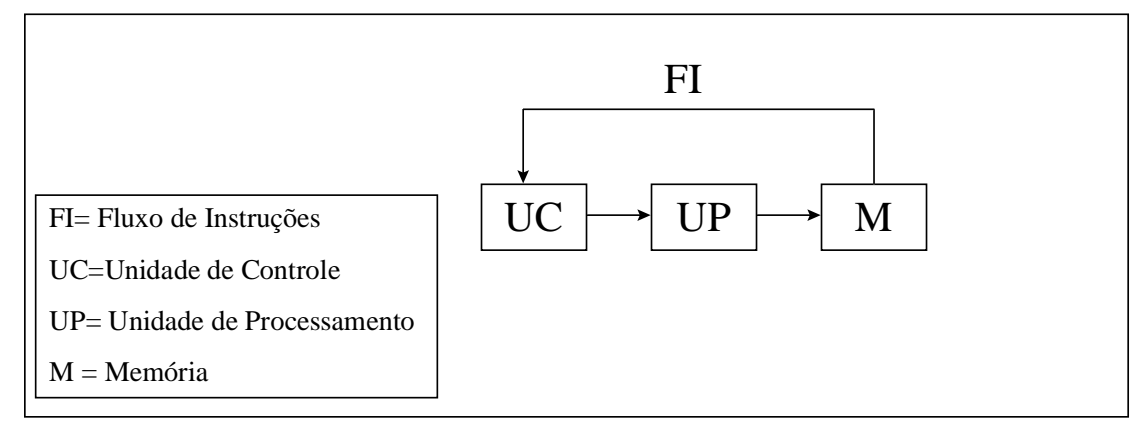

Figura 2-1- Exemplo Arquitetura SISD

As arquiteturas do tipo SIMD, em contraposição às do tipo SISD, possuem várias unidades de processamento, porém continuam com apenas uma unidade de controle. Exemplos de máquinas que pertencem a esse tipo de arquitetura são Convex 3210 e NEC SX-3/11, ou seja, processadores matriciais constituem exemplos dessa categoria. O tipo de memória dessa arquitetura pode ser compartilhado (comum a todas as unidades de processamento), ou distribuída (cada unidade possui seu próprio espaço para endereçamento de memória) (Figura 2-2) [CAL97].

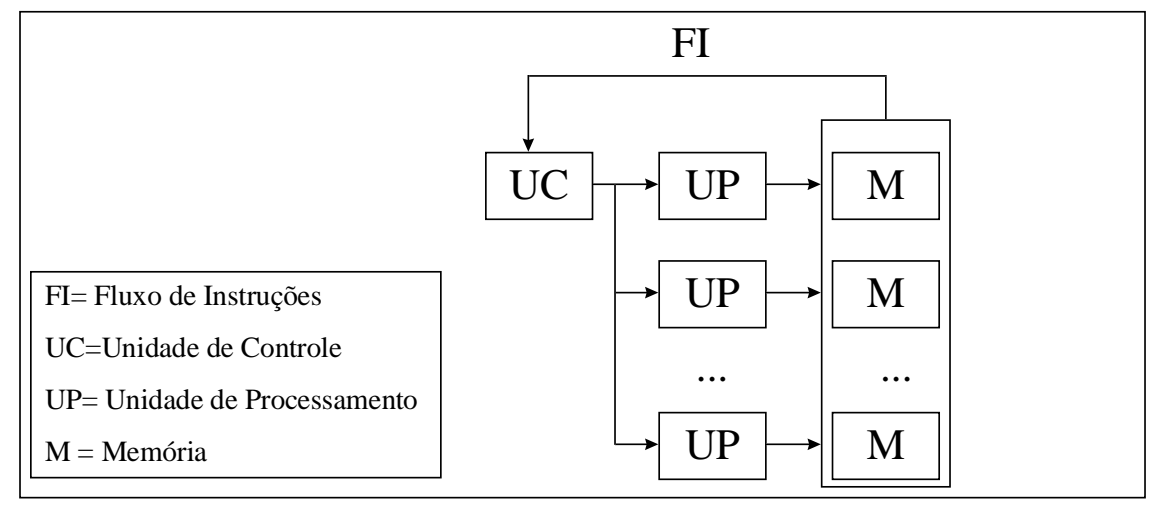

Figura 2-2- Exemplo Arquitetura SIMD 
Apesar de não existirem na prática, representantes da categoria MISD seriam máquinas que possuíssem vários processadores e que processassem diferentes instruções, no entanto operando sobre um mesmo fluxo de dados (Figura 2-3). Alguns autores [ALM94] [NAV89] citam a possibilidade de encaixar o pipeline como representante dessa categoria.

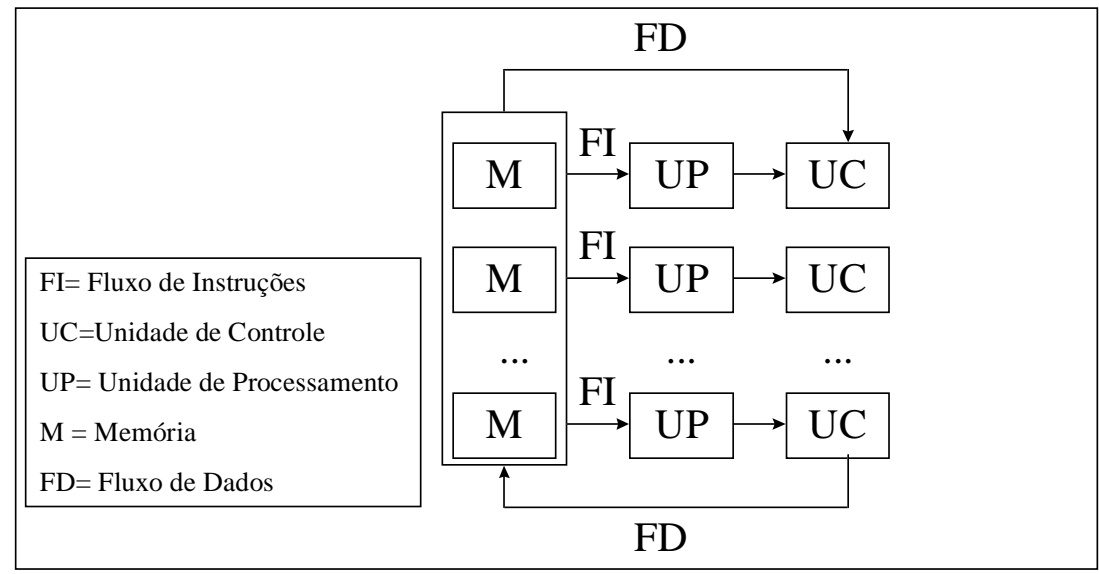

Figura 2-3- Exemplo Arquitetura MISD

Nas arquiteturas do tipo MIMD cada unidade de processamento atua sobre um conjunto de dados diferente e possui uma única unidade de controle (Figura 2-4).

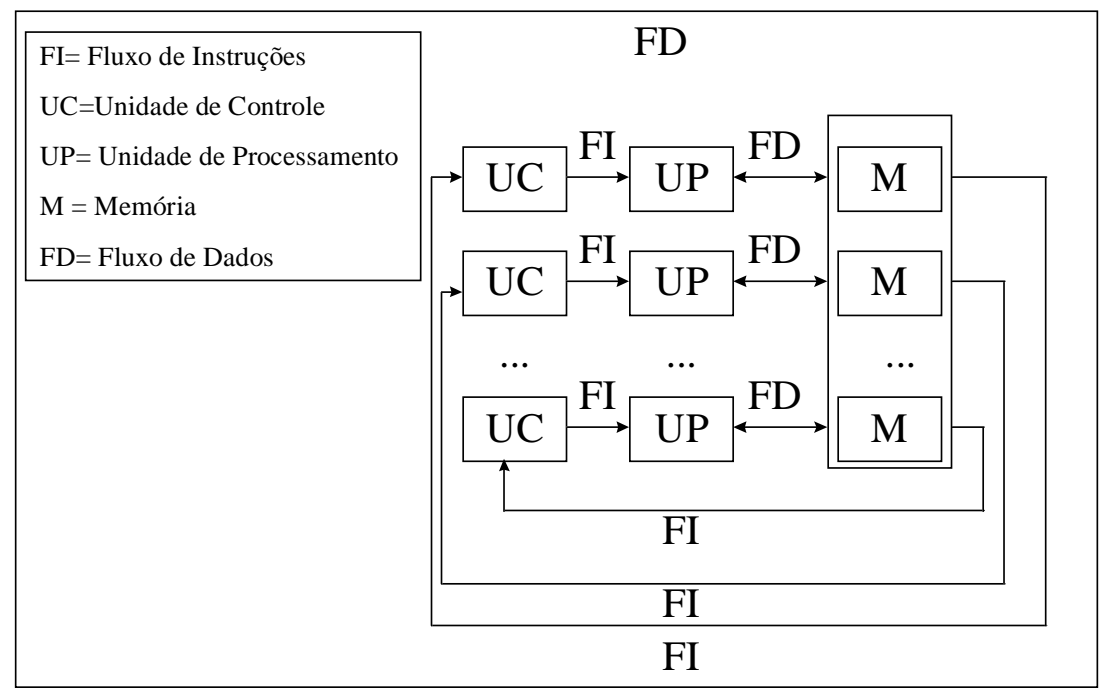

Figura 2-4- Exemplo Arquitetura MIMD 


\subsubsection{Taxonomia de Duncan}

Uma classificação mais refinada com o propósito de acomodar as inovações arquiteturais mais recentes e que não se encaixam na de Flynn foi proposta por Duncan [DUN90]. Essa nova taxonomia conserva a taxonomia de Flynn e divide as arquiteturas em síncronas e assíncronas, possibilitando a inclusão de arquiteturas mais recentes que não são absorvidas pela taxonomia de Flynn. A Figura 2-5 apresenta uma visão geral da classificação de Duncan [CAL97].

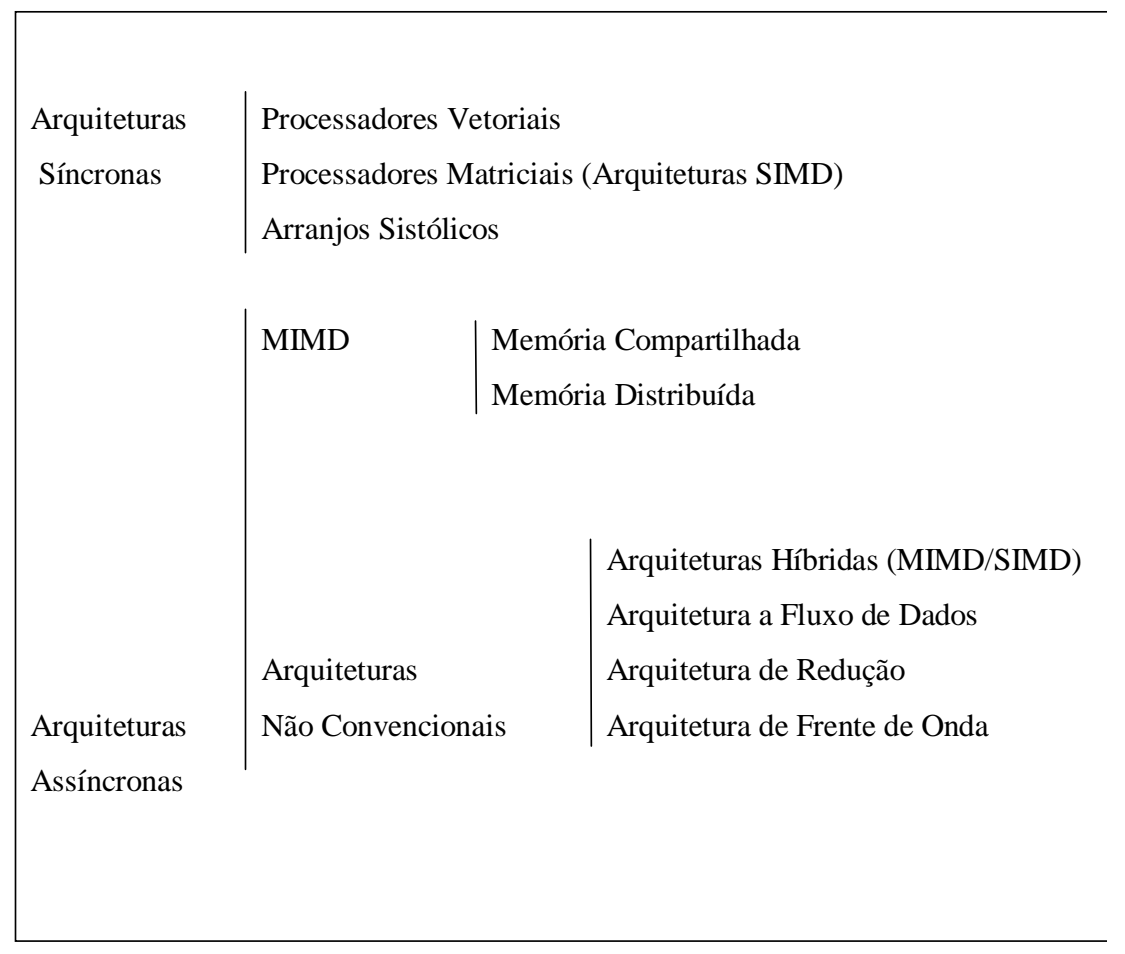

Figura 2-5- Classificação de Duncan

Arquiteturas síncronas são aquelas que coordenam as operações concorrentes com base em sinais de um relógio global e unidades de controle centralizado.

Como apresentado na Figura 2-5 estão presentes nessa classificação (síncrona) os Processadores Vetoriais que, como sugere o nome, são adequados para o processamento de instruções sobre vetores. O paralelismo vetorial é caracterizado pela execução da mesma operação sobre todos os elementos do vetor de uma só vez, de forma a otimizar as operações que são efetuadas. Esses processadores fazem uso de pipeline.

Assim como os processadores vetoriais, os processadores matriciais também se encaixam, na classificação de Duncan, dentro das arquiteturas síncronas. Por fazerem parte das 
máquinas SIMD, operam com múltiplos processadores que trabalham de forma paralela e síncrona.

Outro tipo de arquitetura presente na categoria síncrona são os arranjos sistólicos. Nesse tipo de arquitetura todos os processadores executam a mesma instrução e implementam algoritmos para aplicações específicas. Dados fluem da memória para a rede de processadores e voltam para a memória sincronamente. De acordo com Almasi [ALM94], o nome sistólico se deve à semelhança existente entre o pulsar do sangue no coração com o pulsar síncrono das informações nos processadores (que por sua vez são organizados em pipeline).

As arquiteturas assíncronas, que constituem o outro grande grupo no qual é dividida a classificação de Duncan, caracterizam-se pelo controle descentralizado do hardware e cada instrução é executada em elementos de processamento diferentes. Essa categoria é composta por máquinas MIMD, convencionais ou não.

Arquiteturas MIMD são computadores assíncronos e, como mencionado anteriormente, caracterizam-se pelo controle do hardware descentralizado. Nessas arquiteturas a memória pode ser centralizada (Figura 2-6) ou distribuída (Figura 2-7) [DUN90].

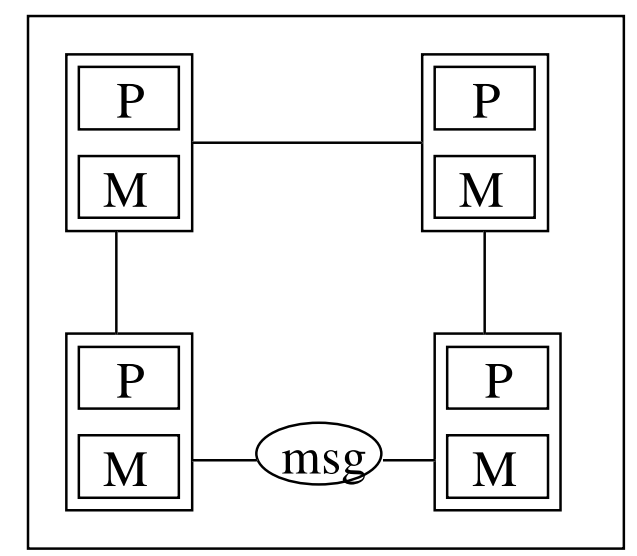

Figura 2-6- Estrutura de arquitetura MIMD de memória distribuída 


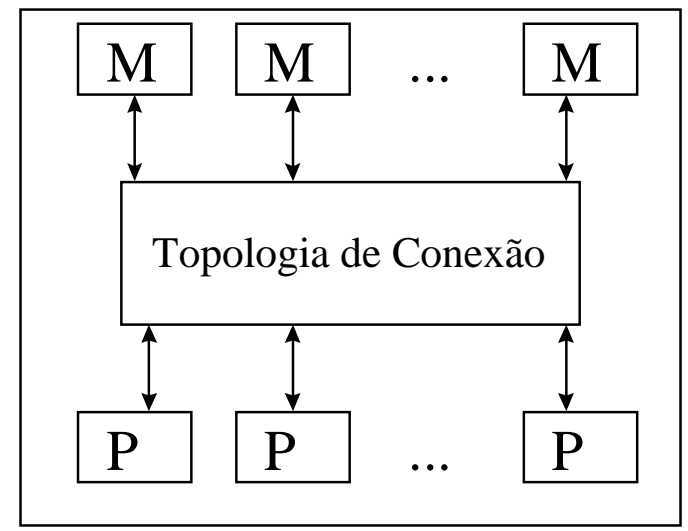

Figura 2-7 - Estrutura de arquitetura MIMD com memória compartilhada

Nas arquiteturas de memória distribuída, cada processador possui sua memória local e os nós são interconectados através de redes de interconexão, dessa forma, os nós se comunicam através de passagens explícitas de mensagens.

Diversas topologias de interconexão de rede podem ser utilizadas, destacando-se entre elas as arquiteturas de topologias em anel, árvore, hipercubo e reconfigurável.

As arquiteturas de memória compartilhada, por sua vez, provêm uma única memória que é compartilhada pelos processadores. Essas arquiteturas são também chamadas de multiprocessadores e não possuem problemas no que diz respeito à troca de mensagens, forma pela qual são implementadas a comunicação e o sincronismo dos processos. Várias topologias de interconexão também são propostas para esse tipo de arquitetura: crossbar, barramento, múltiplos estágios.

Pertencendo às arquiteturas não convencionais, encontram-se as arquiteturas híbridas, de fluxo de dados, redução e de frente de onda. Nessa categoria encontram-se os sistemas não enquadrados nas demais arquiteturas.

Arquiteturas híbridas são aquelas em que partes de arquiteturas SIMD são controladas por arquiteturas MIMD [HAY82].

As arquiteturas Dataflow (de fluxo de dados) compõem-se da execução de seqüenciais de instruções baseadas na dependência de dados, que permitem a essas arquiteturas explorarem concorrência em nível de tarefas, rotinas e até instruções [HAY82].

Arquiteturas de redução, também conhecidas como dirigidas, apresentam um paradigma a partir do qual instruções são preparadas para executar quando os resultados são solicitados pelo 
operando ou por outras instruções. Redução implica na troca de parte do código fonte pelo seu significado [KIR91].

Finalizando as arquiteturas que compõem a taxonomia de Duncan têm-se as arquiteturas de frente de onda, que combinam pipeline de dados sistólicos com o paradigma de execução de dataflow assíncrono [DUN90].

\subsection{Programação Concorrente}

Programação concorrente já foi um assunto de importância restrita ao desenvolvimento de software básico, tal como sistemas operacionais. Entretanto, com a disseminação do uso de máquinas multiprocessadoras e mais recentemente da exploração de paralelismo em sistemas distribuídos os conceitos envolvidos com programação concorrente se tornaram importantes também em outros setores [GEH89].

Em termos gerais, pode-se definir a programação concorrente lembrando-se que, enquanto um programa seqüencial especifica a execução seqüencial de uma lista de instruções, a programação concorrente implica em dois ou mais programas sequienciais, sendo executados concorrentemente de forma que se tenha a impressão de estarem sendo executados em paralelo. Isto é, cria-se um pseudo-paralelismo.

A divisão de determinadas aplicações em partes menores de forma que cada parcela resolva uma porção do problema é, portanto, a idéia básica de programação concorrente. Recursos adicionais, responsáveis por exemplo pela ativação e finalização dos processos concorrentes, se fazem necessários.

\subsubsection{Especificação de Execução Concorrente}

Existe uma variedade de maneiras de se falar sobre concorrência, algumas das quais encontram sua forma nas mais variadas linguagens de programação. Dentre as especificações para ativação de processos concorrentes, Fork/Join foi uma das primeiras notações a ser criada, não separando as definições de ativação e sincronização dos processos. Outras notações (Cobegin/Coend, Co-Rotina) foram propostas, no entanto, distinguem bem os conceitos de ativação e sincronização de processos.

Declaração Fork/Join - O comando fork implica na execução de um determinado conjunto de instruções (processo filho) ser iniciado em paralelo ao conjunto que o executa (processo pai) [AND83] [HWA84] [ALM94]. Quando um comando join é por sua vez executado, ocorre a sincronização do processo pai com os filhos gerados (Figura 2-8). 


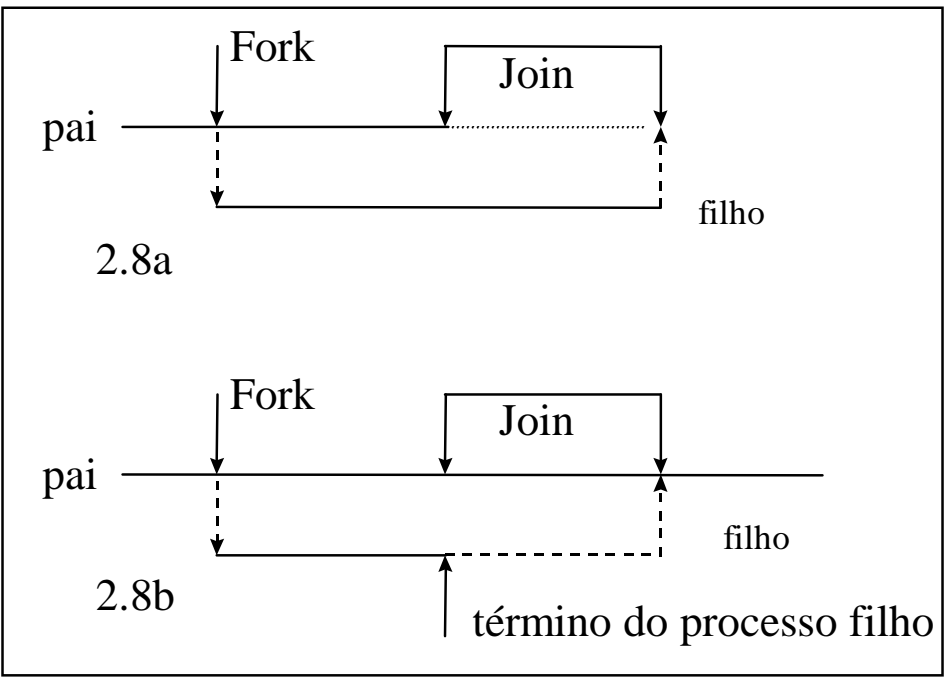

Figura 2-8- Exemplos do Funcionamento dos Comandos Fork/Join

$\mathrm{Na}$ Figura 2-8a, o processo pai terminou de executar sua tarefa e fica esperando que o processo filho termine sua execução, de modo que o comando join sincroniza a execução dos processos. Na Figura 2-8b o inverso ocorre, fazendo com que o filho espere o término da execução do pai.

As sintaxes dos comandos fork e join são:

Fork endereço - Faz com que o processo que esteja localizado no endereço seja executado concorrentemente ao processo em execução;

Join var, end1, end2 - Onde var é decrementado de uma unidade antes de seu valor ser verificado. Caso seu valor seja zero, o processo no endereço end1 é executado, caso contrário a execução é desviada para o endereço end2 que, normalmente, é utilizado para finalizar o processo através da instrução quit. Fork/Join têm como vantagem serem mais flexíveis que as outras notações, pois permitem a representação de qualquer execução paralela/seqüencial. Falta, entretanto, estruturação, fator que dificulta o entendimento do código.

Declaração Cobegin/Coend - O comando cobegin é uma estrutura que indica a execução concorrente de um conjunto de instruções onde o fim desse conjunto é indicado pelo comando coend. Esses comandos são conhecidos também por parbegin e parend ${ }^{3}$. A estrutura

\footnotetext{
${ }^{3}$ Foi primeiramente chamado assim por Dijkstra [NAV89].
} 
cobegin/coend é menos flexível que a fork/join, por exemplo, pelo fato dos processos ativados terem que terminar para que outros processos possam ser executados. A sintaxe desse comando é:

cobegin $\mathrm{S} 1 / / \mathrm{S} 2 / / \mathrm{S} 3 / / . . . / / \mathrm{S} n$ coend

onde $\mathrm{S} 1, \mathrm{~S} 2, \ldots . . \mathrm{Sn}$ são processos que serão executados em paralelo [ALM94]. O processo pai é bloqueado até que $\mathrm{S} 1, \mathrm{~S} 2, \mathrm{~S} 3, \ldots, \mathrm{Sn}$ tenham terminado.

Declaração Co-Rotinas - As co-rotinas são como subrotinas, mas permitem a transferência do controle de forma não hierárquica. Cada co-rotina pode ser vista como a implementação de um processo e podem ser executadas intercaladamente. Alguns comandos estão presentes como:

- resume - utilizado para a transferência do controle de uma co-rotina para outra;

- $\quad$ call - utilizado para iniciar uma co-rotina; e por fim; e

- return - usado para transferir o controle para o programa chamador [SNO92].

Uma subrotina, ativada através de uma chamada call subrotina, ao executar o comando return, retorna o controle ao módulo de programa que a ativou e termina sua execução. Além disso, toda vez que esta é ativada, será executada desde o início. As co-rotinas transferem controle entre si de maneira livre, através do comando resume co-rotina (Figura 2-9). Sempre existe uma única co-rotina ativa em cada instante. As co-rotinas são utilizadas para ativação de processos concorrentes, enquanto que Fork/Join, Cobegin/Coend, são utilizados para ativação de processos paralelos.

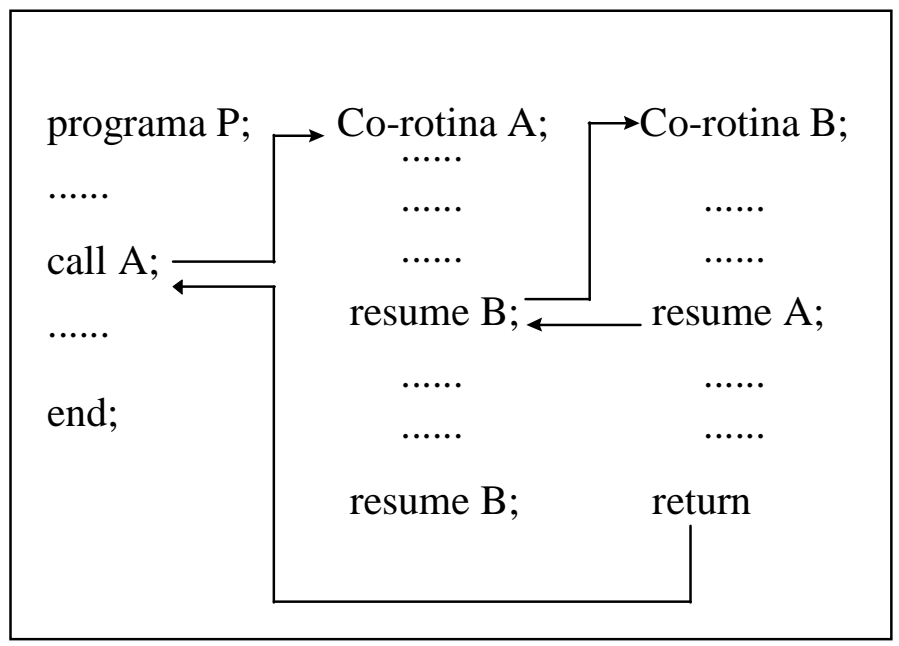

Figura 2-9 - Um uso de Co-rotina 


\subsubsection{Primitivas de sincronização}

Primitivas de sincronização (e consequentemente de comunicação) devem estar presentes para que os processos possam se comunicar uns com os outros e, dessa maneira, interferirem uns nos outros. A sincronização e comunicação são implementadas com o uso de variáveis compartilhadas ou através da passagem de mensagens [GEH89].

Observa-se na literatura [HWA84] [ALM94], que esses mecanismos de comunicação foram desenvolvidos para atuar em um dos dois grandes grupos: arquiteturas com memória compartilhada ou nas de memória distribuída.

Comunicação e Sincronismo em Memória Compartilhada - O controle de acesso e seqüência em memória compartilhada são implementados através da utilização de variáveis compartilhadas entre os diversos processos concorrentes.

Para a implementação de exclusão mútua e controle de seqüência, que utilizam-se de variáveis compartilhadas, vários métodos podem ser utilizados, dos quais destacam-se: espera ocupada, semáforos e monitores [ALM94] [AND83] [QUI87].

- Espera Ocupada - Utilizando-se uma variável compartilhada cujo valor pode ser manipulado (modificado) através de uma primitiva indivisível, criase um modo simples para a sincronização de processos concorrentes. Um processo querendo entrar em uma região crítica deve executar esta primitiva continuamente até conseguir permissão de entrada [KIR91] [ALM94] [TAN92]. Uma das desvantagens da espera ocupada é o gasto supérfluo de tempo de C.P.U..

- Semáforos - Mecanismo de sincronização genérico composto por duas operações atômicas: up e down. Essas operações atuam sobre uma variável compartilhada de modo a permitir o controle de acesso e a exclusão mútua. Em adição, oferecem um meio de sincronização de nível mais elevado do que a espera ocupada, evitando o desperdício de C.P.U., no entanto, apresentam como desvantagem a desestruturação do código.

- Monitores - Oferecem uma maneira estruturada de implementar a exclusão mútua. Um monitor consiste de algumas variáveis permanentes que armazenam o estado do recurso compartilhado e de alguns procedimentos que implementam operações sobre esses recursos. Essas variáveis podem ser acessadas somente pelos procedimentos internos a cada monitor, e a execução desses procedimentos é feita de maneira mutuamente exclusiva [TAN92]. 
Comunicação e Sincronismo em Memória Distribuída - tanto a comunicação como o sincronismo feito em memória distribuída devem ser implementados através de troca de mensagens entre processos [ALM94] [AND83] [QUI87].

Quando esse tipo de comunicação e sincronização é utilizado, processos enviam e recebem mensagens. A comunicação é efetuada porque um processo, após receber uma mensagem obtém valores de algum processo emissor. Dessa mesma forma, a sincronização é efetuada porque uma mensagem pode ser recebida somente depois de ter sido enviada, o que impede a ocorrência dos eventos em ordem inversa [GEH89].

As primitivas send/receive utilizadas na comunicação podem ser bloqueantes ou não bloqueantes (Figura 2-10) [TAN92].

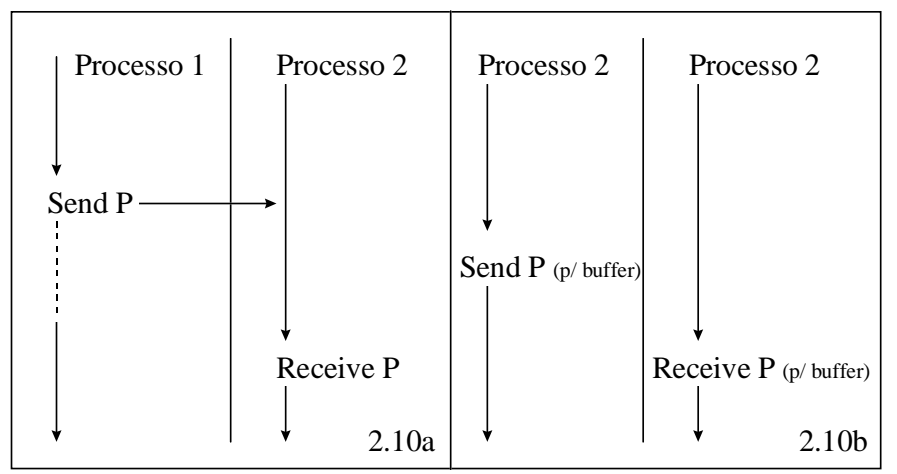

Figura 2-10 - (a) Bloqueante

(b) Não Bloqueante

O processo de comunicação pode ser organizado segundo abstrações distintas [ALM94], [TAN92], [AXF90]:

- Comunicação Ponto a Ponto - Caracteriza-se pelo uso de uma operação send/receive bloqueante, de modo que os processos se sincronizem. Nesse processo a comunicação é unidirecional;

- Rendezvouz - Nesse mecanismo dois processos concorrentes executam as primitivas send/receive duas vezes apresentando comunicação síncrona e bidirecional [AXF90].

- RPC (Remote Procedure Call) - Caracteriza-se pela execução de um procedimento não local a um determinado processo, utilizando uma sintaxe semelhante à chamada de procedimentos locais, sendo que o processo requisitante de serviço é bloqueado até que se obtenha os resultados desejados. O procedimento é iniciado quando é recebida uma requisição de execução. Normalmente, o procedimento remoto retorna valores, tornando a comunicação bidirecional [TAN85]. 


\subsection{Suporte à Programação Concorrente/Paralela}

Ferramentas eficazes, que auxiliem na ativação e paralelização de processos, são atualmente requeridas para o desenvolvimento de algoritmos concorrentes/paralelos. A implementação dessas ferramentas faz-se através de linguagens concorrentes/paralelas ou de ambientes paralelos virtuais. Segundo Andrews [AND83] as linguagens podem ser classificadas em três grupos: orientadas a procedimento, a mensagens e a operações. A diferença entre as orientadas a mensagens e as orientadas a operações é que as primeiras utilizam send/receive para comunicação enquanto as últimas utilizam RPC.

As linguagens compõem-se de comandos específicos que permitirão o paralelismo enquanto que os ambientes paralelos virtuais fornecem bibliotecas de comunicação com mecanismos utilizados nas execuções paralelas. Alguns exemplos de linguagens concorrentes/paralelas são: Occam, Ada, High Performance Fortran; e de ambientes: PVM (Parallel Virtual Machine), MPI, P4, Linda, PARMACS (PARallel MACroS).

Almasi [ALM94], por sua vez, divide as linguagens em imperativas e declarativas. As primeiras constituem a grande maioria das linguagens disponíveis (FORTRAN, Pascal, C) e analisam "como" um determinado problema pode ser resolvido. As últimas são projetadas para enfatizar "o que" o problema quer resolver. Linguagens de programação funcional (fluxo de dados por exemplo) e para programação lógica (Prolog e Prolog Concorrente) são exemplos desta categoria [ALM94]. Como a maioria das linguagens utilizadas são imperativas, o maior número de versões paralelas também é dessa categoria.

Um ambiente de passagem de mensagem consiste basicamente de uma biblioteca de comunicação que atuando como uma extensão das linguagens seqüenciais (como FORTRAN), permite a elaboração de aplicações paralelas.

$\mathrm{Na}$ atualidade, os ambientes de passagem de mensagem foram desenvolvidos com três grandes objetivos:

- Utilizar o potencial dos sistemas distribuídos para o desenvolvimento de aplicações paralelas;

- Permitir a união de plataformas heterogêneas;

- Permitir a portabilidade das aplicações paralelas desenvolvidas.

Exemplos de plataformas portáveis para equipamentos heterogêneos são: P4, PARMACS, Express, PVM, MPI, Linda, entre outros [MCB94] [CAR94] [WAL94] [MAT93] [BUT94] [SUN94]. Esses ambientes, normalmente, utilizam a passagem de mensagens como mecanismo de comunicação. 


\subsection{Sistemas Computacionais Distribuídos}

O termo "sistemas computacionais distribuídos" tem sido usado à exaustão para descrever desde simples sistemas operacionais de rede até complexas implementações de Sistemas Computacionais Distribuídos reais, muitas vezes correndo o risco de perder seu sentido original. É necessário delimitar-se bem o escopo desse termo a fim de se ter certeza de estar falando sobre a mesma "coisa".

Um sistema computacional distribuído, segundo a visão de Tanenbaum [TAN92] e Colouris [COU94], é uma coleção de computadores autônomos, interligados por uma rede de comunicação $^{4}$ e equipados com um sistema operacional distribuído, que permitem o compartilhamento transparente de recursos existentes no sistema. Dessa forma, um sistema distribuído aparenta ser um sistema centralizado, enquanto na realidade o sistema operacional é executado em múltiplas unidades de processamento não dependentes que se comunicam [MUL93].

Uma contribuição importante feita por Müllender [MUL93], uma definição, é o fato de que um sistema distribuído não deve ter pontos críticos de falha, característica que faz com que um sistema distribuído leve vantagem em relação a um sistema centralizado.

Os sistemas distribuídos apresentam inúmeras outras grandes vantagens, que o tornam ainda mais difundidos: confiabilidade (quebra de máquinas não afeta necessariamente o funcionamento do sistema de forma que ele venha a suspender sua execução), expansibilidade (fácil expansão da capacidade computacional do sistema) e transparência, sendo esta última um conceito fundamental e compartilhado pela maioria dos autores [TAN92] [MUL93] [COU94].

Por outro lado, os sistemas distribuídos apresentam também algumas desvantagens tais como: necessidade de consolidação de conceitos do software distribuído, gargalo representado pelas redes de comunicação e falta de segurança apresentada pelo compartilhamento de dados e grande número de usuários.

${ }^{4}$ Constituem os meios através dos quais os recursos, que se encontram separados fisicamente, utilizam para se comunicar. Em sistemas distribuídos os meios de comunicação mais utilizados são as redes de computadores que possuem três topologias básicas: WANs (Wide Area Network redes de longa distância), MANs (Metropolitan Area Network - redes metropolitanas), e LANs (Local Area Network - redes locais) [SOU96]. 


\subsubsection{Características Essenciais de um Sistema Distribuído}

Segundo Couloris [COU94], as características que devem ser encontradas em um sistema para que ele seja distribuído são: compartilhamento de recursos, abertura, concorrência, capacidade de expansão, tolerância a falhas, e transparência.

Por Compartilhamento de Recursos entende-se a necessidade de compartilhar os recursos $^{5}$ pertencentes ao sistema, de forma a usufrui-los da melhor maneira possível. Esse compartilhamento de recursos é de fundamental importância tanto para sistemas centralizados como para sistemas distribuídos. Nos sistemas distribuídos o compartilhamento não é feito de maneira imediata, uma vez que os recursos estão dispersos fisicamente. Além disso, o compartilhamento de recursos está relacionado ao modelo arquitetural do sistema, objetivando a utilização dos seus componentes de modo a obter tanto a redução dos custos como melhor desempenho.

Outra característica é a Abertura (openness) e, para ser considerado aberto, o sistema deve ser expansível tanto em hardware (podendo ser mudados memória, disco, interfaces de comunicação, entre outras) quanto em software (características de sistemas operacionais, protocolos de comunicação, entre outros). Para que isso ocorra, as interfaces devem ser bem definidas, de forma a facilitar a inserção de novos recursos no sistema previamente existente. Essa característica indica, portanto, que um sistema distribuído pode ser expandido quando e se necessário, sem afetar a funcionalidade do sistema atual.

Concorrência e paralelismo emergem de maneira natural em sistemas distribuídos, uma vez que as atividades são divididas entre os usuários; existe independência de recursos e indefinição de localização de execução das tarefas. Isto torna o gerenciamento mais complicado devido à necessidade de sincronização de processos para que a consistência do sistema seja mantida.

A Capacidade de Expansão (scalability) indica que um sistema centralizado é limitado fisicamente, o que nos sistemas distribuídos teoricamente não ocorre. Portanto, não há um limite no número de máquinas para a composição do sistema. $\mathrm{O}$ software distribuído deve continuar executando de maneira natural à medida em que o sistema cresce. Técnicas têm sido utilizadas para permitir maior capacidade de expansão: replicação de dados, cache e múltiplos servidores que executem tarefas semelhantes.

A Tolerância a Falhas, como já mencionado anteriormente, é de extrema necessidade uma vez que erros ocorrem, fazendo com que dados fiquem inconsistentes e resultados fiquem incorretos. Em um sistema distribuído não se sabe exatamente onde as tarefas estão sendo executadas, e por esse motivo a falha em uma máquina ou um erro que venha a ocorrer não deve

5 “Recurso" - Qualquer entidade do sistema passível de ser compartilhada. 
interferir no funcionamento do sistema. Essa tolerância a falhas pode ser alcançada através de redundância de hardware, replicação de componentes, e de redundância de software (utilizandose programas de recuperação de falhas).

Transparência, neste contexto, tem como significado o não conhecimento por parte do usuário de que o sistema não é único e sim composto de várias partes. Oito formas de transparência são apresentadas na literatura [COU94]:

- Transparência de concorrência onde vários processos têm acesso ao mesmo recurso concorrentemente, de forma que um processo não interfira na execução de outro;

- Transparência de falhas onde as falhas ficam encobertas pelo sistema ficando no local onde ocorrem, não interferindo no funcionamento normal do sistema;

- Transparência de acesso que permite acesso a qualquer recurso independentemente da sua localização;

- Transparência de replicação que permite a consistência no sistema onde há replicação de dados, tornando o sistema mais confiável e possibilitando o aumento do desempenho;

- Transparência de escala permitindo que o sistema expanda em escala, sem alteração de estrutura e de algoritmos das aplicações existentes;

- Transparência de migração permite a movimentação dos recursos dentro do sistema, sem que sejam alteradas suas características;

- Transparência de localização que permite a utilização de recursos sem o conhecimento prévio de sua localização; e

- Transparência de desempenho onde o aumento de desempenho é obtido devido à possibilidade de reconfiguração do sistema.

\subsubsection{Modelos Arquiteturais Clássicos, Compostos e Avançados}

Os modelos arquiteturais têm por objetivo definir como os componentes de um sistema distribuído estão organizados e como os usuários interagem com o sistema. Esses modelos dividem-se em três grandes grupos: modelos arquiteturais clássicos, modelos arquiteturais compostos e modelos arquiteturais avançados. Os modelos arquiteturais que serão abaixo 
abordados foram propostos para que as características essenciais de sistemas computacionais distribuídos fossem alcançadas.

\section{Modelos Arquiteturais Clássicos}

Estação de trabalho/servidor é um modelo em que as estações de trabalho são conectadas por uma rede de comunicação, implementando o paradigma cliente/servidor. As máquinas de configurações inferiores constituem as que executam software cliente enquanto as de melhor configuração representam as máquinas servidoras executando software servidor (podem ser servidores dedicados ${ }^{6}$ ou não). As desvantagens desse modelo são a variação da potência computacional, o fato de servidores centralizados representarem gargalos e favorecem a ação de hackers; no entanto apresenta baixo custo de implementação, tempo de resposta previsível e adaptação às necessidades dos usuários.

Banco de processadores neste modelo tem-se um conjunto de terminais e um banco de processadores, gerenciado por um servidor de processamento (responsável pela alocação e liberação de processadores para terminais remotos). A alocação dos processadores pode ser individual ou conjunta, e pode ocorrer dinamicamente. Constitui um bom modelo para processamento numérico intenso, para processamento paralelo e para um melhor aproveitamento de recursos, no entanto, não é recomendado para processamento interativo ou quando a demanda por processadores for muito alta.

\section{Modelos Arquiteturais Compostos}

Modelo Híbrido é representado pela união das estações de trabalho/servidor aos banco de processadores, permitindo a exploração das vantagens de ambos. Minimiza as desvantagens (processamento interativo), possibilita adequação do processador ao usuário e permite o processamento paralelo.

Modelo Integrado é constituído pelo acoplamento das estações de trabalho/servidor aos minicomputadores, microcomputadores e mainframes. Como vantagens tem-se o melhor aproveitamento de recursos. Cada computador possui o software apropriado para desempenhar tanto as tarefas de servidor quanto a função de executar a aplicação.

\section{Modelos Arquiteturais Avançados}

Constituem modelos mais recentes e ainda em desenvolvimento baseados em estações inativas. Têm como vantagens as mesmas obtidas nas estações de trabalho/servidor adicionandose a esta a capacidade ociosa do sistema e como desvantagens as mesmas obtidas nas estações de

${ }^{6}$ Servidores dedicados - exercem somente o papel de servidor. 
trabalho/servidor excluindo-se as estações inativas, além da complexidade no gerenciamento e do incômodo aos usuários.

Modelo Estação de Trabalho/Servidor e (potencialmente) Híbrido esse modelo tem por objetivo organizar de modo orientado a objetos, possuir um gerenciador de recursos para gerenciar objetos; os elementos do sistema são considerados objetos e todas as teorias de orientação a objetos são aplicadas: herança, encapsulamento, polimorfismo e outras. As vantagens apresentadas por esse modelo é uma visão uniforme de todo o sistema, facilidade na migração de processos (que por sua vez também são objetos) e englobam o caso de estações ociosas. Exemplos desse modelo são Amoeba, Mach, Emerald, Arjuma [TAN88].

\subsubsection{Comunicação}

A troca de informações em sistemas distribuídos é fator essencial, tendo em vista a localização fisicamente dispersa dos recursos que o compõem. Essa troca de informação é uma das características diferenciadoras dos sistemas computacionais distribuídos dos sistemas centralizados. Dessa troca de informações depende também o desempenho do sistema.

Duas abordagens para comunicação são apresentadas: Passagem de Mensagem e RPC (Remote Procedure Call).

A passagem de mensagem é a mais simples e constitui-se de primitivas básicas do tipo send e receive, que podem ser bloqueantes e não bloqueantes [TAN92]; as chamadas de procedimento remoto (RPCs), que representam um nível mais alto de abstração que a passagem de mensagem, tem por idéia básica fazer com que a comunicação entre máquinas diferentes seja muito semelhante às chamadas de procedimentos convencionais.

\subsection{Computação Paralela e Sistemas Distribuídos}

O surgimento dos sistemas distribuídos deu-se basicamente pela necessidade de compartilhar recursos, normalmente de alto custo e fisicamente separados.

Com o intuito de aumentar ainda mais o desempenho, a flexibilidade e a versatilidade das máquinas paralelas, decidiu-se empregar a computação paralela sobre sistemas distribuídos de maneira a explorar as características comuns de ambos, concorrência e tolerância a falhas, e usufruir das características individuais.

A convergência deu-se a partir da década de 80, principalmente pelos avanços tecnológicos que permitiram maior flexibilidade e custo mais baixo. 
A computação paralela passou a utilizar-se não só das arquiteturas SIMD, mas de máquinas MIMD com memória distribuída. Essas máquinas passaram a contar com processadores de propósito geral, tornando possível sua visualização como um conjunto de computadores autônomos, interligados por uma rede de comunicação.

Os sistemas computacionais distribuídos foram cada vez mais aperfeiçoados, destacandose como mudanças significativas: maior eficácia dos meios de comunicação e protocolos, e computadores com maior potência computacional [ZAL91].

Devido às características comuns, diversos trabalhos foram desenvolvidos objetivando a utilização da computação paralela sobre sistemas computacionais distribuídos.

Para a realização da computação paralela sobre sistemas computacionais distribuídos são utilizados ambientes de passagem de mensagem, que têm sido constantemente aperfeiçoados, permitindo assim a união de uma quantidade cada vez mais significativa de computadores.

As vantagens apresentadas pela utilização da computação paralela sobre sistemas distribuídos são basicamente: redução do custo com a utilização de hardware existente, aumento de desempenho pela atribuição de tarefas de acordo com a arquitetura apropriada, exploração da heterogeneidade natural das aplicações, utilização de recursos conhecidos, recursos fornecidos pelas máquinas virtuais e o fato da computação distribuída facilitar o trabalho corporativo.

\subsection{Considerações Finais}

O surgimento da computação paralela deu-se pela necessidade de aumentar a potência computacional. Como o aumento do desempenho nas arquiteturas de von Neumann é uma tarefa árdua (limitação tecnológica), a computação paralela compõe uma alternativa mais barata e aprimorada, principalmente para problemas essencialmente paralelos. Classificações de arquiteturas surgiram em conseqüência ao desenvolvimento de várias máquinas paralelas. Duas classificações destacam-se na literatura: a de Flynn e a de Duncan.

Na classificação de Flynn são considerados os fluxos de instruções e de dados criando-se quatro grupos: SISD, SIMD, MISD e MIMD. Embora antiga, esta classificação ainda é muito utilizada. A classificação de Duncan objetiva resolver os problemas da classificação de Flynn. Termos mais genéricos foram utilizados e as arquiteturas foram divididas em síncronas e assíncronas.

O desempenho dos computadores pessoais e das estações de trabalho vem aumentando significativamente nos últimos anos. Quando esses computadores são interligados por uma rede de alta velocidade e alta confiabilidade, podem ser aplicados para solucionar uma variedade de aplicações que necessitam de alto poder computacional. 
A utilização de sistemas computacionais distribuídos, com conceitos utilizados pela computação paralela, fez com que trabalhos fossem desenvolvidos para explorar o grande potencial da computação paralela utilizando os sistemas distribuídos.

Baseando-se nesses princípios, ambientes de passagem de mensagem foram aperfeiçoados e/ou criados. Através de computadores autônomos e heterogêneos interligados por uma rede de comunicação, compôs-se uma arquitetura MIMD virtual, com memória distribuída que, entre outras características, oferece melhores recursos para a execução de aplicações paralelas.

A convergência apresentada entre a computação paralela e os sistemas distribuídos trouxe uma gama muito grande de vantagens, principalmente para a primeira, como a redução de custos, o aumento de desempenho, a utilização mais adequada de recursos evitando ociosidade no sistema, entre outras. Tudo isso tem feito com que cada vez mais surjam trabalhos que têm por objetivo o aumento da potência computacional com o uso da computação paralela sobre sistemas computacionais distribuídos. Como cooperantes para essa redução de custos e aumento de desempenho aparecem os ambientes paralelos virtuais.

O próximo capítulo descreve as principais características de implementação do PVM e MPI, salientando seus aspectos mais importantes desses ambientes paralelos virtuais. 


\section{Ambientes Paralelos Virtuais}

O modelo computacional MIMD tem-se destacado dentro da computação paralela devido à sua flexibilidade e ao seu potencial para execução de programas paralelos de complexidade média e alta. Entre as plataformas MIND destacam-se as de memória distribuída, as quais podem ser computadores paralelos (baseados em arquiteturas paralelas) ou máquinas paralelas virtuais (construídas a partir de sistemas distribuídos)[BLE94] [MCB94] [ZAL91].

Este capítulo aborda as principais características de dois ambientes paralelos virtuais PVM e MPI [SUN94] [GEI94] [DON95] [DOS96], utilizados no desenvolvimento deste trabalho, com o objetivo de proporcionar uma visão mais real da composição e do funcionamento desse ambientes para melhor entendimento das posteriores modelagens existentes neste trabalho.

\subsection{Considerações iniciais}

Os ambientes P.V.M. (Parallel Virtual Machine) [SUN94] e M.P.I. (Message Passing Interface) [WAL94] têm tido grande destaque na literatura, não só pela flexibilidade mas também pelo fato de constituírem um tipo de solução para o problema da portabilidade de programas paralelos entre sistemas diferentes.

O P.V.M. é um ambiente paralelo virtual que alcançou grande aceitação nos mais variados setores (acadêmico, industrial, comercial, etc) podendo ser atualmente descrito como um padrão "de fato" entre os ambientes paralelos virtuais [SUN94] [GEI94].

Apesar da grande utilização do P.V.M., existem numerosas plataformas de programação com objetivos semelhantes, o que gera um problema semelhante com relação à real portabilidade dos programas.

Por volta de 1992, iniciou-se um processo de padronização para plataformas de portabilidade, agregando vários representantes de várias organizações, principalmente européias e americanas, e que gerou o M.P.I. (Message Passing Interface) [DON95] [DOS96] [WAL94].

O M.P.I. baseia-se nas melhores características de todas os ambientes de paralelos virtuais e tenta explorar as vantagens de cada um deles.

\subsection{P.V.M. - Parallel Virtual Machine}

O "Parallel Virtual Machine" é um conjunto integrado de bibliotecas e de ferramentas de software, cuja finalidade é emular um sistema computacional concorrente heterogêneo, flexível e 
de propósito geral [BEG94]. Seu surgimento ocorreu em 1989 no ORNL - Oak Ridge National Laboratory.

Diferente dos demais ambientes portáteis, o P.V.M. nasceu com o objetivo de permitir que um grupo de computadores fossem conectados, permitindo diferentes arquiteturas de maneira a formar uma máquina paralela virtual [GEI94]. O sistema P.V.M. permite que sejam escritas aplicações nas linguagens Fortran, $\mathrm{C}$ e $\mathrm{C}++$, sendo que a escolha desse conjunto de linguagem se deve ao fato de que a maioria das aplicações possíveis de serem paralelizáveis estão escritas nessas linguagens.

Existem inúmeras vantagens em utilizar-se o P.V.M.:

- Possibilidade efetiva de utilização de computação paralela, ainda que em arquitetura não-paralela;

- Redução do tempo total de execução do programa;

- Capacidade de paralelização escalável e dinâmica;

- Facilidade de instalação e uso;

- Software de domínio público;

- Grande difusão e aceitação;

- Flexibilidade;

- Variedade de arquiteturas e redes de trabalho;

- Recurso computacional facilmente expansível;

- Independência das aplicações;

- Fácil atualização;

- Facilidade de Programação graças a bibliotecas para linguagens universalmente usadas (Fortran e C).

O P.V.M. está atualmente disponível para diversas plataformas. A

Tabela 3-1 mostra alguns dos equipamentos que podem ser utilizados pela versão 3.3. 
Tabela 3-1 - Alguns dos principais equipamentos que executam o PVM

\begin{tabular}{|l|}
\hline Alliant FX/8 \\
\hline DEC Alpha \\
\hline Sequent Balance \\
\hline Bbn Butterfly TC2000 \\
\hline 80386/486/Pentium com UNIX (Linux ou BSD) \\
\hline Thinking Machines CM2 CM5 \\
\hline Convex C-series \\
\hline C-90, Ymp, Cray S-MP \\
\hline HP-9000 modelo 300, Hp-9000 PA-RISC \\
\hline Intel iPSC/860, Intel iPSC/2 386 host \\
\hline Intel Paragon \\
\hline DECstation 3100, 5100 \\
\hline IBM/RS6000, IBM RT \\
\hline Silicon Graphics \\
\hline Sun 3, Sun 4, SPARCstation, Sparc multiprocessor \\
\hline DEV Micro VAX \\
\hline
\end{tabular}

As novas tendências apontam para utilização em PC's e Internet, ou seja, PVM-W95 (para plataforma e windows 32 bits) [SOU96] e Java-PVM.

\subsubsection{Modelo P.V.M.}

Com o P.V.M., uma coleção de computadores heterogêneos (seqüenciais, paralelos e vetoriais) desempenham as funções de um computador com memória distribuída e alto desempenho. O P.V.M. oferece funções para inicialização, comunicação e sincronização de tarefas na máquina virtual. Uma tarefa é uma unidade computacional em P.V.M., análoga aos processos UNIX [SUN94] [ GEI94].

O modelo do P.V.M. é baseado na noção de que uma aplicação consiste de diversas tarefas. Cada tarefa é responsável pela execução de uma parte da aplicação. Uma aplicação pode ser paralelizada por dois métodos: o paralelismo funcional e o paralelismo de dados. No paralelismo funcional a aplicação é dividida através das suas funções, isto é, cada tarefa desempenha um serviço diferente. O paralelismo de dados refere-se ao paradigma SPMD descrito a seguir.

Os programas executados nos diversos processadores não devem, necessariamente, ser distintos, podendo utilizar o paradigma S.P.M.D. (Single Program - Multiple Data). Esse paradigma implica que o mesmo código fonte seja distribuído pelos processadores, e cada processador deve executá-lo de maneira independente, o que implica na execução de diferentes partes desse programa, em cada um dos processadores. Quando se distribui códigos fontes 
distintos para os processadores, utiliza-se o paradigma M.P.M.D. (Multiple Program - Multiple Data).

\subsubsection{Componentes do P.V.M.}

O P.V.M. possui dois componentes básicos: o daemon (PVMd) e a biblioteca de rotinas com a interface P.V.M. (Libpvm). O PVMd é um processo Unix, pertencente ao usuário, que é executado em cada host que compõe a máquina virtual, atuando como "gerenciador" da máquina e roteador de mensagens. É, portanto, o responsável pela aplicação P.V.M.. O esquema de controle dos daemons baseia-se no modelo mestre-escravo, onde cada máquina deve possuir a sua versão do daemon, de acordo com a compilação para aquela arquitetura. Durante a maioria das operações os PVMds não possuem diferença, isso ocorre apenas quando há necessidade de operações de gerenciamento, casos em que somente o mestre pode executar.

O PVMd foi projetado para ser instalado por qualquer usuário com um login válido. Quando um usuário deseja executar uma aplicação PVM, ele deve primeiro criar a máquina virtual iniciando-a com o PVMd. A aplicação poderá ser então executada a partir de qualquer máquina pertencente à máquina virtual. Pode haver mais de uma máquina virtual utilizando os mesmos equipamentos simultaneamente, sendo que uma aplicação não interfere nas demais.

As estruturas de dados mais importantes no PVMd são as tabelas de hosts e de tarefas, que descrevem a configuração da máquina virtual e determinam as tarefas que estão sendo executadas [BEG94] [GEI94].

A biblioteca Libpvm foi desenvolvida com o objetivo de torná-la tão pequena quanto possível, pelo fato de compartilhar espaço de endereçamento com o código desenvolvido pelo usuário. As rotinas pertencentes à Libpvm podem ser chamadas pelo usuário para efetuar passagem de mensagens, solicitar geração de processos, coordenar tarefas e modificar a máquina virtual.

Suas funções de mais alto nível são responsáveis pela interface com o usuário e são escritas de forma independente da máquina onde o P.V.M. está executando. Já as de mais baixo nível, que são dependentes da plataforma escolhida, foram separadas para permitir a sua substituição quando há necessidade de portabilidade.

A Figura 3-1 ilustra a localização dos componentes do P.V.M.: 


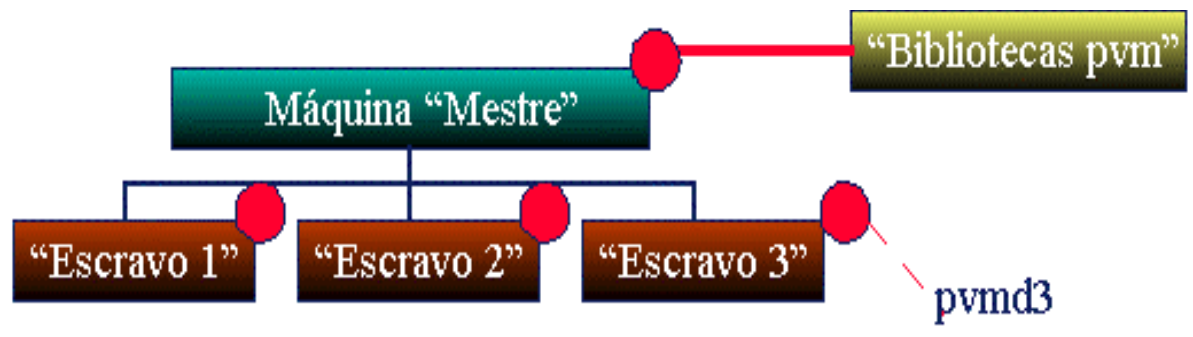

Figura 3-1 - Componentes do P.V.M.

\subsubsection{Tratamento das mensagens no P.V.M.}

O P.V.M. oferece rotinas para o "empacotamento" e o envio de mensagens entre tarefas. $\mathrm{O}$ modelo permite a qualquer tarefa enviar uma mensagem para outra, sem limites para o tratamento ou número dessas mensagens.

Enviar uma mensagem no P.V.M. consiste em três passos:

- um buffer deve ser criado para que as mensagens enviadas sejam depositadas temporariamente;

- a mensagem deve ser "empacotada" dentro do buffer;

- a mensagem inteira (o conteúdo do buffer) é enviada para outra tarefa ou grupo de tarefas.

O recebimento de mensagens, entretanto, pode ser feito por uma função bloqueante ou não-bloqueante. A mensagem é então "desempacotada", retirando do buffer os dados enviados. As rotinas que manipulam o recebimento das mensagens podem ser instruídas para aceitar:

- quaisquer mensagens;

- quaisquer mensagens de uma tarefa específica;

- quaisquer mensagens com um identificador específico (número de mensagem);

- somente mensagens de uma tarefa específica com um identificador específico. 
Para o usuário P.V.M., a comunicação empregada utiliza send bloqueante assíncrono, receive bloqueante assíncrono e receive não bloqueante. $\mathrm{O}$ send é chamado de bloqueante porque retorna o buffer utilizado para enviar a mensagem esteja livre para ser novamente utilizado e é chamado de assíncrono porque não depende do receptor executar um receive para poder retornar. O send só bloqueia quando a mensagem exceder o tamanho do buffer e precisar ser dividida. Nesse caso o send fica bloqueado até o receptor executar um receive e liberar o buffer para continuar o envio da mensagem.

Um receive é não bloqueante quando ele retorna imediatamente após ter verificado o buffer no host receptor. No caso da mensagem não estar disponível, é retornado um código indicando que o buffer não possui a mensagem. Um receive bloqueante não retorna enquanto a mensagem esperada não for recebida e inserida no buffer [GEI94] [BEG94] [SUN94].

O P.V.M. oferece comunicação ponto-a-ponto, broadcasting e multicasting.

\subsubsection{Iniciar e Finalizar o P.V.M. Daemon (PVMd)}

Quando iniciado, o PVMd é configurado como mestre ou como escravo, dependendo dos argumentos informados. Como suas principais finalidades são o roteamento de mensagens e a configuração da máquina virtual, o primeiro passo é criar mecanismos de comunicação entre processos e permitir a sua utilização, permitindo assim a comunicação com as tarefas e outros hosts e sobre as tarefas P.V.M., que estão em execução sob a sua supervisão.

Depois de configurado o PVMd entra em loop na função work(), cuja finalidade é aguardar o recebimento de mensagens. Pacotes são recebidos e são colocados em filas para posterior envio ao seu verdadeiro destino, ou, ainda, são recuperados no PVMd. Nesse caso as mensagens recebidas são requisições para que o PVMd adicione hosts, retire hosts, informe como está configurada a máquina virtual, entre outras atividades do PVMd.

Quando o PVMd termina suas atividades (é finalizado) ele realiza duas ações: envia um sinal (signal SIGTERM) eliminando todas as tarefas subordinadas a ele; segundo, ele envia uma mensagem que finaliza todos os outros PVMds informando sua saída da máquina virtual. Os outros PVMds têm condições de descobrir sozinhos a falta de outro host, visto que a cada período de tempo é feita uma comunicação para verificar as condições da máquina virtual. Porém a mensagem indicando uma finalização acelera o processo.

A finalização do PVMd mestre implica na finalização de toda a máquina virtual, visto que não há tratamento dessa condição no P.V.M.. 


\subsubsection{Protocolos de Comunicação}

A comunicação realizada pelo P.V.M. é baseada em TCP (Transmission Control Protocol), UDP (User Datagram Protocol) e sockets do domínio UNIX assumindo-se, portanto, que todos os hosts pertencentes à máquina virtual sejam capazes de conectarem-se através desses mecanismos de comunicação. Algumas máquinas multiprocessadoras, entretanto, não possuem sockets disponíveis em seus elementos de processamento, possuindo hosts que atuam como front-end, onde é possível executar tais mecanismos de comunicação.

O trabalho de gerenciar a memória, executar o chaveamento de contextos e operações de cópia, quando feitas no espaço do usuário, torna-se caro. O desempenho aumentaria se o código estivesse no kernel ou se a interface da rede estivesse disponível diretamente para os processos.

Uma abordagem que está sendo investigada é habilitar as operações do P.V.M. diretamente na camada de enlace de dados, ao invés de utilizar a camada de transporte. Protótipos do P.V.M. que operam com essa mudança têm sido desenvolvidos e a melhoria no tempo de latência tem sido de aproximadamente 50\%. Os trabalhos atuais têm o objetivo de incorporar essa melhoria no P.V.M., permitindo-lhe determinar onde é melhor a sua utilização ou não, considerando desempenho, portabilidade e confiabilidade [SUN94].

A comunicação no P.V.M. é feita em três formas: entre Pvmds, entre um Pvmd e suas tarefas e entre tarefas. No decorrer deste trabalho essas conexões também serão referenciadas como: protocolo de comunicação Pvmd $\Leftrightarrow \mathrm{Pvmd}$, Pvmd $\Leftrightarrow$ Tarefa e Tarefa $\Leftrightarrow$ Tarefa.

\subsubsection{Tolerância a Falhas}

O P.V.M. (versão 3) foi projetado para resistir à maioria das falhas envolvendo hosts e redes. Ele não recupera automaticamente uma aplicação depois de algum erro, porém fornece os recursos necessários para que o usuário construa aplicações tolerantes a falhas (pelo menos à maioria delas).

Quando um host escravo perde a comunicação com o mestre, ele mesmo (o escravo) provoca a sua saída da máquina virtual, eliminando também todas as tarefas e operações pendentes nos salvadores de contexto, permitindo que a máquina virtual continue operando.

Por outro lado, quando o host mestre perde a comunicação com um host escravo, este é retirado da máquina virtual pelo mestre.

Quando o host mestre for "perdido", toda a máquina virtual é finalizada. 


\subsubsection{P.V.M. em Sistemas com Multiprocessadores}

Desenvolvido inicialmente para executar em estações de trabalho com UNIX, o P.V.M. foi também adaptado para as máquinas com multiprocessadores, devido à necessidade de seus usuários executarem aplicações específicas.

Baseando-se em uma das suas principais características que é a portabilidade, o P.V.M. foi reconfigurado e, como resultado final, as aplicações desenvolvidas para as estações de trabalho puderam executar em computadores com multi-processadores (necessitando obviamente de recompilação). Os resultados podem ser exibidos em uma estação de trabalho ou outro equipamento que faça o papel de front-end.

Computadores com memória compartilhada podem ser utilizados para as aplicações com menor granulosidade. Isso é feito colocando-se as informações necessárias em um buffer, que agora pode ser compartilhado por outros processadores.

A máquina virtual esconde os detalhes de configuração do usuário. Os processadores físicos podem ser uma rede de estações de trabalho ou nós de um computador com multiprocessadores. O usuário não sabe como as tarefas são criadas ou onde elas estão sendo executadas. É responsabilidade do P.V.M. estabelecer quais tarefas irão executar em cada processador. Entretanto, há possibilidade de se especificar uma configuração desejada para determinadas tarefas, onde o objetivo é atingir o máximo de desempenho possível mesmo com o custo imposto pela portabilidade [BEG94].

\subsubsection{Limitações no PVMd e na Libpvm}

O P.V.M. foi projetado para, sempre que possível, não impor nenhum tipo de limitação de acesso aos seus recursos. Normalmente os limites são impostos pelo hardware e/ou pelo sistema operacional utilizados. Sistemas multi-usuários afetam dinamicamente os limites do sistema.

A quantidade de tarefas que cada P.V.M. pode gerenciar e a quantidade de memória disponível para tais processos são os dois grandes fatores de limitação do PVMd.

O número de tarefas P.V.M. é limitado por dois fatores. O primeiro está relacionado com o número de processos concorrentes permitidos pelo sistema operacional, sendo raramente esgotado pelo P.V.M.. Não faz sentido ter uma quantia demasiadamente grande de processos em um único host. O segundo fator é o número de descritores de arquivos permitidos ao PVMd, ou seja, quantos arquivos um processo pode manter aberto ao mesmo tempo. É bom lembrar que cada mecanismo de comunicação (socket) representa um descritor utilizado, assim como cada tarefa filha do PVMd (a grande maioria das tarefas P.V.M. são filhas do daemon) também utiliza 
um descritor. O PVMd pode tornar-se o "gargalo do sistema" se todas as tarefas tentarem comunicar-se através dele.

O PVMd aloca memória dinamicamente para armazenar as mensagens roteadas por ele. Enquanto a tarefa destino não aceita a sua mensagem, os pacotes são armazenados em filas no PVMd, sendo que não há nenhum controle de fluxo para tais pacotes, ou seja, o PVMd irá aceitar qualquer pacote que chegue para ele, até não conseguir mais alocar memória para armazená-los.

As tarefas P.V.M. também possuem um limite no número de conexões diretas que elas podem fazer com outras tarefas, embora esse problema não exista se a comunicação for feita através do PVMd.

A maior mensagem P.V.M. possível para uma tarefa é limitada pela quantia de memória disponível para a tarefa. Quando a mensagem é enviada via PVMd, este aloca memória para poder roteá-la, o que diminui o tamanho considerado como disponível.

Se muitas tarefas enviam mensagens, ao mesmo tempo, para a mesma tarefa destino, tanto o PVMd quanto a tarefa destino ficam sobrecarregados, tentando armazenar as mensagens. Esses problemas devem ser considerados, projetando-se aplicações para usarem mensagens pequenas, eliminarem "gargalos" e gerenciarem as mensagens na mesma ordem que elas foram geradas.

\subsection{M.P.I. - Message Passing Interface}

Message Passing Interface consiste em uma tentativa de padronização, independente de plataforma paralela, para ambientes de programação via troca de mensagens. O M.P.I. surgiu da necessidade de se resolver alguns problemas relacionados às plataformas de portabilidade, tais como o grande número de plataformas existentes ocasiona restrições em relação à real portabilidade de programas e ao mau aproveitamento de características de algumas arquiteturas paralelas.

David Walker [WAL94] relaciona, de maneira mais geral, uma série de motivos que explicam a necessidade de um padrão para este tipo de sistema:

- Portabilidade e facilidade de uso: À medida que aumentar a utilização do M.P.I., será possível transportar, transparentemente, aplicações entre um grande número de plataformas paralelas;

- Fornecer uma especificação precisa: Fabricantes de hardware podem implementar em suas máquinas eficientemente um conjunto bem definido de rotinas; 
- Crescimento da indústria de software paralelo: A existência de um padrão torna a criação de software paralelo (ferramentas, bibliotecas, aplicativos, etc.) por empresas uma opção comercialmente viável;

- Incentivar uma maior utilização de arquiteturas paralelas: $O$ crescimento da indústria de software paralelo implica em maior difusão do uso de computadores paralelos.

O processo de padronização envolveu cerca de 80 pessoas, provenientes de 40 organizações, principalmente americanas e européias. A maioria dos principais fabricantes de computadores paralelos participaram do desenvolvimento do M.P.I., além de universidades e laboratórios ligados ao governo americano. Os principais objetivos que guiaram o processo de padronização foram [DON95] [DOS96]:

- Lançar uma versão inicial em um tempo predefinido, de maneira que não se perdesse o controle sobre o padrão;

- Prover portabilidade real;

- Prover implementação eficiente em plataformas paralelas distintas;

- Possuir uma aparência compatível com a atualidade, visto que uma interface totalmente nova dificultaria a sua aceitação.

Procurou-se aproveitar as melhores características de cada uma das plataformas de portabilidade, de maneira que todo o esforço e estudo que já havia sido despendido nesse tipo de plataforma fosse aproveitado, levando-se também em consideração a necessidade de eficiência em todas as plataformas paralelas. O problema da eficiência em qualquer plataforma gera complicações, uma vez que determinadas operações são feitas com diferente eficiência em diferentes plataformas paralelas e por diferentes protocolos. Por isso, algumas rotinas no MPI são implementadas de várias formas (de maneira que se aproveitem as qualidades intrínsecas de cada plataforma paralela), o que gera uma certa complexidade. Porém, tal problema é inevitável quando se almeja um padrão que englobe diferentes tipos de arquiteturas computacionais.

\subsubsection{A História do M.P.I.}

O processo de desenvolvimento do M.P.I. foi iniciado em abril de 1992, sendo que, em novembro do mesmo ano uma primeira versão foi apresentada (M.P.I. 1). Essa versão, ainda incompleta, tinha como principal função mostrar que o esforço era válido [DOS96] [WAL94].

A partir do M.P.I. 1 decidiu-se colocar o processo de padronização em bases mais formais, de maneira mais organizada. Foram então criados comitês, um para cada componente 
do M.P.I., e também foram criadas lista de discussões para cada um desses comitês. O grupo de desenvolvimento passaria a se encontrar de 6 em 6 semanas, e o conjunto dessas reuniões e lista de discussões se definiu como o Fórum M.P.I..

Em novembro de 1993 foi apresentada a especificação do padrão M.P.I. versão 1.0, sendo esta publicada em maio de 1994. Em junho de 1995, foi publicada a versão 1.1, apresentando correções de erros e melhor esclarecimento de determinadas propriedades do M.P.I..

\subsubsection{Especificação do M.P.I.}

Levando-se em consideração o limite de tempo imposto à formulação do padrão, definiuse um conjunto básico de rotinas relacionadas à comunicação ponto-a-ponto e coletiva, deixando para uma próxima versão uma maior abrangência de operações.

O M.P.I. define um conjunto de 129 rotinas, que oferecem os seguintes serviços [DON95] [MAC96] [SNI96]:

- Comunicação ponto-a-ponto;

- Comunicação coletiva;

- Suporte para grupos de processos;

- Suporte para contextos de comunicação;

- Suporte para topologia de processos.

Analisando-se cada um dos tópicos anteriores, têm-se [DON95] [MAC96] [PAP95] [SNI96] [WAL94]:

- Comunicação Ponto-a-Ponto e Coletiva: O M.P.I. implementa diversos tipos de comunicação.

- Suporte para Grupos de Processos: O M.P.I. relaciona os processos em grupos, e esses processos são identificados pela sua classificação dentro desse grupo, a partir de zero. Essa classificação dentro do grupo é denominada rank. O M.P.I. apresenta primitivas de criação e destruição de grupos de processos. Então, um processo no M.P.I. é identificado por um grupo e por um rank dentro deste grupo.

- Suporte para Contextos de Comunicação: Contextos podem ser definidos como escopos que relacionam um determinado grupo de processos. Esses tipos de 
instâncias são implementadas com o intuito de garantir que não existam mensagens que sejam recebidas ambiguamente por grupos de processos não relacionados. Então, um grupo de processos ligados por um contexto não consegue comunicar-se com um grupo que esteja definido em outro contexto. Esse tipo de estrutura não é visível nem controlável pelo usuário, e o seu gerenciamento fica a cargo do sistema. Para a criação de contextos, o M.P.I. se utiliza do conceito de communicator. Um communicator é um objeto manuseado pelo programador e relaciona um grupo (ou grupos) de processos com um determinado contexto. Se existem, por exemplo, aplicações paralelas distintas executando em um mesmo ambiente, para cada uma delas será criado um communicator. Isso criará contextos distintos que relacionarão os grupos de processos de cada aplicação e evitará que esses interfiram entre si.

- Suporte para Topologias: O M.P.I. fornece primitivas que permitem ao programador definir a estrutura topológica que descreve o relacionamento entre processos. Como exemplo de uma topologia, pode-se citar uma malha, onde cada ponto de intersecção na malha corresponde a um processo.

O padrão M.P.I. apresenta as seguintes características:

- Eficiência - foi cuidadosamente projetado para executar eficiente em máquinas diferentes. Especifica somente o funcionamento lógico das operações. Deixa em aberto a implementação. Os desenvolvedores otimizam o código usando características específicas de cada máquina.

- Facilidade - Define uma interface não muito diferente dos padrões P.V.M., Express, P4, etc, e acrescenta algumas extensões que permitem maior flexibilidade.

- Portabilidade - É compatível com sistemas de memória distribuída, shared-memory, NOWs (network of workstations) e uma combinação deles.

- Transparência - Permite que um programa seja executado em sistemas heterogêneos sem mudanças significativas.

- Segurança - Provê uma interface de comunicação confiável. O usuário não precisa se preocupar com falhas na comunicação.

- Escalabilidade - O M.P.I. permite crescimento em escala sob diversas formas, por exemplo, uma aplicação pode criar subgrupos de processos que permitem operações de comunicação coletiva para melhorar o alcance dos processos.

As principais implementações do M.P.I. são apresentadas na Tabela 3-2 : 
Tabela 3-2 - Implementações do M.P.I.

\begin{tabular}{|l|}
\hline IBM MPI : Implementação IBM para Clusters \\
\hline $\begin{array}{l}\text { MPICH : Argonne National Laboratory; Mississipi State } \\
\text { University }\end{array}$ \\
\hline UNIFY: Mississipi State University \\
\hline CHIMP: Edinburgh Parallel Computing University \\
\hline LAM: Ohio Supercomputer Center \\
\hline PM PIO: NASA \\
\hline $\begin{array}{l}\text { MPIX: Mississipi State University NSF Enginnering } \\
\text { Research Center }\end{array}$ \\
\hline
\end{tabular}

\subsubsection{Comunicação no M.P.I.}

As rotinas de comunicação (ponto-a-ponto e coletiva) formam o núcleo básico do M.P.I. [DON95] [MAC96] [PAP95] [SNI96] [WAL94]. Antes de apresentar essas rotinas, é importante entender como o M.P.I. organiza uma mensagem.

Uma mensagem no M.P.I. é definida como um vetor de elementos de um determinado tipo. Ao se enviar uma mensagem, deve-se indicar o endereço do primeiro elemento desse vetor e o número de elementos que o formam. Esses elementos devem ser do mesmo tipo.

Deve-se indicar na mensagem o tipo dos elementos sendo enviados. Essa característica é essencial quando a comunicação é realizada entre sistemas heterogêneos, tornando necessária a conversão dos dados.

O M.P.I. permite que se criem tipos definidos pelo usuário, tornando possível enviar mensagens compostas por elementos de tipos distintos, como por exemplo, estruturas (structs) [MAC96].

Para as operações de comunicação, o M.P.I. define:

Rotina Send(): A maneira eficiente de implementação de uma rotina send( ) depende, de certa maneira, do protocolo e da plataforma paralela sobre as quais o M.P.I. está executando. Para garantir a eficiência em qualquer plataforma, o M.P.I. define vários modos de comunicação, que definem diferentes semânticas para a rotina. Os modos disponíveis, que apresentam versões bloqueantes e não bloqueantes, são:

- Síncrono: o transmissor, ao enviar uma mensagem, espera uma confirmação de recepção da mensagem; 
- Com Buffer: mensagens são transmitidas via buffers explicitamente criados pelo programador;

- Padrão: o modo mais eficiente de comunicação, podendo ser síncrono ou com buffer;

- Ready: necessita que o receive( ) correspondente tenha sido iniciado.

A definição de bloqueio de rotinas utilizada pelo Fórum M.P.I., caracteriza-se pela sobreposição ou não de operações de comunicação, em relação à execução do programa.

Outras variantes para rotinas de comunicação ponto-a-ponto também são definidas tais como rotinas de comunicação em dois sentidos e requisições persistentes.

Rotina Receive( ): Uma mensagem é selecionada para recebimento pelo rank do processo que a enviou e pelo seu identificador ( $t a g$ ), dentro de um determinado contexto. Esses dois valores podem ser wild-cards, isto é, podem utilizar rotinas que recebam de qualquer processo mensagens de qualquer tag. A rotina receive( ) não possui desdobramento em modos, podendo ser bloqueante ou não.

Rotinas Coletivas: O M.P.I. define todos os tipos de rotinas coletivas, que são rotinas broadcast( ), aritméticas globais e de sincronização. Também, outras variantes de rotinas coletivas foram definidas: rotinas gather( ), scather( ), e uma combinação das duas anteriores [DON95] [MAC96] [SNI96].

Essa grande variedade de funções coletivas se explica pelo fato de se garantirem operações coletivas eficientes em todas as plataformas paralelas. Todas as operações coletivas no MPI são bloqueantes e executam no modo padrão. 


\subsection{Diferenças entre P.V.M. e M.P.I.}

Portabilidade versus Interoperabilidade:

\begin{tabular}{|c|c|}
\hline P.V.M. & M.P.I. \\
\hline Nível de Interoperabilidade & Nível de Portabilidade \\
\hline $\begin{array}{l}\text { Além da portabilidade (como o } \\
\text { M.P.I.), os programas permitem } \\
\text { interoperabilidade, tornando possível } \\
\text { execuções em arquiteturas distintas } \\
\text { sem quaisquer modificações no fonte. }\end{array}$ & $\begin{array}{l}\text { Programas escritos para uma } \\
\text { arquitetura podem ser compilados } \\
\text { para uma outra arquitetura, } \\
\text { executados sem quaisquer } \\
\text { modificações. }\end{array}$ \\
\hline
\end{tabular}

Máquina Virtual

\begin{tabular}{|c|c|}
\hline P.V.M. & M.P.I. \\
\hline Completa Abstração & (Não há Suporte) \\
\hline $\begin{array}{l}\text { O P.V.M. permite que se veja a } \\
\text { rede como uma coleção dinâmica de } \\
\text { recursos computacionais } \\
\text { (potencialmente heterogêneos), } \\
\text { administrados como um computador } \\
\text { paralelo único. }\end{array}$ & $\begin{array}{l}\text { O M.P.I. não possui o } \\
\text { conceito da máquina virtual paralela, } \\
\text { centralizando-se no conceito de } \\
\text { message passing. }\end{array}$ \\
\hline $\begin{array}{l}\text { Controle de Processos: } \\
\text { Capacidade de iniciar, interromper e } \\
\text { controlar processos, em tempo de } \\
\text { execução; }\end{array}$ & $\begin{array}{l}\text { Controle de Processos: } \\
\text { Bastante restrito - permite somente o } \\
\text { controle de grupos de tarefas; }\end{array}$ \\
\hline $\begin{array}{l}\text { Controle de Recursos: } \\
\text { Bastante dinâmico - permite abstração, } \\
\text { graças ao conceito da máquina virtual } \\
\text { paralela; }\end{array}$ & $\begin{array}{l}\text { Controle de Recursos: } \\
\text { Essencialmente estático - não de } \\
\text { suporte a qualquer nível de abstração; }\end{array}$ \\
\hline $\begin{array}{l}\text { Topologia: } \\
\text { O P.V.M. exige que o programador } \\
\text { arranje manualmente tarefas em } \\
\text { grupos, segundo a organização } \\
\text { desejada. }\end{array}$ & $\begin{array}{l}\text { Topologia: } \\
\text { O M.P.I. provê um alto nível de } \\
\text { abstração, em termos de topologia. }\end{array}$ \\
\hline
\end{tabular}


Tolerância a Falhas

\begin{tabular}{|l|l|}
\hline \multicolumn{1}{|c|}{ P.V.M. } & \multicolumn{1}{c|}{ M.P.I. } \\
\hline Básico & Rudimentar \\
$\begin{array}{l}\text { Existem esquemas básicos de } \\
\text { notificação de falha, para alguns casos. } \\
\begin{array}{l}\text { Porém, permite flexibilidade de forma } \\
\text { que, ainda em certas situações onde } \\
\text { não existe resposta de uma máquina, } \\
\text { uma aplicação receba resultados das } \\
\text { outras. }\end{array}\end{array}$ & $\begin{array}{l}\text { As versões iniciais, não } \\
\text { incluíam qualquer esquema de } \\
\text { tolerância , mas a partir das últimas } \\
\text { especificações, esquemas similares ao } \\
\text { de P.V.M. são providos. }\end{array}$ \\
\hline
\end{tabular}

Segurança e Comunicação

\begin{tabular}{|l|l|}
\hline \multicolumn{1}{|c|}{ P.V.M. } & \multicolumn{1}{|c|}{ M.P.I. } \\
\hline Existente & Excelente \\
\multicolumn{1}{|c|}{ O daemon que mantém a } \\
$\begin{array}{l}\text { máquina virtual pode ser usado para } \\
\text { criar rótulos únicos de contexto. } \\
\begin{array}{l}\text { Processos podem se comunicar com } \\
\text { grupos, permitindo recuperação de } \\
\text { falhas. As novas versões pretendem } \\
\text { fazer uso de communicators, como os } \\
\text { do M.P.I.. }\end{array}\end{array}$ & $\begin{array}{l}\text { O conceito de communicators } \\
\text { no M.P.I., permite um elevado nível } \\
\text { permitindo diferenciar mensagens de } \\
\text { bibliotecas de mensagens de usuários. }\end{array}$ \\
\hline
\end{tabular}

\subsection{Considerações Finais}

Os ambientes paralelos virtuais constituem uma abordagem eficiente para a implementação de programas paralelos utilizando troca de mensagens. A possibilidade de transportar programas diretamente entre ambientes heterogêneos, incluindo arquiteturas paralelas e sistemas distribuídos é um grande atrativo.

Dentre as plataformas de portabilidade destaca-se o P.V.M. por sua generalidade e adequabilidade a uma grande gama de aplicações. Assim, ele é caracterizado como a plataforma mais utilizada dentre todas [MCB94], sendo inclusive considerado por muitos um padrão "de fato" [SUN94]. 
Entretanto, fazia-se ainda necessária uma plataforma de portabilidade que possibilitasse eficiência e segurança em qualquer plataforma paralela e que fosse um padrão "oficial", de modo a ser aceito largamente na comunidade computacional,, além de oferecer ferramentas não proporcionadas pelo P.V.M., devido à sua simplicidade.

O fato do M.P.I. ter sido projetado para fornecer eficiência, não implica que necessariamente sua implementação o será. O Fórum M.P.I. define apenas indicações de possíveis maneiras eficientes de implementação de determinadas partes do padrão.

Como tendência futura aparece o PVMPI, que consiste em uma proposta da Oak Ridge National Laboratory at University of Tennessee, viabilizando uma mistura entre as características do P.V.M. e do M.P.I..

Seu funcionamento dar-se-ia de modo a utilizar implementações específicas de hardware, quando disponíveis em máquinas multiprocessadores; permitir acesso à idéia de uma máquina virtual, com controle de recursos e tolerância a falhas; usar a rede de comunicação P.V.M. transparentemente, para transferir dados entre diferentes implementações de M.P.I., permitindo a interoperabilidade. Enfim, seria um misto entre funções do P.V.M. e do M.P.I., mantendo, tanto quanto possível, as identidades desses dois ambientes de passagem de mensagens.

Enquanto o PVMPI não se torna disponível, a decisão entre a utilização de um ou do outro ambiente deve ponderar as características e necessidades da aplicação, levando em conta as configurações do ambiente e da arquitetura. Uma regra básica para a escolha é levar-se em consideração as seguintes recomendações:

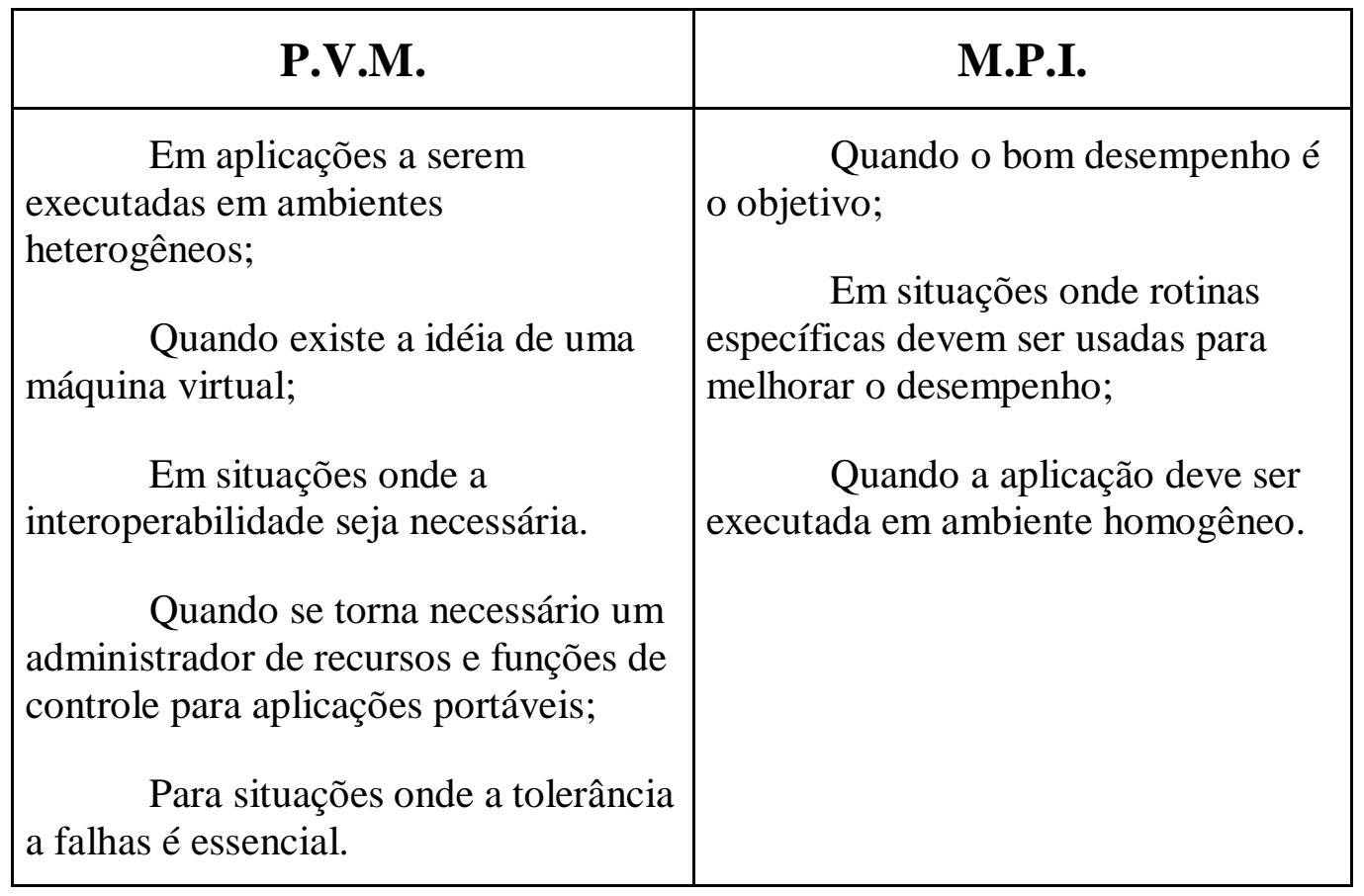


Independente da escolha desses ambientes, não existem muitas ferramentas que auxiliem a escritas desses programas, tanto por usuários com conhecimento, como por usuários que não tenham conhecimento do ambiente mas possuam um mínimo de conhecimento de programação paralela.

Dessa maneira, o próximo capítulo apresenta uma revisão das ferramentas para desenvolvimento de programas paralelos indicando os objetivos da existência dessas ferramentas, quais as ferramentas existentes e a motivação para desenvolvimento desse tipo de ferramentas. 


\section{Ferramentas para Desenvolvimento de Programas Paralelos}

Técnicas, cada vez mais aprimoradas, têm sido criadas para o desenvolvimento de ferramentas que auxiliem o desenvolvimento de sistemas computacionais tanto no que diz respeito à criação de arcabouços quanto no apoio à documentação de programas aplicativos.

Este capítulo tem como objetivo apresentar a motivação para o uso de ferramentas que auxiliem o desenvolvimento de programas paralelos, indicando o funcionamento dessas ferramentas e mostrando alguns exemplos existentes.

\subsection{Considerações Iniciais}

Dentre as áreas que compõem a ciência, sem dúvida, uma das quais apresentou desenvolvimento surpreendente nas últimas décadas é a ciência computacional. A engenharia eletrônica tem proporcionado um alto grau de desenvolvimento ao hardware, o que entretanto não vem ocorrendo nas mesmas proporções com o software, pelo fato de não existir suporte estável a aplicações e documentações atualizadas [PRE95].

O constante avanço tecnológico, forçando uma redução do custo do hardware, permitiu a entrada de computadores pessoais dentro das casas e dos escritórios. Esses fatores combinados implicam em uma análise da evolução das arquiteturas (Capítulo 2) e demonstram a necessidade do aumento significativo do desempenho de programas, que pode ser obtido com a paralelização do código, implicando na utilização de arquiteturas paralelas.

Plataformas de desenvolvimento de aplicações estáveis para máquinas seqüenciais não foram ainda estabelecidas e já apareceram os problemas relacionados às arquiteturas paralelas e ao fato das ferramentas utilizadas para o desenvolvimento de software paralelo serem dependentes do hardware.

Alguns problemas da programação paralela, decorrentes da utilização das arquiteturas paralelas, podem ser enumerados:

- o desenvolvimento de algoritmos paralelos;

- determinação de condições de parada dos programas;

- gerenciamento de recursos ou dados para as subtarefas paralelas;

- granulosidade da aplicação e subtarefas;

- utilização de mecanismos de comunicação e balanceamento de cargas; e 
- gerenciamento da complexidade desses programas.

Na tentativa de solucionar alguns desses problemas surgem as ferramentas de auxílio à construção de programas paralelos, permitindo fácil manutenção e apoiando a documentação desses programas.

\subsection{Motivação para o Uso de Ferramentas de Apoio à Programação}

A existência de problemas na implementação de programas paralelos é incontestável, embora a tarefa de distribuição de dados e códigos nas máquinas paralelas possa ser feita automaticamente pelo sistema, de forma estática ou dinâmica.

Quando o uso de paralelismo se faz necessário, decorrente da possibilidade de ganho em desempenho e potência computacional, há conscientização das dificuldades impostas por essa abordagem e a adequação do software ao hardware é apresentada como fator determinante na obtenção do desempenho. Essa adequação tem se refletido nos sistemas computacionais modernos de modo a especificarem modelos arquiteturais aos softwares, determinando o domínio para o qual é desenvolvido. Assim, diversas técnicas, modelos matemáticos e métodos têm sido desenvolvidos com o intuito de reduzir o tempo de execução dos programas paralelos, otimizando-os da melhor forma possível.

Em conseqüência, pesquisas têm sido feitas no sentido de automatizar o processo de paralelização de programas seqüenciais. No entanto, ainda se faz necessária a presença de programadores experientes para que alterações sejam efetuadas na solução de problemas referentes ao balanceamento de cargas, sincronismo e comunicação [ZIM92].

A Tabela 4-1 [CAR94] apresenta as tendências de evolução dos sistemas e dos métodos computacionais, o desenvolvimento de linguagens de programação, técnicas de análise e projeto de sistemas, modelos de dados e arquiteturas dos computadores, apontando para a utilização de arquiteturas paralelas.

A pesquisa em programação paralela aponta para um futuro análogo ao da programação seqüencial, isto é, há necessidade do desenvolvimento e aprimoramento das técnicas de programação paralela/concorrente, fazendo-se necessário, também, o desenvolvimento de ferramentas que auxiliem essa programação. 
Tabela 4-1- Evolução dos Sistemas e Métodos Computacionais

\begin{tabular}{|c|c|c|c|c|}
\hline 2000 & & & & $\begin{array}{l}\text { Arquiteturas } \\
\text { maciçamente } \\
\text { paralela }\end{array}$ \\
\hline 1990 & $\begin{array}{l}\text { Geradores de código usando } \\
\text { ferramenta CASE para Análise } \\
\text { Orientada a Objetos. } \\
\text { Ambientes de passagem de } \\
\text { mensagem. Ferramentas para } \\
\text { conversão de programas } \\
\text { seqüenciais em paralelos. } \\
\text { Paradigma SPMD, Ling. de } \\
\text { Prog. Paralelas. }\end{array}$ & $\begin{array}{l}\text { Bancos de Dados Orient. } \\
\text { a Objetos } \\
\text { (Versant/Objective) }\end{array}$ & $\begin{array}{l}\begin{array}{l}\text { Análise } \\
\text { Orientada a } \\
\text { Objetos }\end{array} \\
\text { Análise } \\
\text { Estruturada }\end{array}$ & $\begin{array}{l}\text { Sistemas } \\
\text { Abertos, } \\
\text { Arquiteturas } \\
\text { paralelas, Discos } \\
\text { óticos. }\end{array}$ \\
\hline 1980 & $\begin{array}{l}\text { Geradores de código } \\
\text { associados a ferramentas } \\
\text { CASE, usando Análise } \\
\text { Estruturada. C++, Ling de } 4^{\text {a }} \text {. } \\
\text { Geração, SQL }\end{array}$ & $\begin{array}{l}\text { Modelo Entidade } \\
\text { Relacionamento } \\
\text { Modelos Relacionais } \\
\text { (DB2/Oracle) }\end{array}$ & $\begin{array}{l}\text { Moderna } \\
\text { Análise } \\
\text { Essencial } \\
\text { Análise } \\
\text { Estruturada }\end{array}$ & $\begin{array}{l}\text { Computação } \\
\text { Paralela/Con- } \\
\text { corrente Arq. } \\
\text { RISC. Redes }\end{array}$ \\
\hline 1970 & Smalltalk & $\begin{array}{l}\text { Modelo Hierárq. Modelo } \\
\text { de Rede (CODASYL) }\end{array}$ & $\begin{array}{l}\text { Análise } \\
\text { baseada na } \\
\text { decomp. } \\
\text { funcional } \\
\end{array}$ & $\begin{array}{l}\text { Sistemas de } \\
\text { Banco de Dados }\end{array}$ \\
\hline 1960 & $\begin{array}{l}\text { Ling. de } 3^{\text {a }} \text {. Geração (COBOL, } \\
\text { FORTRAN, PL/1) }\end{array}$ & $\begin{array}{l}\text { Sist. de Gerenc. de } \\
\text { Arquivos } \\
\text { (ISAM/VSAM) }\end{array}$ & & $\begin{array}{l}\text { Unidades de } \\
\text { Disco }\end{array}$ \\
\hline 1950 & Linguagem de máquina & & & Arq. SISD \\
\hline & Linguagens & Banco de Dados & $\begin{array}{l}\text { Análise de } \\
\text { Sistemas }\end{array}$ & Hardware \\
\hline
\end{tabular}

O processo de paralelização do código não pode, normalmente, ser totalmente automatizado. Dessa forma, a contribuição de maior benefício implica em prover uma ferramenta de paralelização de código onde ocorra interferência do usuário nos pontos críticos ou de paralelismo potencial [IER95]. Atualmente, para o programador, o desafio está em minimizar a alteração do código (de modo que, o código paralelo seja o mais similar possível ao código seqüencial) e gerar um código paralelo tão eficiente quanto possível.

Num mundo ideal, a implementação de software em sistemas paralelos deveria requerer os mesmos esforços gastos para a implementação do mesmo software em um sistema seqüencial convencional. Ou seja, um compilador altamente automático deveria permitir que o programador criasse códigos paralelos com o mínimo conhecimento de paralelização. 
Todo esse processo é tedioso e passível de erros. Uma forma de solucionar esses problemas é fazer uso de um conjunto de ferramentas que auxiliem, de forma prática, a automação de paralelização dos processos [CRO95]. Essas ferramentas tendem a evoluir em função das arquiteturas.

O que se espera dessas ferramentas é um grande aumento da produtividade e da qualidade dos programas por elas produzidos. Essa produtividade deve ocorrer basicamente na produção e manutenção do código gerado, de maneira que este código gerado seja condizente com a documentação.

Atualmente, ferramentas que têm por objetivo auxiliar a organização do código, estruturá-lo e simplificar seu desenvolvimento, são consideradas ferramentas CASE (Computer Aided Software Engineering) [TOW89].

\subsection{Ferramentas para Geração de Código Paralelo}

O desenvolvimento das arquiteturas paralelas objetiva o aumento do desempenho dos sistemas computacionais. Atrelados a esse desempenho encontram-se os altos custos, tanto para o desenvolvimento do hardware quanto para o software. Quanto mais próximas estiverem as implementações do software ao hardware, melhores serão os desempenhos obtidos [FOS95].

Os softwares têm se tornado mais flexíveis, e essa flexibilidade pode diminuir os custos de manutenção além de permitir maior portabilidade [CAL97].

Uma maneira de flexibilizar o software é através da utilização de ferramentas que auxiliem a geração automática de código paralelo. paralelo.

A seguir serão descritas algumas ferramentas de auxílio à geração automática de código

\subsubsection{CAPTools}

O CAPTools (Computer Aided Parallelisation Tools) foi concebido com a noção de que o processo de paralelização do código não deve ser totalmente automático, e que informações oriundas do programador são de vital importância durante o processo de paralelização.

A ferramenta CAPTools busca automatizar, tanto quanto possível, o processo de geração de código paralelo para Fortran 77, utilizando heurísticas para gerar partições de dados sendo especializada para aplicações numéricas. O seu ambiente foi projetado para permitir que o 
usuário explore e interaja na confecção do código, e insira seus conhecimentos para facilitar a geração automática de códigos paralelos mais eficientes.

Uma noção da estrutura do CAPTools é apresentada na Figura 4-1. Percebe-se que o componente chave do conhecimento do usuário é a especificação da estratégia de paralelização.

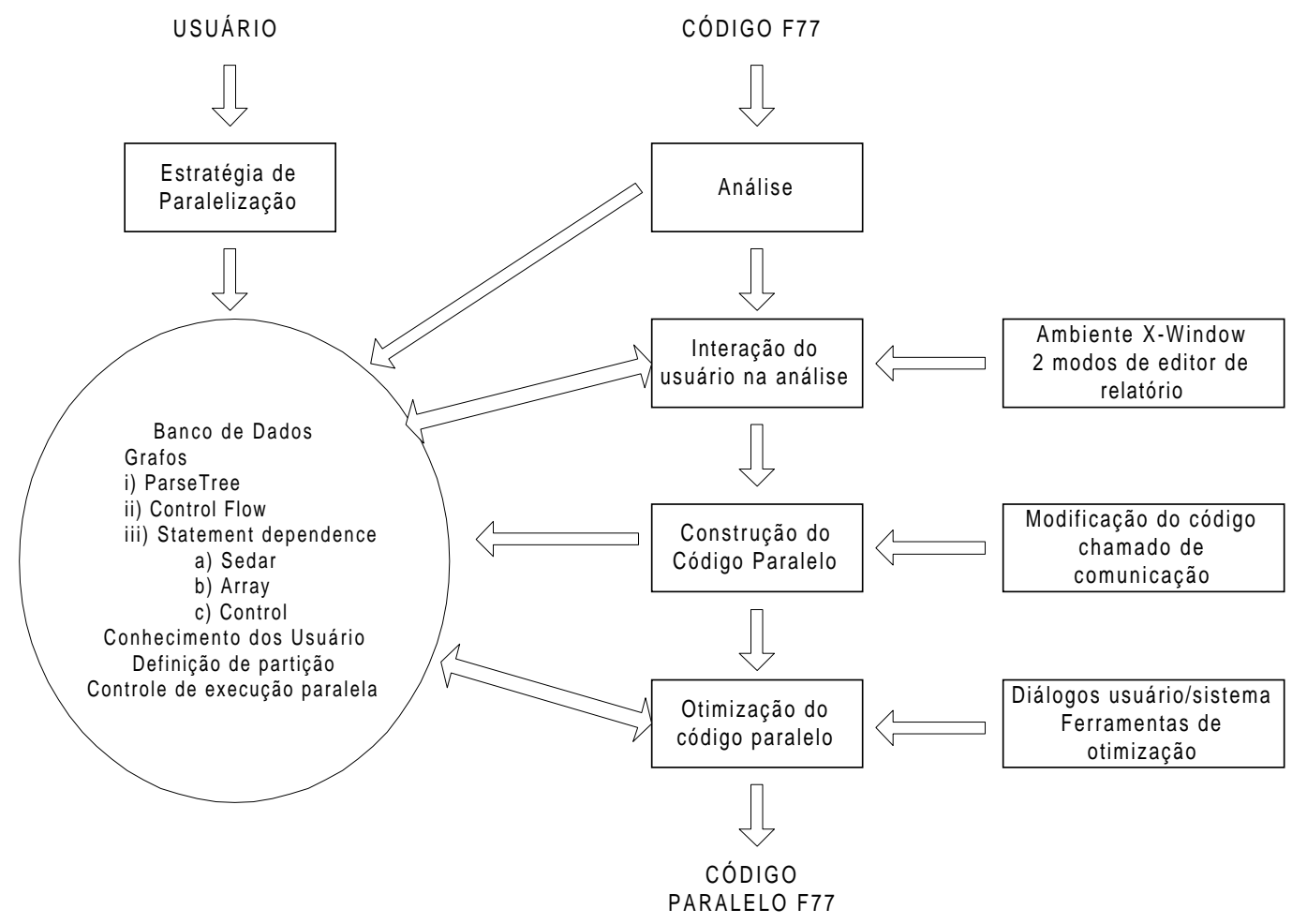

Figura 4-1- Arquitetura do CAPTools

Portanto, é sempre deixada para o usuário a opção de selecionar ou especificar a estratégia de paralelização. Um conceito chave, identificado no CAPTools, é o reconhecimento de que, se ferramentas realmente serão utilizadas no processo de paralelização, então elas devem permitir aos usuários a geração de versões paralelas do seu código de forma tão eficiente quanto se tivessem sido feitas à mão. Uma razão para isso é que pequenas diminuições na eficiência da paralelização tornam-se mais significativas com o aumento do número de processadores.

\subsubsection{Forge 90}

Forge 90 é um sistema de paralelização intuitiva que executa fluxo de dados e análise de dependência; também da suporte a transformações de níveis de loop. Forge 90 utiliza uma definição de partição especificada pelo usuário e um conjunto de loops também especificado 
pelo usuário para distribuir e gerar M.P.F. (Message Passing Fortran) usando uma ferramenta de processador separado. O usuário pode inspecionar a estrutura do código paralelizado em companhia das inserções das diretivas do Forge 90 para partição de dados, distribuição de loops e comunicação de dados [APR92].

\subsubsection{Sistema de Compilação Fortran Vienna (VFCS)}

O sistema de compilação Fortran Vienna derivado do projeto SUPERB, é um sistema interativo que executa uma translação fonte para fonte do Vienna Fortran para MPF paralelo, explicitamente, provendo paralelização e vetorização automáticas.

Vienna Fortran é similar ao HPF, provendo segmentos de código distribuído para especificar o particionamento de vetores nos processos. A janela principal do VCFS mostra o código fonte da rotina selecionada e permite que o usuário selecione as instruções do programa, para transformá-las ou para requisitar informações do sistema. VCFS provê um número de formas para edição e visualização de informações interativamente durante o processo de paralelização, incluindo dependência, partições e comunicações. $O$ processo de paralelização envolve o usuário primeiro especificando quais vetores serão distribuídos (se a distribuição de informação não for fornecida pelo código fonte) e, possivelmente, aplicando loop de transformação. O próximo estágio consistem em dois passos - inserção de comunicação e "mapeamento" [CHA92] [CHA94].

\subsubsection{Programação Gráfica e Modular em PVM}

Programação gráfica e modular em P.V.M. P-Rio (Parallel Reconfigurable Interconnectable Objects): é uma metodologia de construção de software baseada em objetos, que provê abstração de alto nível para a construção modular de programas concorrentes, facilitando a utilização do software e o desenvolvimento de sistemas. Inclui-se também nessa proposta uma interface gráfica para a construção e o gerenciamento de sistemas paralelos e distribuídos.

O ambiente P-Rio possui um modelo, ferramentas e mecanismos para a construção de software distribuído e programação paralela. A metodologia de construção de software imposta pelo ambiente faz distinção entre a construção de módulos individuais do sistema e dos sistemas construídos a partir desses módulos. Dentro desse propósito, o conceito de interconectividade modular é adotado. Elementos de sistema são chamados módulos, sendo um módulo composto de código e dados, e um ou mais pontos de conexão chamados conectores. Módulos constróem blocos e não há restrição quanto ao número de módulos utilizados para implementar um módulo composto, nem à quantidade de aninhamento de módulos (ex: módulos compostos podem ser componentes de outros módulos). 
Existem dois conceitos ligados ao módulo: classes e instâncias. Instância está relacionada à unidade operacional, classe é a forma utilizada para a criação dessa unidade. Através de uma linguagem de configuração podem-se criar instâncias de classes e conectá-las, configurando a aplicação.

A metodologia por si própria não impõe restrições à linguagem usada na construção dos componentes, nem à alocação física dos módulos da aplicação. Para reconfiguração e reuso, módulos podem ser programados e armazenados em uma biblioteca. Após a utilização da modularidade e reuso, a metodologia inclui um conjunto de mecanismos simples de interconexão que permite o projeto de estruturas complexas de comunicação inter-modular.

Os pontos de interconexão interna são os conectores. Cada conector possui um ou mais pinos de ligação, que são os elementos básicos da comunicação. $O$ pino possui um conjunto de características: tipos de dados das mensagens (formato), direção (sentido) e origem ou destino de uma mensagem. As conexões são usadas para ligar pinos (Figura 4-2). Todas as mensagens enviadas por um pino são recebidas pelos pinos aos quais o mesmo está conectado.

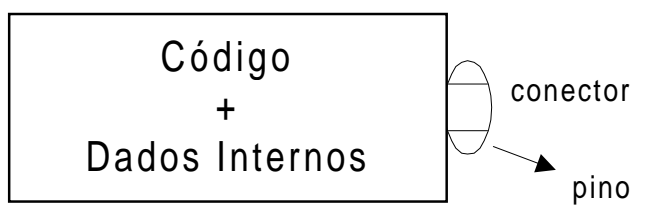

Figura 4-2 - Representação de um módulo

As conexões entre pinos e módulos compostos e pinos de seus módulos componentes só são possíveis se os pinos forem equivalentes (mesmo tipo e sentido), portanto não complementares (mesmo tipo e sentido oposto). Isso se deve ao fato de que o módulo não interage com seu componente. Vale lembrar que ou o módulo possui código diretamente, ou é composto, nunca ambos.

Por outro lado, o P.V.M. (Parallel Virtual Machine) não faz distinção entre componentes de implementação e componentes de interação, tornando mais difícil conseguir atar modularidade e reuso do software. Assim, a filosofia de criação do P.V.M. permitiu um conjunto de primitivas de baixo nível para que camadas de alto nível pudessem ser adicionadas. O P-Rio utiliza as chamadas existentes no P.V.M. para construir uma interface de comunicação fácil de se usar e uma metodologia de alta portabilidade para suprir a programação distribuída e paralela.

Para atender aos requisitos de portabilidade, eficiência na utilização de recursos, foi empregado o conceito de micro núcleo, associado ao ambiente de suporte à comunicação local e à execução concorrente de instâncias. Esse conjunto de funções forma o núcleo, onde também estão controles de escalonamento, mecanismos de time-out e exclusão mútua. Sobre esse núcleo está a camada de suporte à operação que fornece serviços de configuração local, nomeação e comunicação. O sistema de comunicação é composto de vários módulos, principalmente gerentes 
de entrada e saída e tratadores multiprotocolo, os quais fornecem suporte aos protocolos diversos. Assim é possível a construção de aplicações distribuídas sem vínculos quanto à localização de seus componentes.

A estratégia de simbiose do P-Rio para o ambiente P.V.M., pretende fundir mecanismos e abstrações de alto nível oferecidas pela metodologia apresentada em um ambiente com a portabilidade entre arquiteturas de hardware providos pelo P.V.M.. Testes para avaliação de desempenho mostram que o P-Rio não introduz sobrecarga significativa na troca de mensagem quando comparado a um sistema P.V.M. puro. As ferramentas originais de visualização e depuração do P.V.M. podem, também, ser utilizadas com o sistema P-Rio. Além disso, o P-Rio provê uma interface gráfica que dá suporte à composição de classes e descrição de configuração de aplicações.

Protótipos de aplicações paralelas podem ser rapidamente construídos usando o ambiente P-Rio e suas ferramentas gráficas [CAR95].

\subsubsection{Ferramenta de Apoio à Programação Paralela (F.A.P.P.)}

Ferramenta de Apoio à Programação Paralela (F.A.P.P.) é uma ferramenta que utiliza um meta-modelo orientado a objetos para a teoria dos grafos. Para modelar-se a teoria dos grafos, consideram-se definições levantadas de diversas propostas encontradas na literatura [BOA79] e que são são apresentadas ao longo desta seção, juntamente com a respectiva proposta de criação de classes-base para representá-las. Para o desenvolvimento dessa ferramenta, utilizou-se a análise orientada a objetos, especificamente o método Fusion [COU94] por se tratar da síntese de características de outros métodos.

Essas classes, por sua vez, constituem o núcleo do meta-modelo proposto que, por ter sido projetado orientado a objetos, possue um relacionamento definido pelas características básicas da orientação a objetos: herança, polimorfismo, encapsulamento, etc.

Os modelos finais construídos a partir desse meta-modelo proposto para a teoria dos grafos podem explorar livremente essas características oferecidas pela orientação a objetos.

\subsubsection{Modelo para Arcos e Nós}

Um nó pode representar um elemento do mundo real ou um conjunto de características comuns a vários elementos. Analogamente ao conceito de nó, um arco pode representar associações entre elementos do mundo real ou um conjunto dessas associações. Tanto para nós quanto para arcos, é necessário o estabelecimento de regras que definam a interface, de forma não ambígua, para diferenciar associações entre elementos e associações entre conjuntos. Dessa 
forma, os nós podem ser utilizados para modelar elementos do mundo real (ou conceitos) e os arcos podem representar as suas associações.

$\mathrm{Na}$ maioria das aplicações, cuja base teórica do modelo é a teoria dos grafos, faz-se necessária a utilização de rótulos para identificar os nós e os arcos objetivando não modelar o conjunto de aplicações, mas sim identificar os elementos pertencentes ao conjunto no e arco de maneira única, e não por meio de uma relação de ordem no conjunto.

Da mesma forma, na utilização de nós e arcos, cada elemento deve ser identificado de modo único: cada nó e cada arco deve possuir seu identificador. O identificador de um nó ou de um arco não é o rótulo a ele associado, mas um atributo associado a cada elemento

O número de arcos que chegam e que saem de cada um dos nós de um dígrafo é tido como o elemento mais abstrato do mesmo. Isso sugere uma classe abstrata na qual seja representado o grau do nó. A utilização de uma classe virtual abstrata é consequiência direta da elaboração de um modelo orientado a objetos.

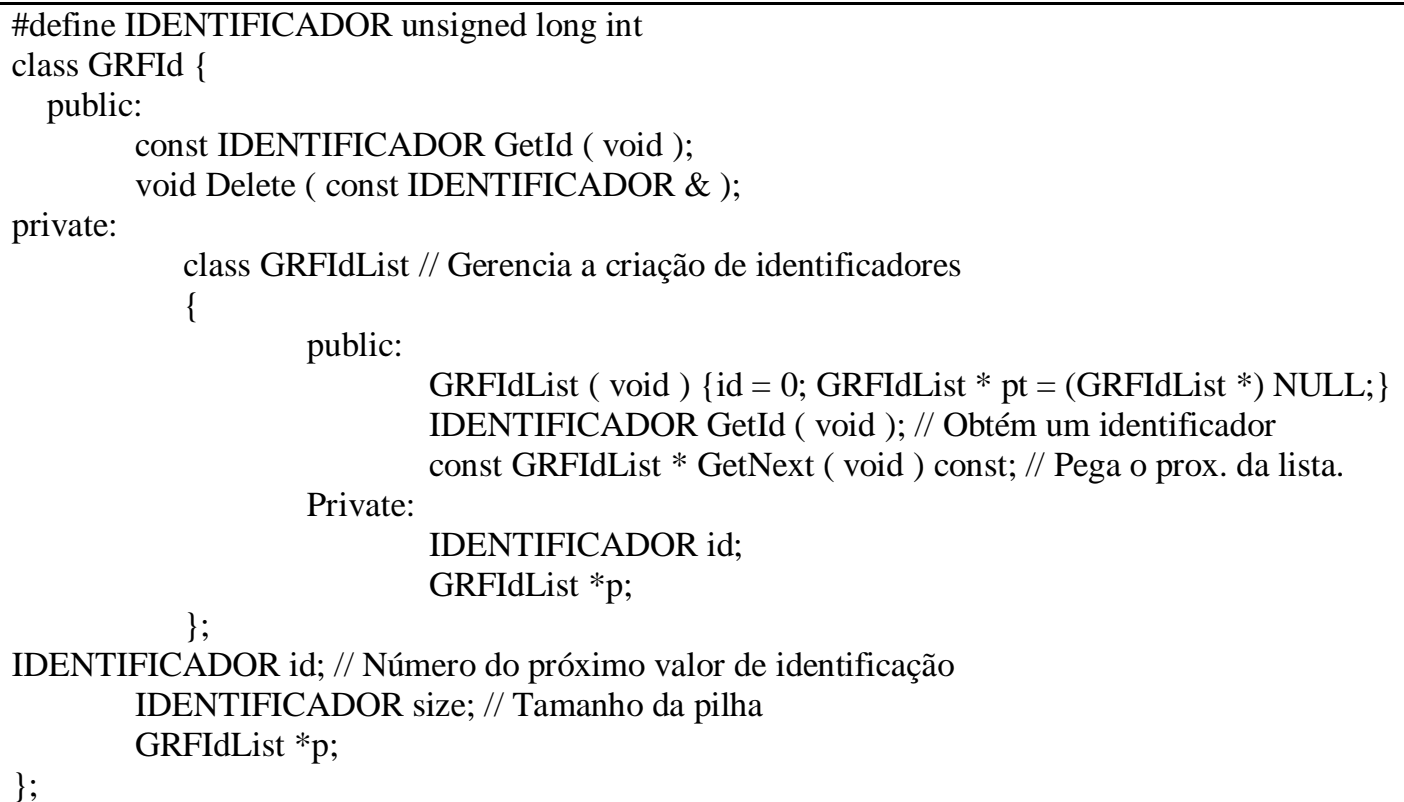

Figura 4-3 - Geração de Identificadores

A classe GRFIdList permite que sejam instanciados objetos para o controle de identificadores. Uma única instância do objeto da classe GRFIdList pode ser utilizada para todo o sistema, conforme ilustra a Figura 4-3. Entretanto, se o sistema for relativamente complexo, 
restrições para a capacidade de representação são apresentadas e por isso é sugerido que existam objetos de controle diferentes para elementos instanciados a partir de classes diferentes.

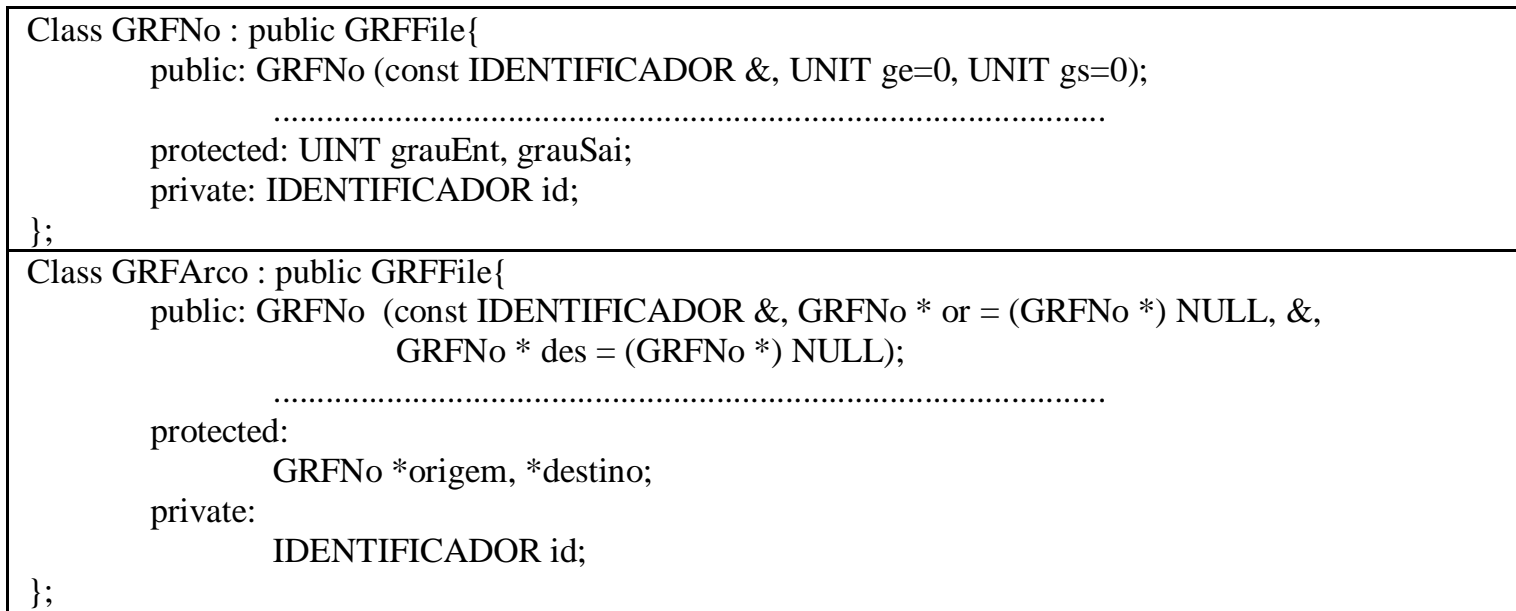

Figura 4-4 - Classes Bases GRFNo e GRFArco

Notação: as linhas pontilhadas indicam que a classe é abstrata (embora essa notação seja utilizada pelo método Fusion para indicar conjunto), ou seja, não podem ser instanciados objetos desse tipo de classe.

Por uma questão de consistência da documentação a sigla GRF (GRaFo) é utilizada como prefixo para as classes que modelam os conceitos da teoria dos grafos. Por exemplo: GRFNo e GRFArco, apresentados na Figura 4-4, são as classes que representam, respectivamente, as fatorações dos atributos comuns a todos os nós e arcos de um dígrafo. $\mathrm{O}$ agrupamento de atributos modela a representação dos conjuntos No e Arco. A nomenclatura utilizada para os atributos da classe GRFArco, apresentados na Figura 4-5b, permite a representação de semântica no modelo, dado que é conceito de dígrafo a característica de representação de nó-origem e nó-destino.

Os elementos do grafo devem possuir identificador único, garantindo a propriedade da geração de objetos persistentes para a reconstituição do grafo a partir de arquivo. As linhas pontilhadas indicam essa modelagem, conforme ilustra a Figura 4-6. 


\begin{tabular}{|l|}
\hline GRFNo \\
\hline $\begin{array}{l}\text { GrauEntrada } \\
\text { GrauSaida }\end{array}$ \\
\hline
\end{tabular}

(a)

\begin{tabular}{|l|}
\hline GRFArco \\
\hline Origem \\
Destino \\
\hline
\end{tabular}

(b)

Figura 4-5 - Classes GRFNo (a), GRFArco (b) e seus atributos

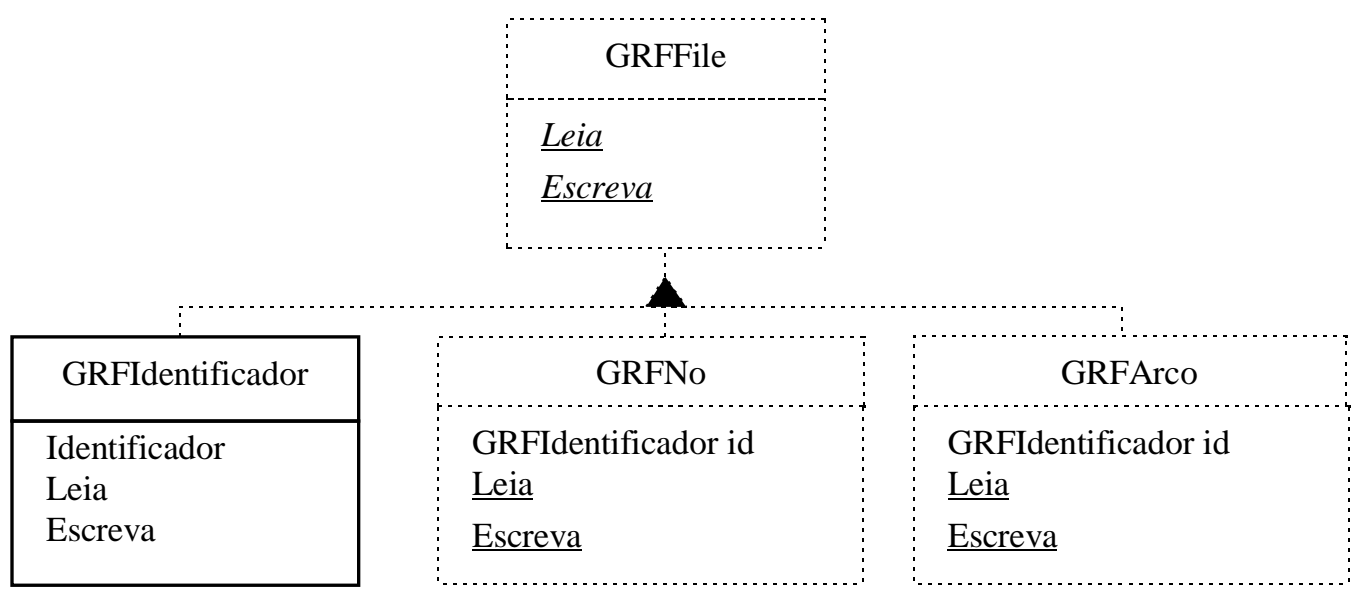

Figura 4-6 - Classe para a Geração de Objetos Persistentes 


\subsubsection{Modelo para Arcos e Nós Rotulados}

Sendo os elementos do mundo real considerados abstrações identificadas por nomes, ou rótulos, faz-se uma analogia ao conceito de nó rotulado. Assim, um nó rotulado é um nó com a característica de possuir um rótulo, e tanto os nós quanto os arcos rotulados podem armazenar e restaurar os conteúdos de seus atributos a partir de arquivos. As Figuras 4-7 e 4-8 ilustram a hierarquia das classes e os seus respectivos protótipos.

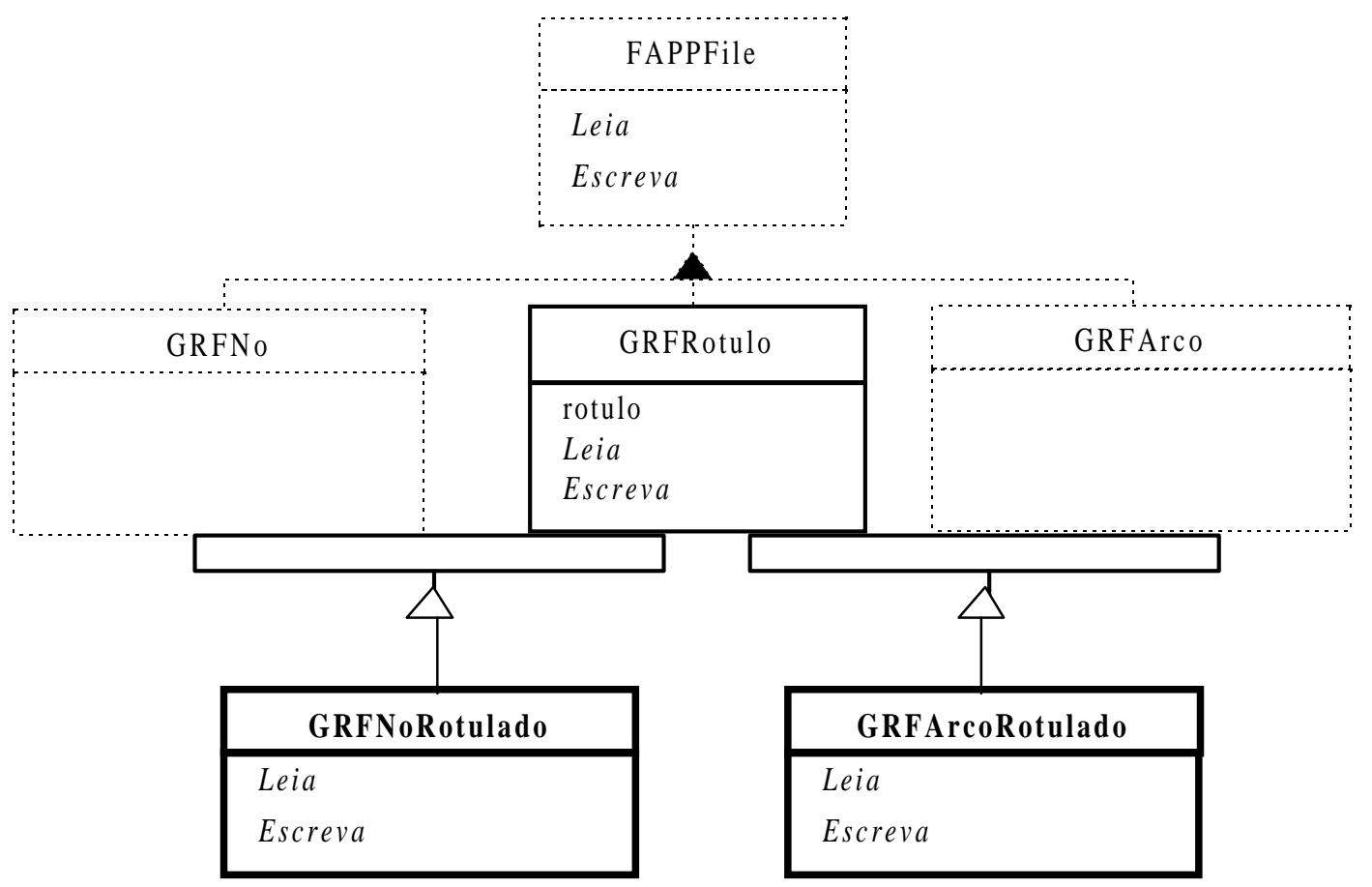

Figura 4-7 - Classe para a Representação de Nós Rotulados 


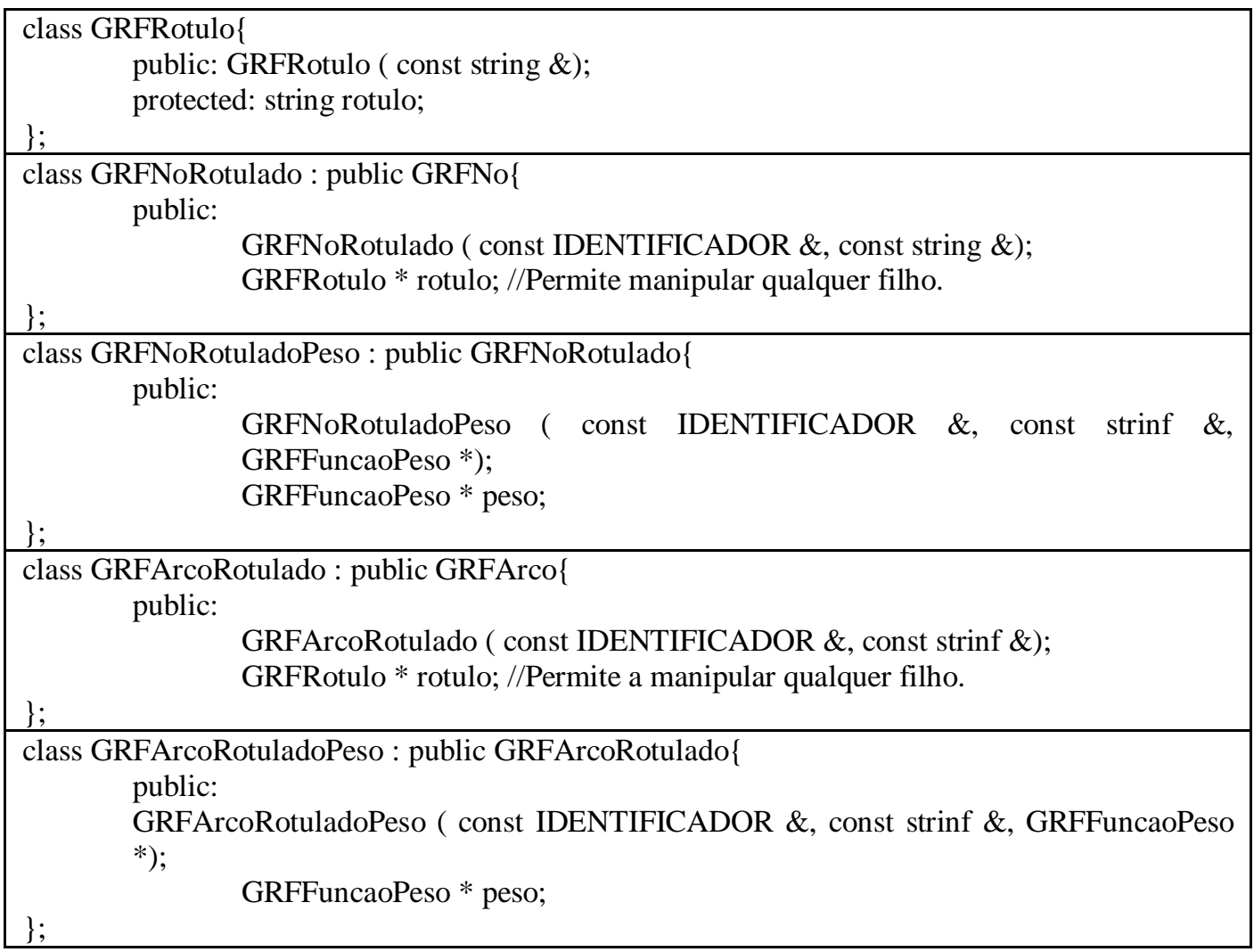

Figura 4-8 - Classes de GRFRotulo, GRFNoRotulado, GRFArco

Outras definições existentes nesse contexto são nós e arcos com peso. Em alguns sistemas cujas atividades possam ser representadas por arcos e nós, pode-se supor casos onde é possível a parametrização dessas atividades. Peso é o conjunto das funções que podem ser utilizadas para parametrizar o desempenho das atividades e/ou associações em um sistema. Um nó com peso é um nó que adquire a característica de poder representar o custo ou eficiência, por exemplo, da atividade que o mesmo representa, bem como um arco com peso.

Os nós e arcos podem ainda compor novos conjuntos: nós e arcos rotulados com peso. $\mathrm{O}$ conjunto NoRotuladoPeso é um conjunto cujos elementos agregam as características de serem nó, rótulo e peso, enquanto que ArcoRotuladoPeso é um conjunto cujos elementos possuem as características de serem arco, rótulo e peso.

Os nós e arcos rotulados representam os elementos básicos que compõem as aplicações desejadas. Dessa forma, pode-se propor que nós e arcos possuam funções que representem esforços, trabalho, custo ou outros, em analogia aos grafos rotulados com peso. 
Assim, acredita-se que uma classe-base abstrata possa modelar diversos conjuntos distintos de funções bem como duas classes derivadas de GRFNoRotulado e GRFArcoRotulado, conforme ilustram as Figura 4-9a e a Figura 4-9b, respectivamente.

O atributo "funcao", pertencente à classe GRFNoRotuladoPeso, permite que quaisquer objetos, instanciados a partir dessa classe, estejam associados a algum objeto, derivado da classe GRFFuncaoPeso, através de um dos conceitos de orientação a objetos: o polimorfismo ${ }^{7}$.

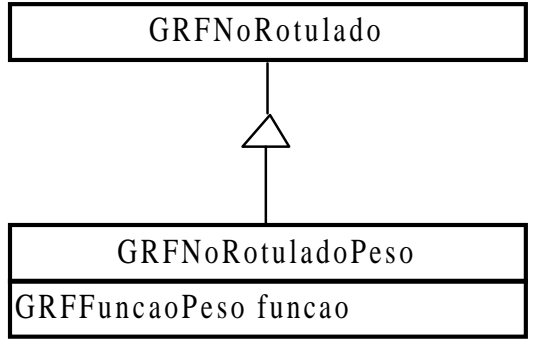

(a)

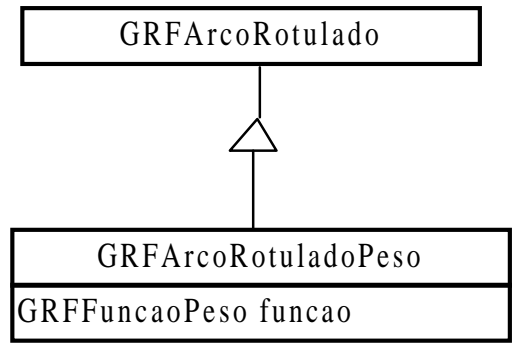

(b)

Figura 4-9 - Classes Hierárquicas para Nó e Arco Rotulados

\subsubsection{Modelos para Grafos e Dígrafos}

Grafos e dígrafos são compostos dos conjuntos de Nós e Arcos, independentemente da sua representação gráfica.

Grafos consistem de um conjunto, não vazio, de NO e um conjunto de ARCO. Assim, pode-se dizer que cada um dos arcos associa dois nós e que cada nó tem como característica estar associado a um conjunto não vazio de arcos.

Um dígrafo, por sua vez, consiste de dois conjuntos de NO e ARCO. O conjunto ARCO é formado por pares ordenados de nós, onde NO é um conjunto não vazio de nós. Uma possível representação gráfica para um dígrafo pode ser efetuada através da utilização de segmentos lineares orientados, que estabeleçam alguma relação de ordem para os pares ordenados do conjunto ARCO.

Isto requer a criação de duas novas classes. Essas classes são estruturas de listas lineares que referenciam objetos instanciados a partir das classes GRFNo e GRFArco, conforme ilustra a

\footnotetext{
${ }^{7}$ Polimorfismo "significa que o transmissor de estímulos não precisa conhecer as instâncias das classes receptoras. A instância receptora pode pertencer a uma classe qualquer" [JAC92].
} 
Figura 4-10, permitindo que quaisquer elementos das classes GRFNo e GRFArco possam ser referenciados. Isso garante que futuras especializações, ou implementações de aplicações, possam fazer uso das classes de armazenamento GRFNos e GRFArcos.

Um grafo é um conjunto capaz de representar todos os nós e todos os arcos. Essa característica pode ser modelada pelo mecanismo de herança múltipla através de um conjunto que especialize as características das classes de armazenamento GRFNos e GRFArcos, conforme ilustra a Figura 4-11. Ao ser imposta a restrição de que todo arco parte de um nó origem e alcança um nó destino, fica estabelecido o conceito de dígrafo. Assim, pode-se dizer que um dígrafo é uma especialização de um grafo. Essa hierarquia está ilustrada na Figura 4-11.
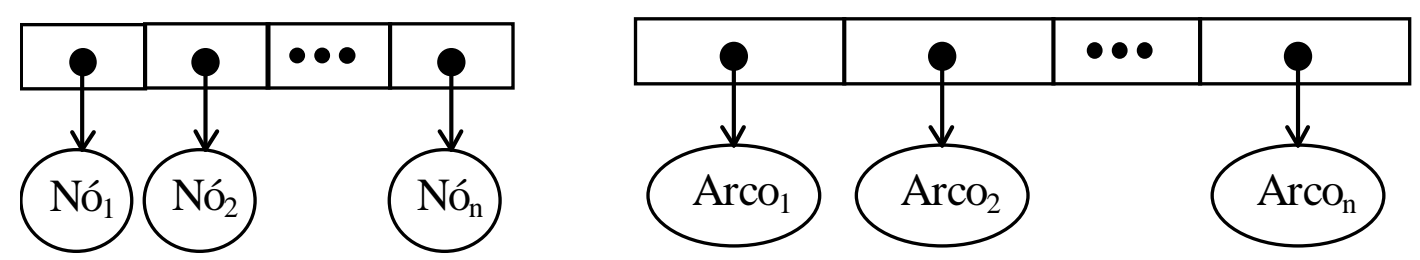

Figura 4-10 - Classe para Gerenciamento dos Objetos do Sistema

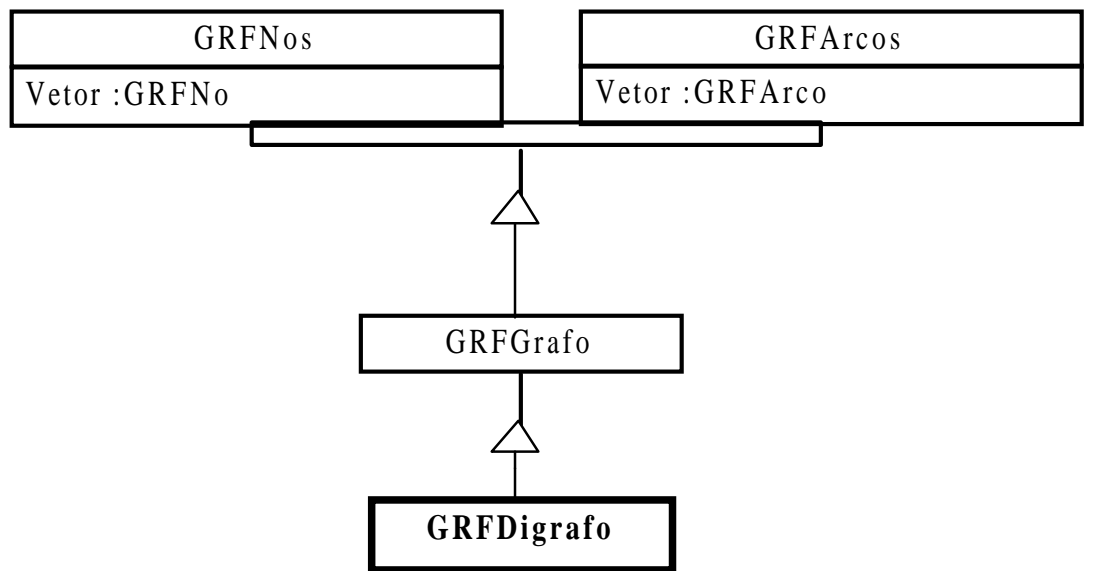

Figura 4-11 - Classes Grafo e Dígrafo 


\subsubsection{Modelo para Subgrafos e Subdígrafos}

Com a utilização do polimorfismo, tanto os elementos do mundo real quanto as suas associações podem ser modelados através de grafos ou dígrafos. Entretanto, há casos em que é necessário representar agrupamentos de objetos, de maneira análoga aos subgrafos. Por exemplo, nos casos onde são desejáveis representações de níveis diferentes de visão ou a representação de hierarquias de abstração, conforme o exemplo ilustrado na Figura 4-12.

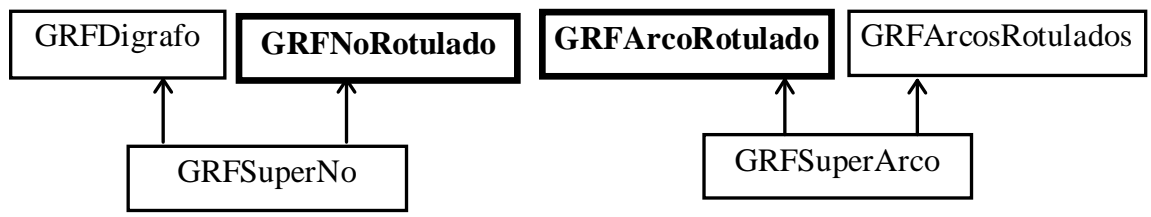

Figura 4-12 - Classe Supernó e Super-Arco

Para que uma visão macroscópica do sistema possa ser obtido, o agrupamento de diversos arcos e nós pode ser necessário. Desse modo, foram criados os conceitos de supernó, super-arco e superdígrafo. Um supernó é um dígrafo rotulado. Um super arco é um arco rotulado e um conjunto de arcos, conforme ilustra a Figura 4-13

Subconjuntos de nós podem ser agrupados para que um novo nó seja gerado. O supernó é composto por elementos que pertençam a um conjunto de nós e arcos a eles associados, possuem a característica de serem representados por um único nó e identificados univocamente.

Para o conjunto de arcos, há a possibilidade de existir mais de uma associação entre dois nós. O super-arco é um conjunto no qual os elementos formam um subconjunto do conjunto ARCO e que associam um par de nós ou de supernós. Cada subconjunto possui um identificador único.

Assim como os nós e os arcos, os supernós e os super-arcos podem compor novos conjuntos como SupernóRotulado e SuperArcoRotulado. Também, analogamente ao conceito de arcos e nós, super-arcos e supernós rotulados e com peso, permitem a representação de grandezas como custo e eficiência com que um conjunto de atividades é efetuado.

Da existência de supernós e super-arcos derivam os supergrafos e superdígrafos. Supergrafo é um conjunto, não vazio, no qual cada um de seus elementos é identificado univocamente e compostos por pares pertencentes aos conjuntos SUPERNÓ e SUPER-ARCO; o superdígrafo é, por sua vez, um dígrafo composto por super-arcos e supernós, tal que a relação de ordem no subconjunto SUPER-ARCO é preservada, de acordo com a definição de dígrafo.

Analogamente aos arcos e nós, supergrafos e superdígrafos podem compor novos conjuntos de SuperGrafoRotulado e SuperDigrafoRotulado, bem como SuperGrafoRotulado com peso e SuperDigrafoRotulado com peso. 
Um superdígrafo é um dígrafo, um conjunto de supernós e um conjunto de super-arcos é uma especialização do conceito de dígrafo. Para a implementação dessa proposta, o fato dos nós e arcos formarem as bases para a classe GRFDigrafo é suficiente.

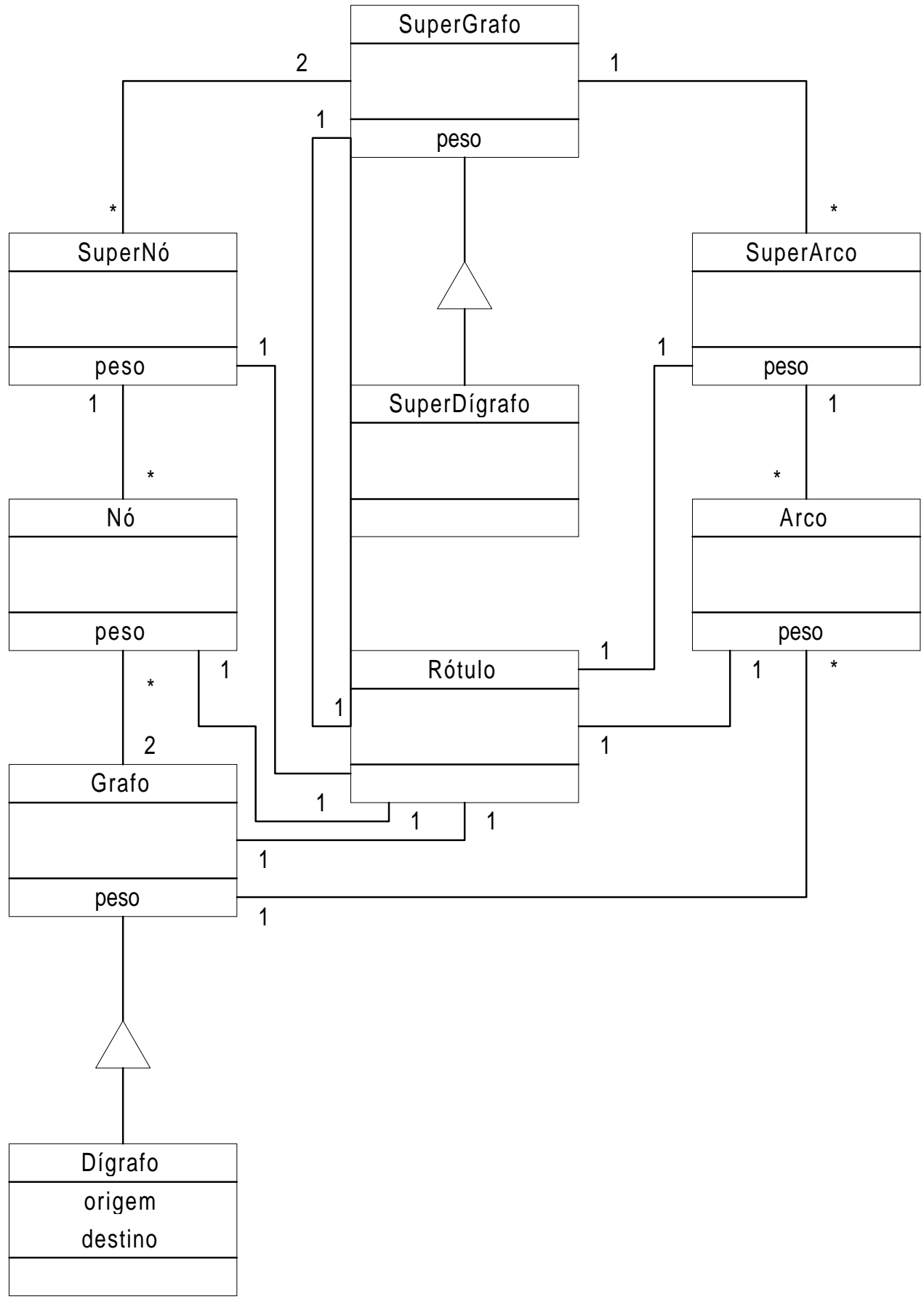

Figura 4-13 - Meta-Modelo Orientado a Objetos 
A Figura 4-13 apresenta o modelo de objetos das classes do meta-modelo orientado a objetos para a teoria dos grafos.

\subsubsection{Arquitetura da Ferramenta F.A.P.P.}

Três níveis de abstração podem ser identificados na Figura 4-14 que apresenta uma visão macroscópica da ferramenta:

- Primeiro nível: "Banco de Dados", é uma interface entre o nível superior e o dispositivo de armazenamento das informações;

- Segundo nível: "Componentes de Hardware", "Componentes de Software", e " Estrutura para os Modelos Arquiteturais Propostos", onde são implementadas as classes de objetos para a descrição do Hardware, do Software e um núcleo para a descrição da aplicação. A "Estrutura para os Modelos Arquiteturais Propostos" implementa classes para modelagem dos conceitos da teoria dos grafos criando tipos abstratos de dados.

- Terceiro nível: Corresponde à interface da ferramenta.

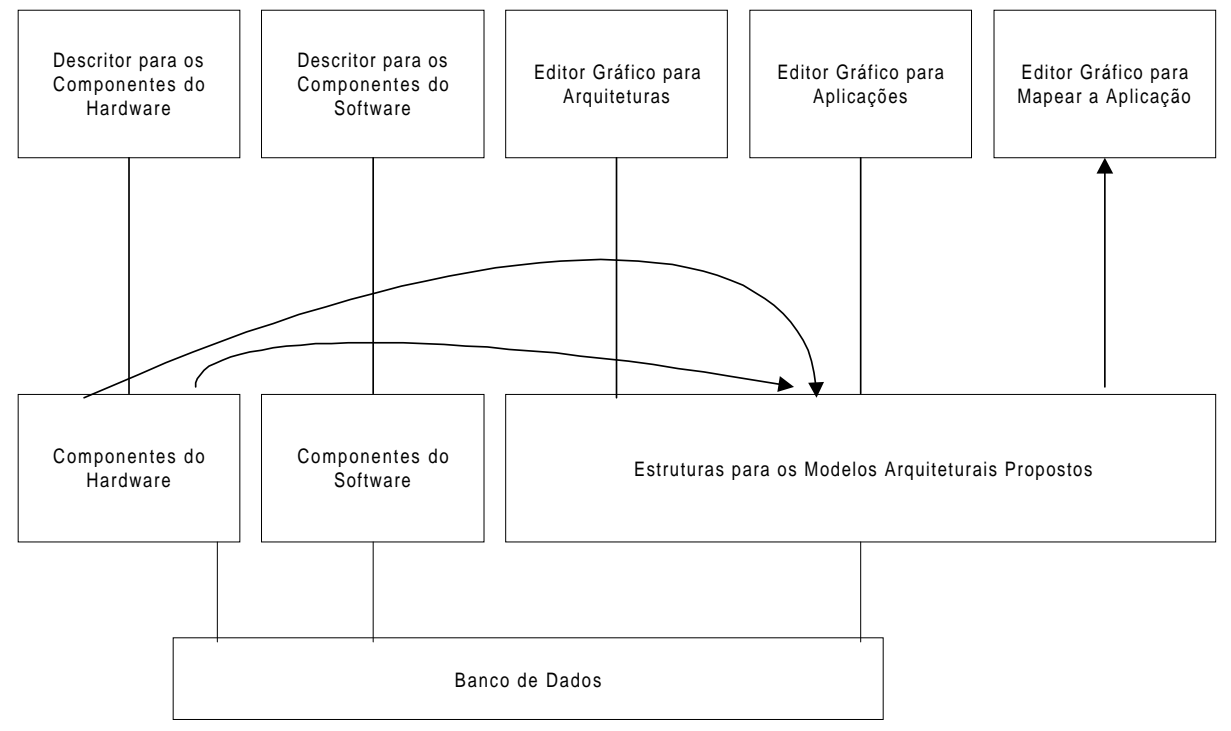

Figura 4-14 - Arquitetura do Sistema 
O projeto da ferramenta especifica:

- Um conjunto de classe-base fundamentado na teoria dos grafos que constitui o núcleo para as aplicações;

- Um conjunto de classes que modela os componentes básicos, que têm que ser utilizados para a especificação do Hardware da arquitetura paralela;

- Um conjunto de classes-base que permite a descrição do esqueleto do programa para aplicações paralelas;

- Um subsistema gráfico que permite o mapeamento do esqueleto da aplicação no hardware especificado;

- Um conjunto de interfaces gráficas para a manipulação das demais estruturas.

Uma ferramenta para apoio à programação paralela deve considerar as necessidades intrínsecas dessa atividade, bem como estabelecer uma arquitetura de software com domínio específico, objetivando atender ao requisito de obtenção de desempenho máximo do sistema. Nesse contexto, estabelece-se uma relação de composição de um conjunto de programas adequados a um conjunto de arquiteturas. Para essa composição é necessário estabelecer as relações entre os componentes de software (para definição da arquitetura do software) e a relação entre os componentes do hardware (para a definição da arquitetura do hardware).

Os elementos da organização da arquitetura são modelados tais como: unidade central de processamento, memória, dispositivos para entrada e saída de dados, e outros [CAL97], pois as relações de associações/composições entre esse elementos é que caracterizam modelos arquiteturais distintos. As taxonomias presentes na literatura apresentam abstrações de especializações para os diversos modelos arquiteturais. A arquitetura mais abstrata é obtida fatorando os elementos comuns aos modelos propostos.

Partindo-se do meta-modelo, ou seja, do modelo matemático da teoria dos grafos sob o paradigma da orientação a objetos, pode-se criar um subsistema capaz de representar diversos modelos arquiteturais.

Para implementação da ferramenta, a taxonomia de Duncan [DUN90] foi escolhida por abranger a taxonomia de Flynn e estabelecer adicionalmente uma visão macroscópica para uma hierarquia de classes.

O modelo para as arquiteturas pressupõe que não pode existir nenhum componente em alguma arquitetura que não esteja associado a pelo menos um outro componente através de algum meio de transmissão. Assim, cada um dos itens acima é modelado com a finalidade de serem utilizados como classe-base para elementos mais específicos, conforme ilustram as Figuras 4-15 e 4-16. 


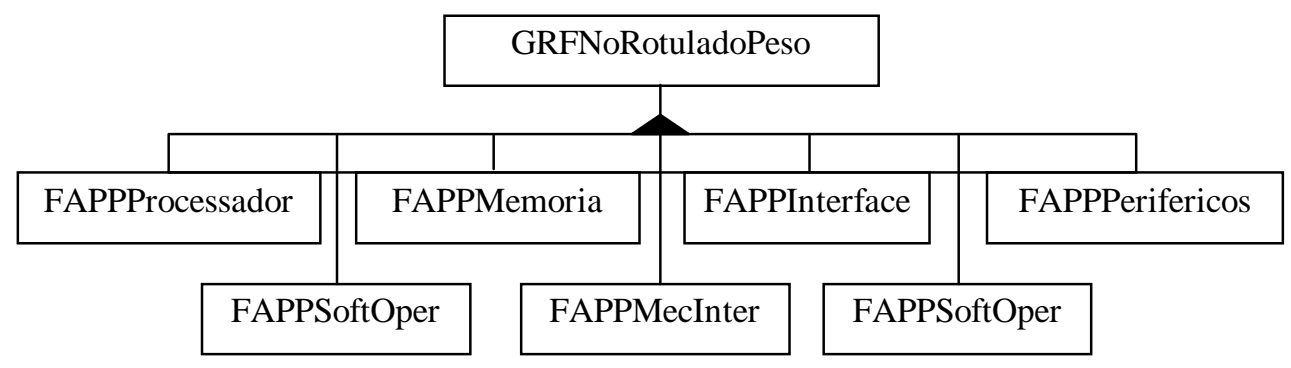

Figura 4-15 - Classes-Base para o Modelo dos Componentes das Arquiteturas

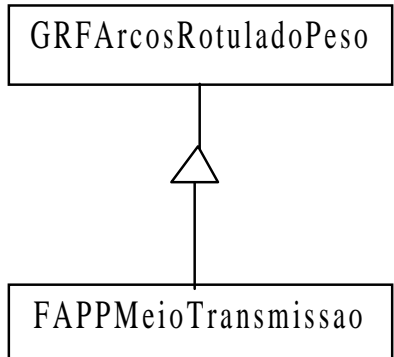

Figura 4-16 - Classe-Base para os Meios de Transmissão

Utiliza-se o prefixo FAPP (Ferramenta de Auxílio à Programação Paralela) para que se possa diferenciar as classes-base dos componentes do hardware das demais classes. Os elementos processadores devem ser modelados segundo esse conjunto de classes-base. Para cada tipo de elemento processador a ser acrescentado à ferramenta deve ser elaborada uma classe, derivada da classe GRFNoRotuladoPeso, que encapsule as demais características desse elemento.

A classe GRFArcoRotuladoPeso é base para a classe FAPPMeioTransmissao, pois define as características dos arcos de um dígrafo rotulado e ponderado. Os demais componentes básicos devem pertencer às classes que representem suas respectivas características e cujas instâncias sejam identificadas univocamente. Devem possuir um rótulo e permitir que sejam definidos custos de utilização de cada unidade. Os atributos são característicos dos objetos que pertencem à classe GRFNoRotuladoPeso, permitindo que as classes-base para os componentes do hardware sejam derivadas da classe GRFNoRotuladoPeso, conforme ilustra a Figura 4-17. 


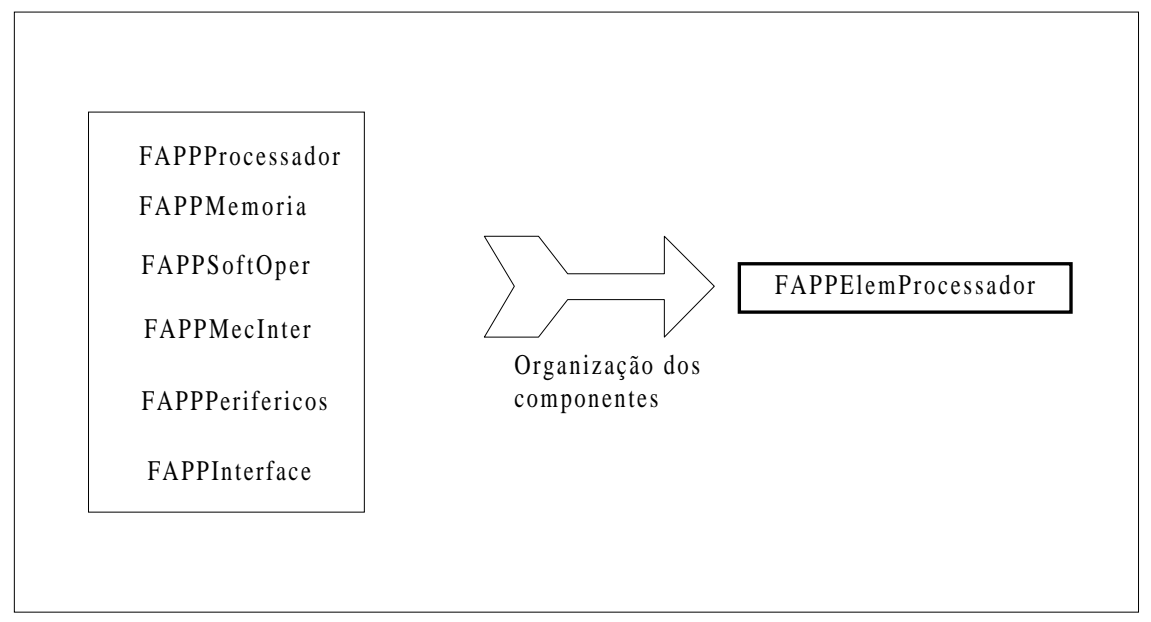

Figura 4-17 - Elemento Processador

Sendo assim, a arquitetura paralela é descrita por meio de um grafo, onde os elementos processadores são os nós e os meios de ligação dos processadores são os arcos. A Figura 4-18, ilustra a representação gráfica de uma arquitetura paralela que contém 5 elementos processadores $\left(E P_{i}, 0 \leq i \leq 5\right), 7$ canais de comunicação $\left(\mathrm{C}_{\mathrm{i}}, 0 \leq \mathrm{i} \leq 7\right)$ e uma topologia.

Os objetos elemento-processador são subgrafos ou supernós. A Figura 4-19 representa a classe GRFSuperNo como superclasse de FAPPElemProcessador, sendo a representação do encapsulamento de todos os componentes que compõem os objetos desse tipo.

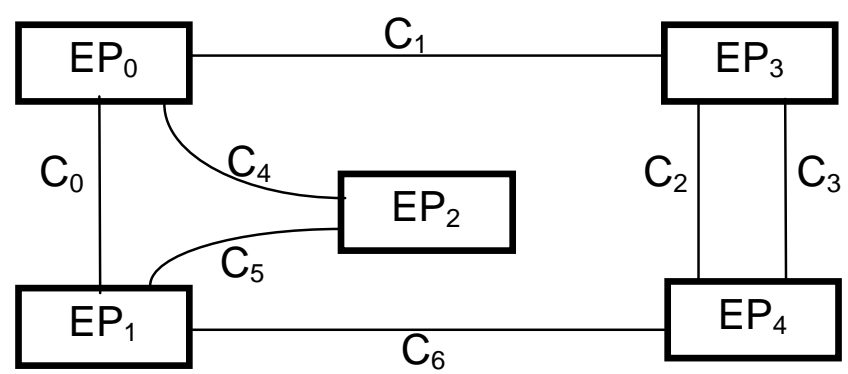

Figura 4-18 - Representação gráfica dos grafo de conexão dos elementos processadores 


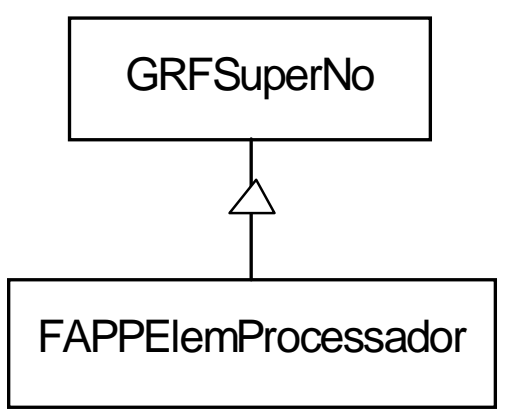

\section{Figura 4-19 - A Classe FAPPElemProcessador}

Os dígrafos conexos modelam a composição de uma arquitetura paralela utilizando-se um conjunto de elementos processadores, caracterizando que todos os elementos de processamento estão interligados. A estrutura apresentada na Figura 4-20 representa uma hierarquia de classe que modela a taxonomia de Duncan. É utilizado o prefixo AP (Arquiteturas Paralelas) para caracterizar que a classe APArquiteturaParalela é uma especialização de um dígrafo conexo. As demais subclasses são prefixadas com AP para indicar qual a sua classe-base.

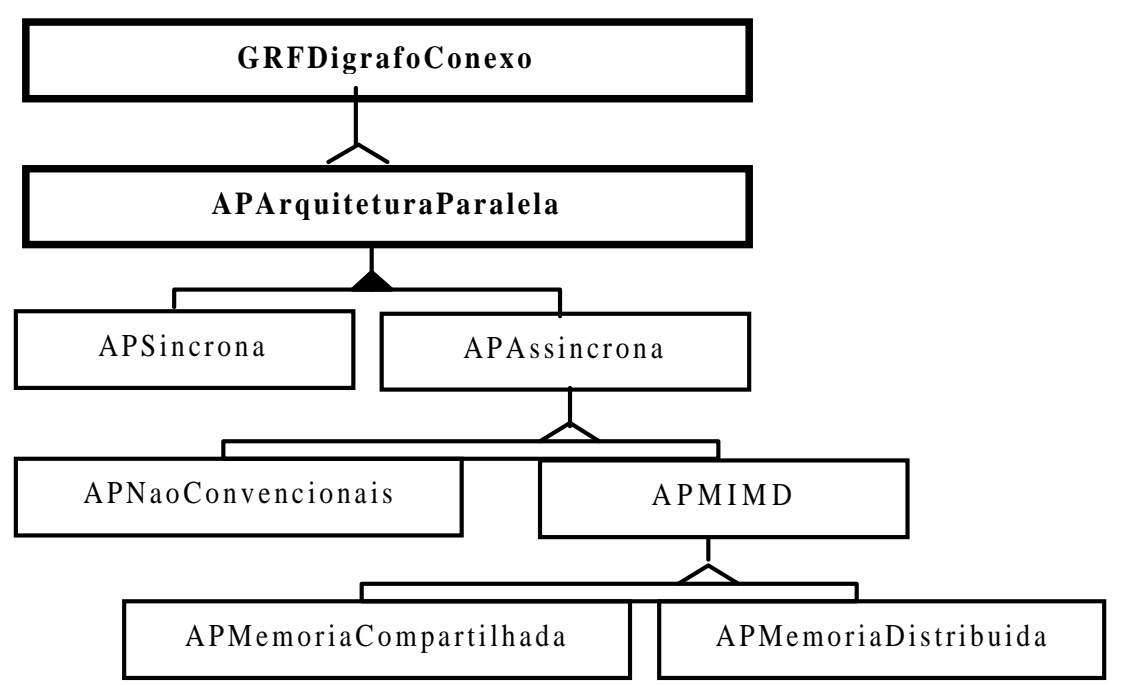

Figura 4-20 - Hierarquia de classes para a taxonomia de DUNCAN 


\subsubsection{Esqueletos para Aplicações Paralelas}

Foster [FOS95] propôs uma série de passos, que proporcionam uma maneira uniforme através da qual auxilia-se o desenvolvimento de programas paralelos, baseados em quatro princípios: partição, comunicação, aglomeração, e mapeamento.

Sendo assim, assume-se que um programa paralelo consiste de uma ou mais tarefas que têm suas execuções concorrentes ou paralelas e podem ser criadas ou destruídas dinamicamente. As tarefas encapsulam uma memória local, as portas de comunicação com outras tarefas e um programa. Cada tarefa pode executar as operações de comunicação (transmissão/recepção de mensagem), criar outras tarefas ou terminar sua execução. As tarefas podem ser alocadas aos diversos processadores e assume-se que o mapeamento não altera a semântica do programa. A transmissão das mensagens é assíncrona, porém a recepção é síncrona.

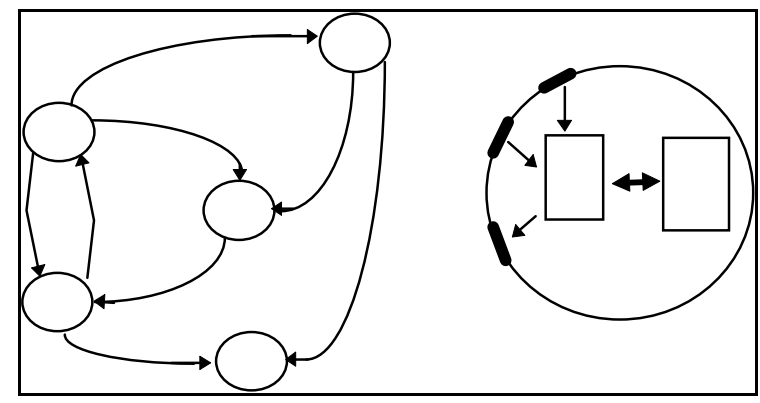

Figura 4-21 - Um Modelo para Programas Paralelos

O conceito de memória local, definido para as tarefas [FOS95], está associado ao conceito de localidade de dado, que reflete a disponibilidade para o acesso aos mesmos, podendo o acesso ser remoto ou local. Definem-se canais de comunicação para o acesso aos dados remotos.

No projeto do programa, as tarefas são modeladas por nós e os canais são modelados por arcos, conforme ilustra o dígrafo apresentado na Figura 4-21. As tarefas são pedaços de código que podem ser executadas sequiencialmente em um único processador. Caso duas tarefas, que compartilham um canal, sejam alocadas a processadores diferentes, então deve haver um canal de comunicação físico, interligando os processadores no qual os canais lógicos são mapeados.

Um mecanismo único de comunicação é definido entre as tarefas (canais) no projeto do programa, fazendo com que estes sejam executados independentemente da localização dos dados. Assim, o algoritmo pode ser proposto sem que haja preocupação do programador com a alocação das tarefas nos processadores.

Partindo do princípio que cada processo é um comando básico da linguagem, tem-se que cada comando é um nó do grafo que gera processos. Um processo é, por sua vez, um supergrafo e as tarefas representam a aglomeração desses supergrafos, conforme ilustra a Figura 4-22. 
Os objetos da classe SFTProcesso são conseqüência das partições geradas pelo algoritmo e os objetos da classe SFTTarefa são as aglomerações criadas para distribuir os processos nos processadores. O prefixo SFT caracteriza o conjunto de classes-base para modelar os modelos computacionais para o software.

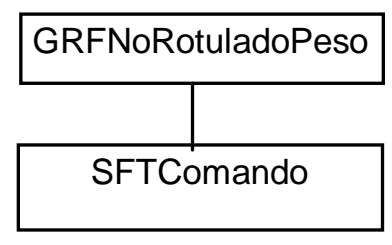

Figura 4-22 - Meta modelo para programas paralelos

\subsubsection{Interface}

A interface da F.A.P.P. é baseada em menu e oferece ao usuário uma visão do ambiente no qual está desenvolvendo suas aplicações, sendo específica para cada modelo arquitetural. Essa interface gráfica permite ao usuário descrever e manipular os elementos que compõem seu software e hardware.

A Figura 4-23 ilustra o esquema de visões do ambiente que é oferecido ao usuário.

Os componentes são descritos e armazenados em arquivos com a finalidade de serem utilizados para compor o Hardware e o Software das aplicações. Cada visão representa um ambiente de desenvolvimento distinto.

A visão da ferramenta corresponde à estrutura de classes e grafos de instruções entre objetos, que permitem ao projetista especializar o sistema em função da necessidade do ambiente.

Para implementar a interface, uma classe-base foi construída de maneira a evoluir de acordo com as especializações arquiteturais que venham a ser acrescidas à ferramenta. 


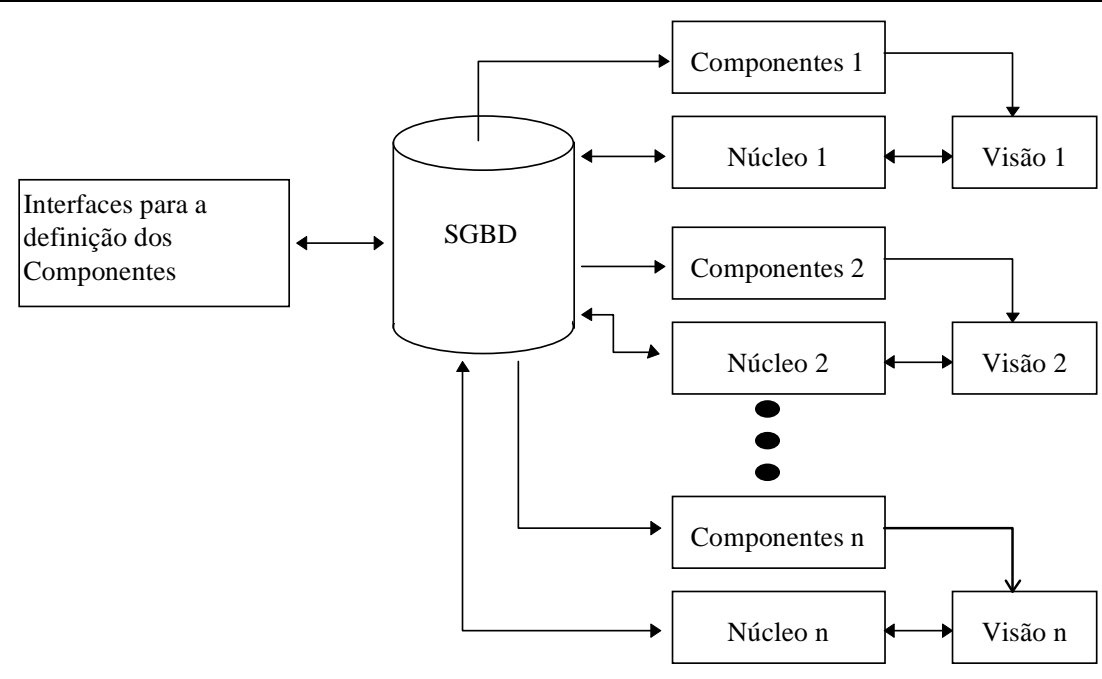

Figura 4-23 - Visões da Aplicação

Cada item do menu principal é composto por sub-itens que geram eventos que são capturados pelo Sistema Operacional e passados para a janela da aplicação, ilustrado na Figura 4-24.

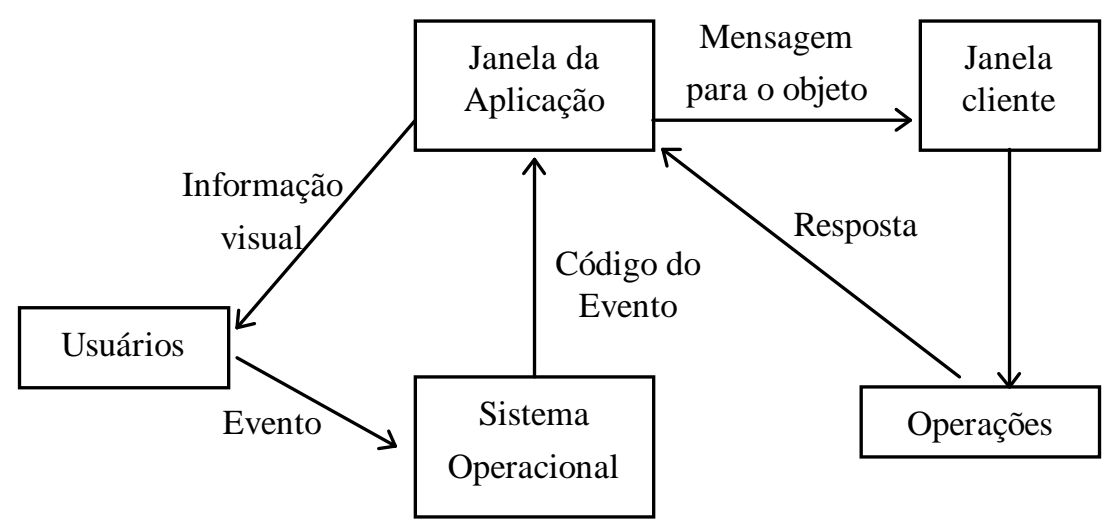

Figura 4-24 - Interação Usuário/Interface/Sistema

Abaixo são apresentadas algumas amostras de tela da ferramenta em questão: 

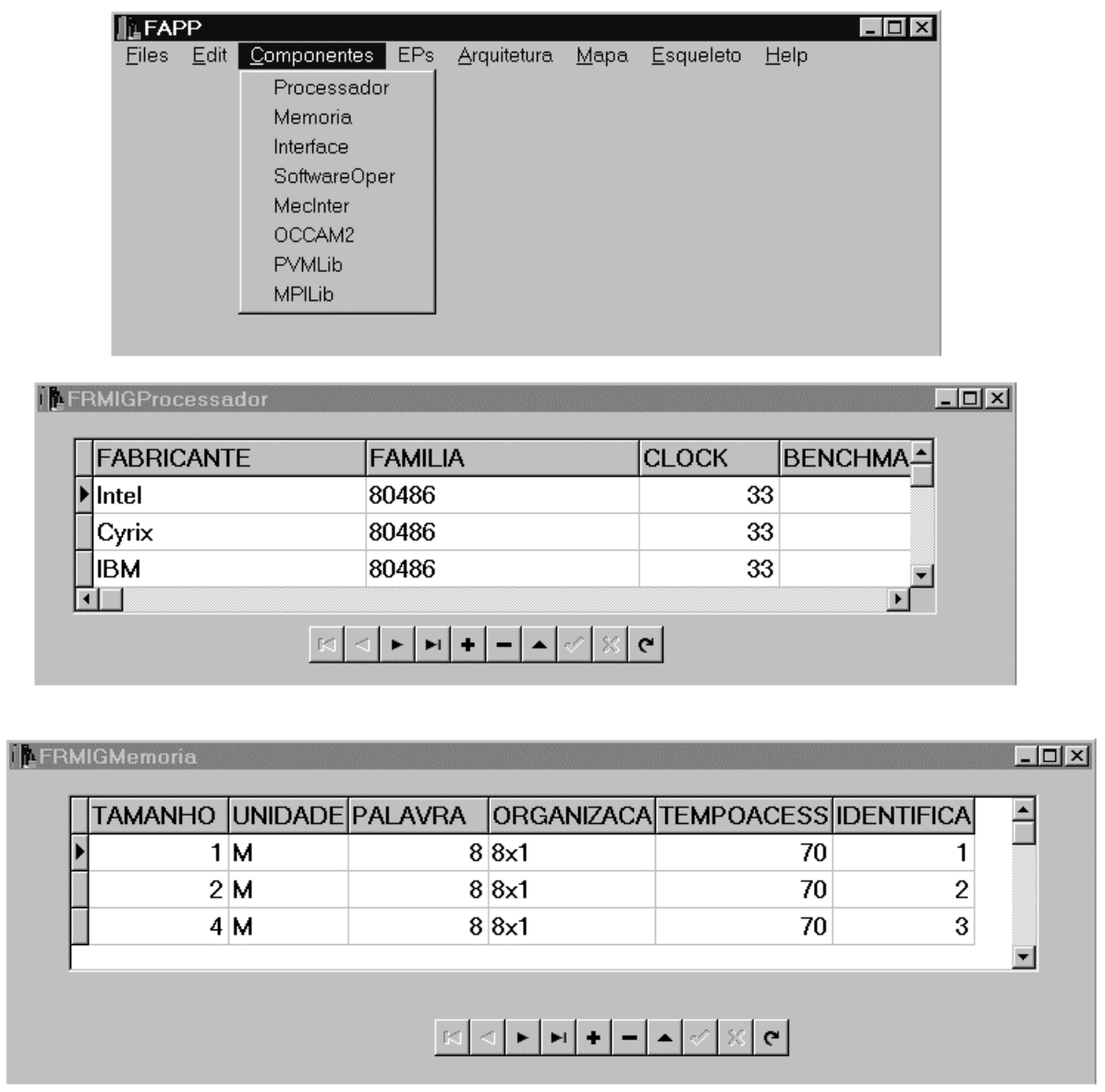

\section{Figura 4-25 - Elementos da Interface da Ferramenta}

Na tela da Figura 4-25 são informados os elementos de interface, ou seja, elementos que compõem o hardware e que por sua vez permitirão a criação do grafo de software. Nela são indicados os processadores, a família a que pertencem, o clock, entre outras características pertinentes ao processador. Ainda nessa tela devem ser especificadas os elementos de memória sendo indicados seu tamanho, unidade, tamanho da palavra, organização e identificador. 

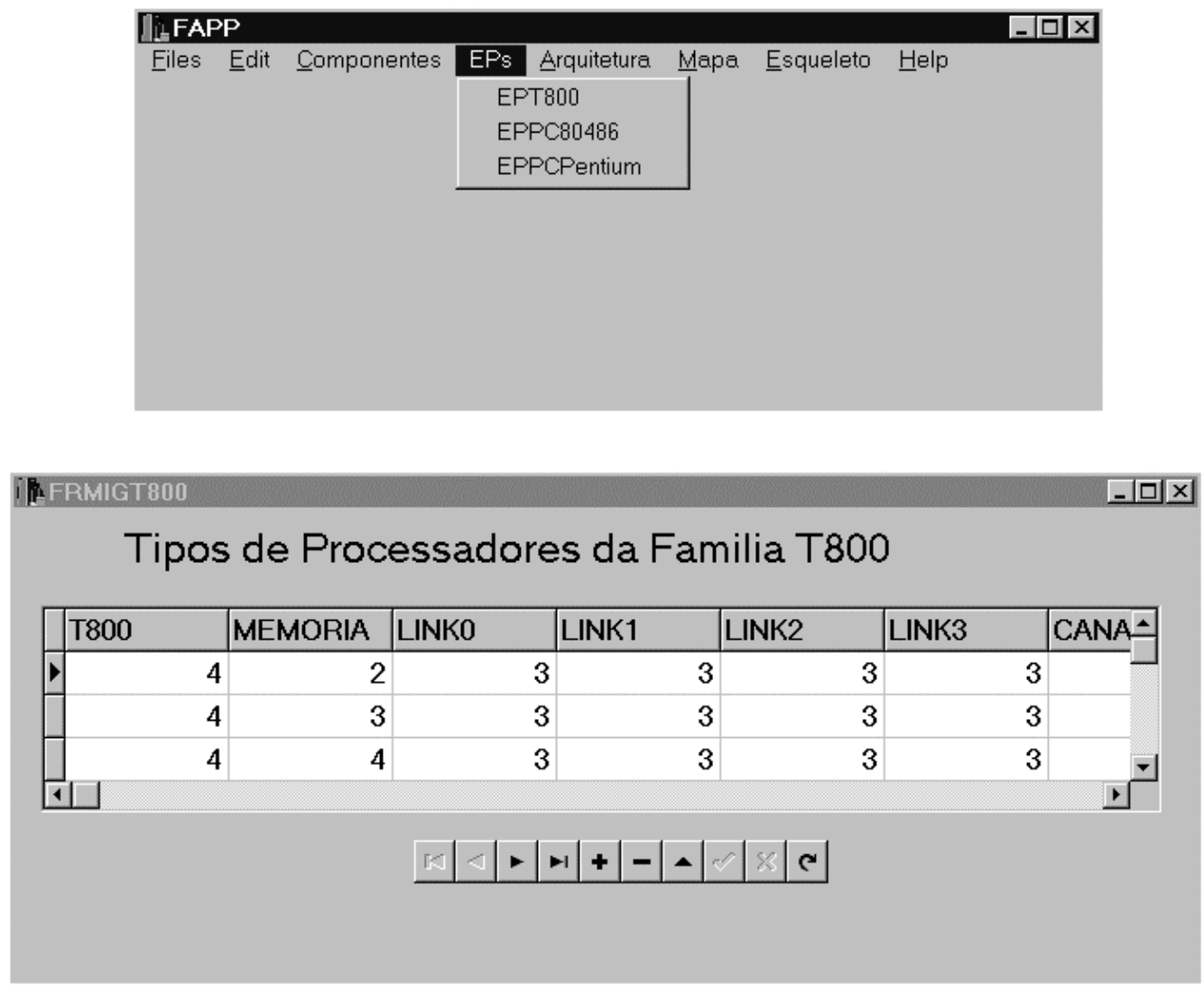

Figura 4-26 - Elemento Processador

Na tela da Figura 4-26, devem ser especificados os elementos pertinentes à classe processador; nesse caso específico a ferramenta está preparada para receber os dados do processador transputer onde podem ser apresentados os links, a memória e os canais de entrada e saída. 

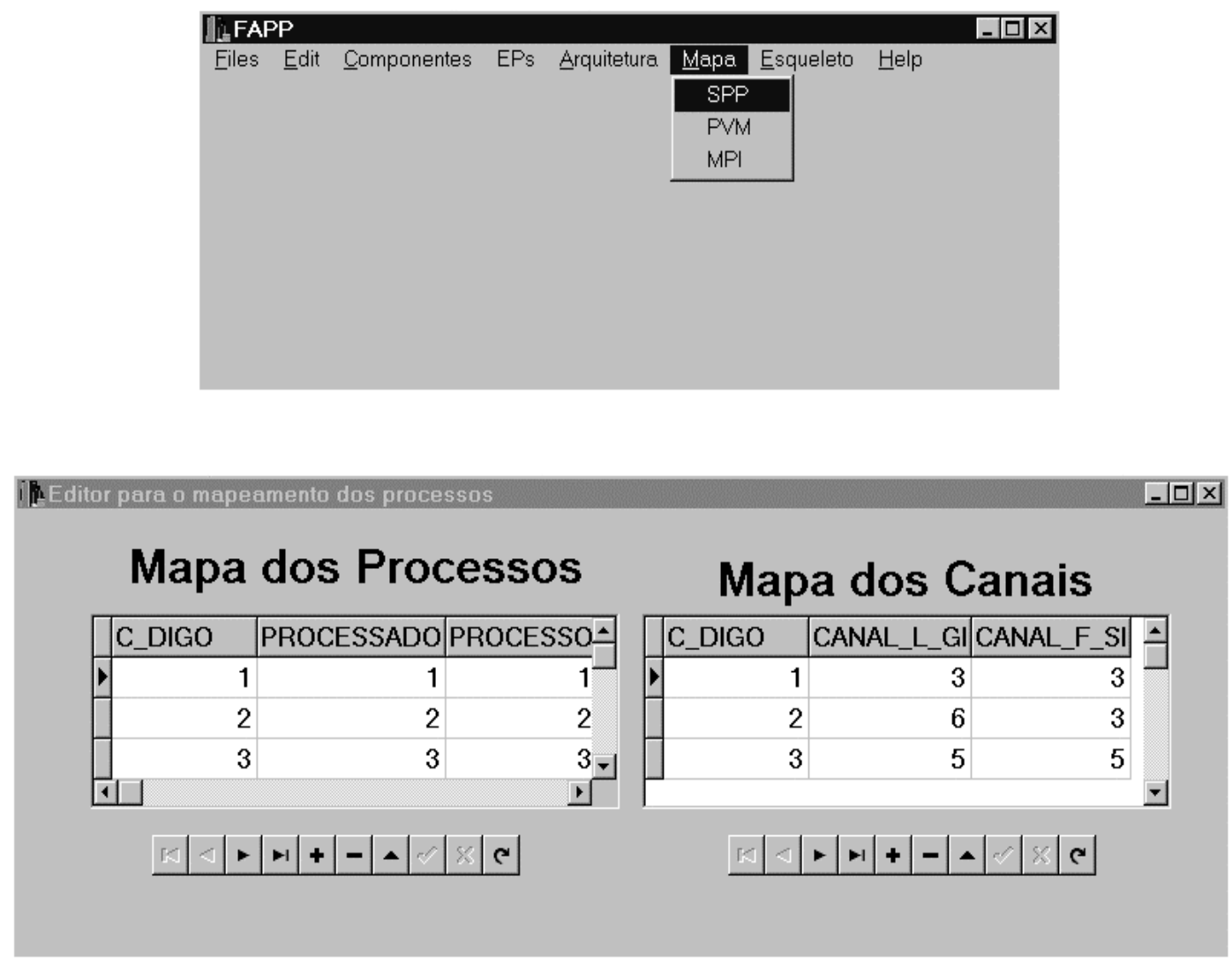

Figura 4-27 - Mapa de Processos e Canais

Na Figura 4-27 é apresentada a tela onde é feito o mapeamento de processos a processadores além do relacionamento entre canais lógicos e físicos de entrada e saída para o SPP nesse caso.

\subsection{Considerações Finais}

As ferramentas de desenvolvimento de sistemas implementam técnicas que são aprimoradas com o passar do tempo, o que provoca a manutenção do sistema no sentido de atender aos novos requisitos inerentes à evolução. Os métodos e técnicas que devem ser utilizados para o desenvolvimento de uma ferramenta de auxílio à programação paralela/concorrente levam em conta o contexto do desenvolvimento de sistemas das últimas décadas. 
A análise da evolução das arquiteturas apresentada por Carmichael [CAR94] aponta como tendência a utilização de arquiteturas paralelas. Embora existam problemas para produção de programas paralelos, a tarefa de distribuição de dados e código em máquinas paralelas pode ser efetuada automaticamente pelo sistema, de maneira estática ou dinâmica. Quando o principal na geração de um programa paralelo é minimizar o tempo de execução, a migração dos programas para outras arquiteturas é quase impraticável [ZHO93], pois a solução do problema está associada à plataforma de desenvolvimento e a migração afeta sensivelmente o desempenho global do sistema [CAL94].

Aqueles que têm a necessidade de aumentar significativamente o desempenho de programas, percebem o potencial que o paralelismo do código pode oferecer, e se deparam com as dificuldades impostas por essa abordagem. Os problemas normalmente encontrados, e citados na literatura, apontam a adequação dos algorítmos ao hardware como fator crucial na obtenção do aumento de desempenho. Em inúmeros casos há necessidade do desenvolvimento de novas técnicas, modelos matemáticos e métodos que solucionem o problema e minimizem o tempo de execução dos programas [FOS95] [HOA85] [AND83].

A complexidade no desenvolvimento de sistemas paralelos/concorrentes durante a última década tem feito com que equipes desenvolvam ferramentas que auxiliem a geração desses programas. Exemplos desse tipo de ferramentas são: FORGE 90, VIENNA, CAPTools, P-RIO, F.A.P.P., entre outras.

A grande inovação da ferramenta, é utilizar-se do modelo matemático da teoria dos grafos para modelar os componentes de hardware e software. Foram apresentados neste capítulo os modelos computacionais, os meta-modelos e a forma pela qual a ferramenta implementa os conceitos de programação paralela por esqueleto de aplicação. Por último, foram apresentadas as interfaces componentes da ferramenta que, baseadas em menus, podem ser alteradas com facilidade, pois não requerem alterações dos eventos gerados, mas sim do tratamento a eles aplicados. A F.A.P.P. constitui uma ferramenta muito interessante para o desenvolvimento de programas paralelos, cuja utilização permite a geração de esqueletos de aplicações paralelas em nível satisfatório. A orientação a objetos aplicada como técnica para modelagem da teoria dos grafos produz um meta-modelo com potencial para ser usado como base em diversas aplicações.

O exemplo de ferramenta de apoio à construção de software paralelo apresentado, ilustra uma possível utilização do modelo, como base para resolver um problema de importância no cenário computacional atual.

Uma das grandes vantagens do meta-modelo desenvolvido é a capacidade de gerar aplicações em que evoluções futuras são facilmente incorporadas, isso devido ao uso da orientação a objetos.

Potencialmente, a ferramenta exemplo F.A.P.P. pode ser estendida para apoiar o desenvolvimento de programas paralelos em outros ambientes como por exemplo para ambientes paralelos virtuais, e linguagens como $\mathrm{C}++$ e Fortran. 
O próximo capítulo a modelagem dos ambientes paralelos virtuais apresentados no Capítulo 3 para a Ferramenta de Apoio a Programação Paralela. 


\section{Aplicando a Abordagem da F.A.P.P. para Aplicações Paralelas Virtuais}

Partindo do embasamento teórico, das metodologias utilizadas e do meta-modelo orientado a objetos proposto por Calônego [CAL97], é possível aplicar a abordagem da F.A.P.P. para Ambientes Paralelos Virtuais.

Este capítulo apresenta a aplicação do meta-modelo proposto por Calônego para Ambientes Paralelos Virtuais, bem como as extensões necessárias para tornar possível a especificação da ferramenta para apoiar a elaboração de programas em P.V.M. [BEG94] [GEI94] [SUN94] e M.P.I. [DON95] [DOS96].

\subsection{Considerações Iniciais}

A extensão da F.A.P.P., fornece recursos necessários para que os usuários possam produzir código em P.V.M. e M.P.I. de maneira mais fácil e intuitiva, pois ela permite que não haja necessidade de um conhecimento das linguagens, mas sim um mínimo de conhecimento em programação paralela/concorrente.

O objetivo principal é, portanto, permitir que a utilização de Ambientes Paralelos Virtuais seja viabilizada para um maior número de usuários, os quais tenham conhecimentos mínimos de programação paralela/concorrente, mas não possuem conhecimentos dos Ambientes Paralelos Virtuais, e até mesmo para os que possuem conhecimentos sobre esses ambientes pois gera um protótipo livre de erros e de fácil manutenção, ficando o usuário ciente que o bug estará na parte do código inserida por ele e não no que diz respeito às rotinas de comunicação e de inicialização das tarefas filhas.

A escolha dos ambientes P.V.M. e M.P.I., já comentada no Capítulo 3, deu-se pela sua ampla aceitação, e por terem grande destaque na literatura, não só pela flexibilidade mas por ser um tipo de solução para o problema da portabilidade de programas entre sistemas diferentes.

A escolha da F.A.P.P. [CAL97] deu-se por ser uma ferramenta baseada em uma técnica de modelagem bastante flexível, permitindo incorporação de novas tecnologias, tanto em nível de hardware como em nível de software. 


\subsection{Especializações da Ferramenta}

Através da observação das características da F.A.P.P. e do fato da unidade de processamento dos ambientes paralelos ser a tarefa, alguns conceitos existentes na F.A.P.P. foram utilizados e outros foram criados e adaptados, estendendo assim a ferramenta existente.

Dessa forma, as classes de hardware e software utilizadas pelo embasamento teórico da F.A.P.P. foram adotadas para o mapeamento dos componentes de hardware em sua integridade, mas as classes para mapeamento de software não o foram, tendo em vista que o paralelismo em Occam2 dá-se através de comandos, ou seja, existe uma granulosidade fina. Já para Ambientes Paralelos Virtuais, as unidades de paralelização são os processos ou tarefas, tendo uma granulosidade média ou grossa.

Assim, a utilização do embasamento da F.A.P.P. dar-se-á em partes. Um novo modelo de objetos para software foi elaborado estendendo assim a ferramenta para dar suporte a Ambientes Paralelos Virtuais onde arcos e nós passarão a representar as tarefas e comunicações, como será exemplificado nas seções que seguem.

A Figura 5-1 apresenta como dar-se-á a implementação do gerador de protótipos para os Ambientes Paralelos Virtuais. 


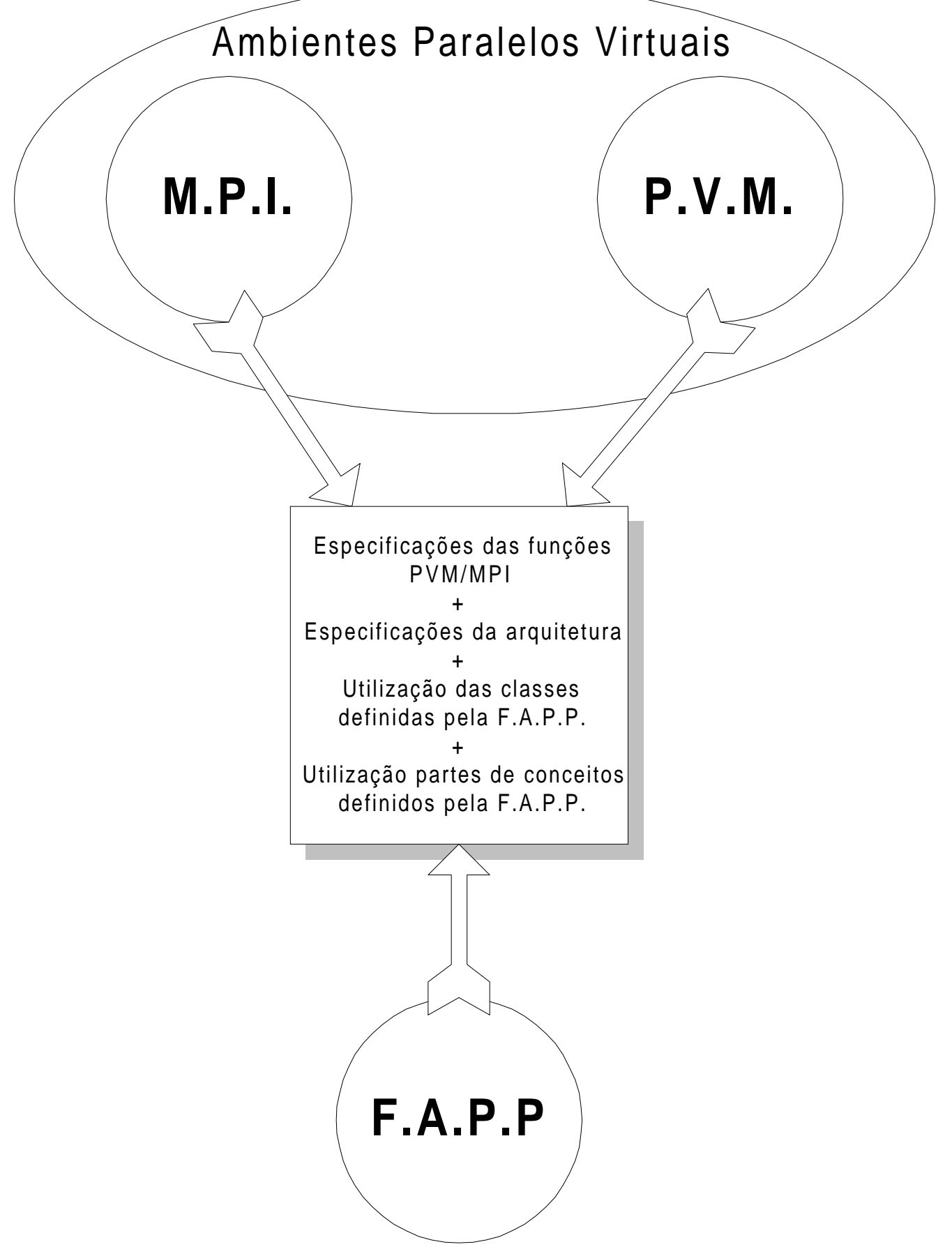

Figura 5-1 - Modelo Gráfico da Implementação do Gerador 
Tomando como base o meta-modelo apresentado por Calônego [CAL97] e reproduzido anteriormente na Figura 4-13 no Capítulo 4, passou-se à análise das arquiteturas de hardware e software dos ambientes P.V.M. e M.P.I., visando a definição e implementação da extensão da F.A.P.P. para esses ambientes.

\subsection{A Arquitetura do Hardware no P.V.M.}

Para que seja desenvolvido um programa P.V.M., faz-se necessária a definição, por parte do programador, dos elementos de processamento que compõem a sua arquitetura, o conjunto de processos que serão executados e o paradigma de programação (Single Program Multiple Data ou Multiple Program Multiple Data). Tendo como base as informações fornecidas pelo usuário, será possível a definição do hardware no qual será executada a aplicação gerada.

A definição do hardware pode ser feita através da especificação de um arquivo de configuração. Isso será feito na Ferramenta F.A.P.P. através da especialização da classe Elemento Processador. Essa classe de componentes permitirá a composição do ambiente de hardware necessário para a execução das aplicações P.V.M.. Com a composição do ambiente de hardware será possível identificar quais máquinas têm melhor condição de executar quais tarefas, permitindo um "pseudo-escalonamento" de processos, ou seja, através da função peso existente, isso poderá ser realizado.

Gerar a estrutura do hardware para uma aplicação P.V.M., consiste em fornecer aos usuários o conjunto de elementos processadores que podem ser selecionados. Para que um elemento processador possa ser instanciado, classes abstratas foram modeladas, ou seja, classe memória, entrada/saída, processador e meios de transmissão (Figura 5-2 e Figura 5-3). 


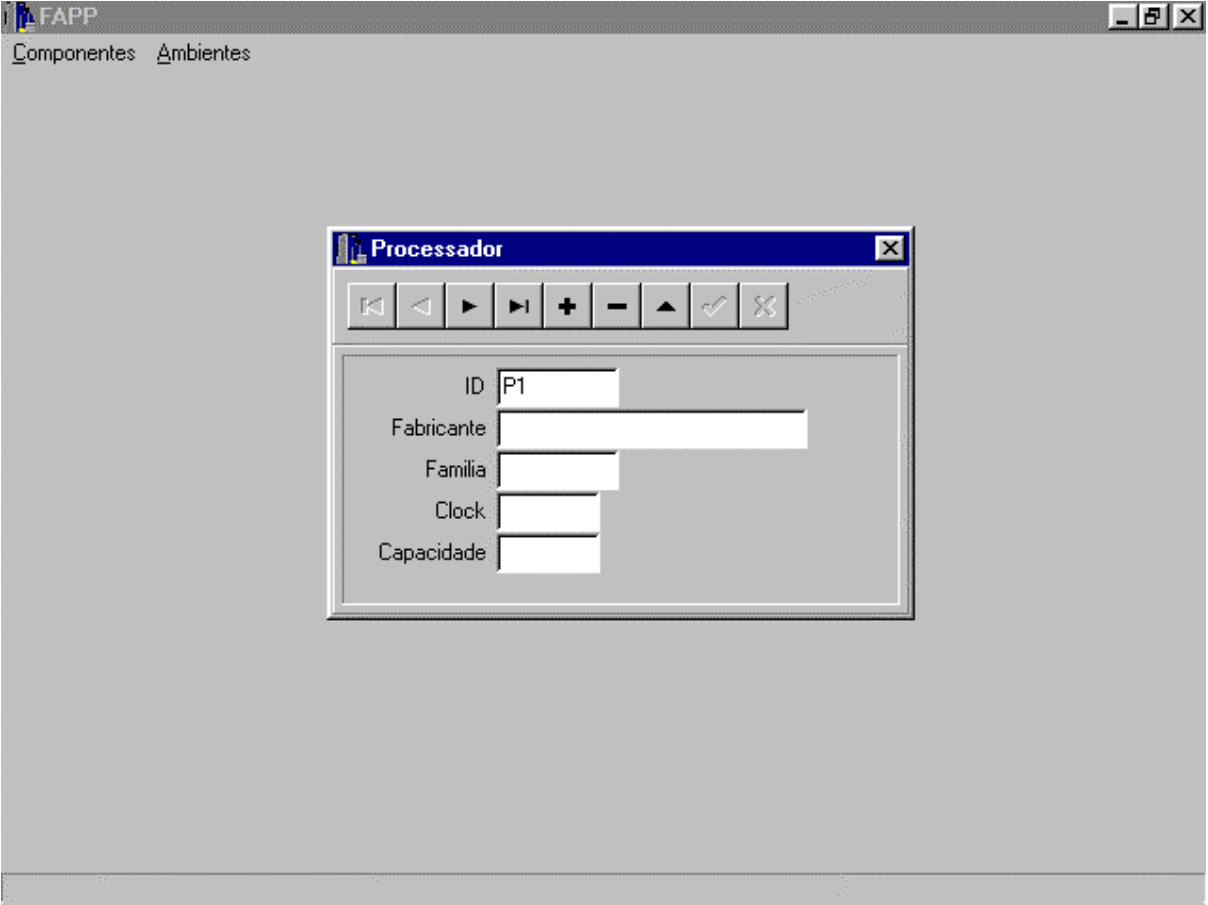

Figura 5-2 - Cadastro de Processadores

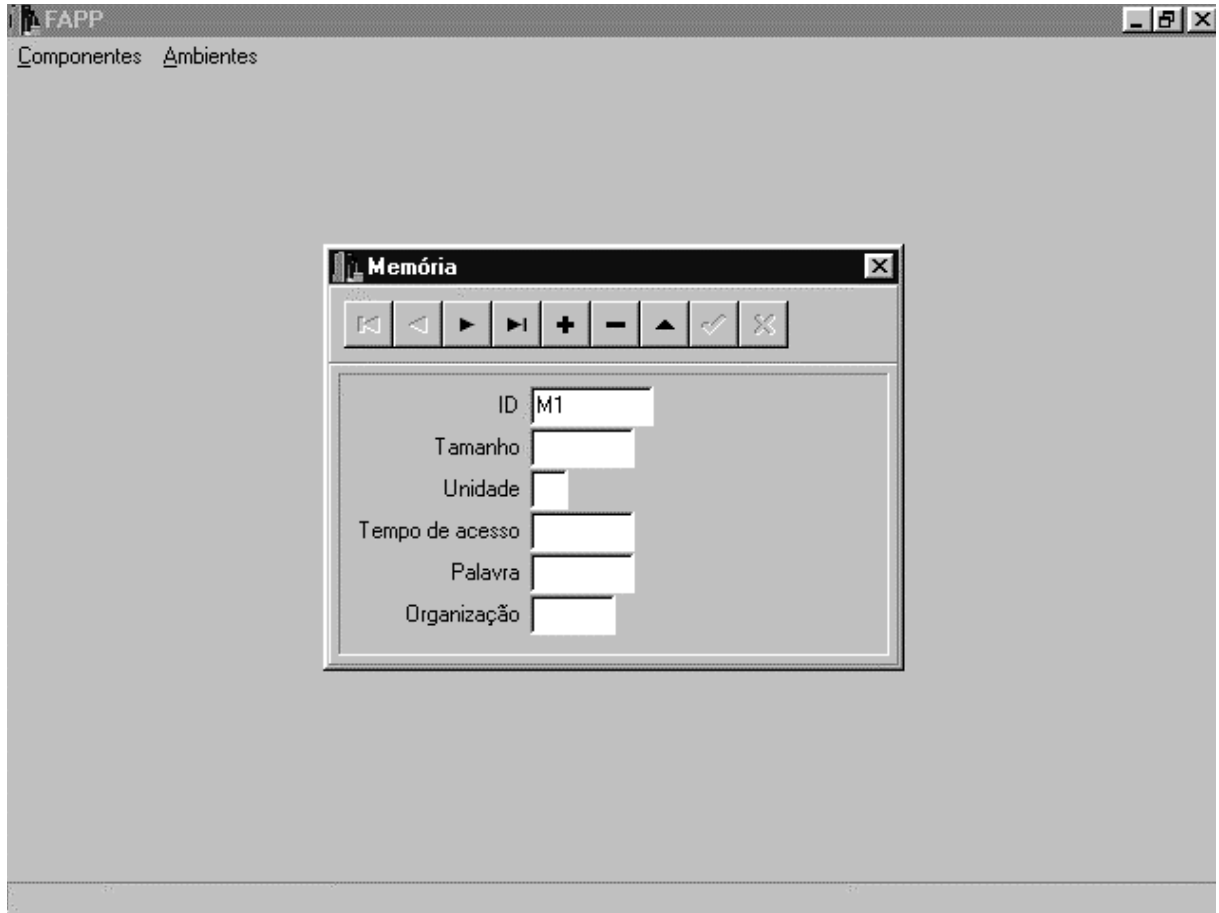

Figura 5-3 - Cadastro de Memórias 
O modelo de objetos utilizado para que possa ser feito o mapeamento das máquinas que serão utilizadas na execução da aplicação P.V.M. e que irão compor a máquina paralela virtual é apresentado na Figura 5-4.

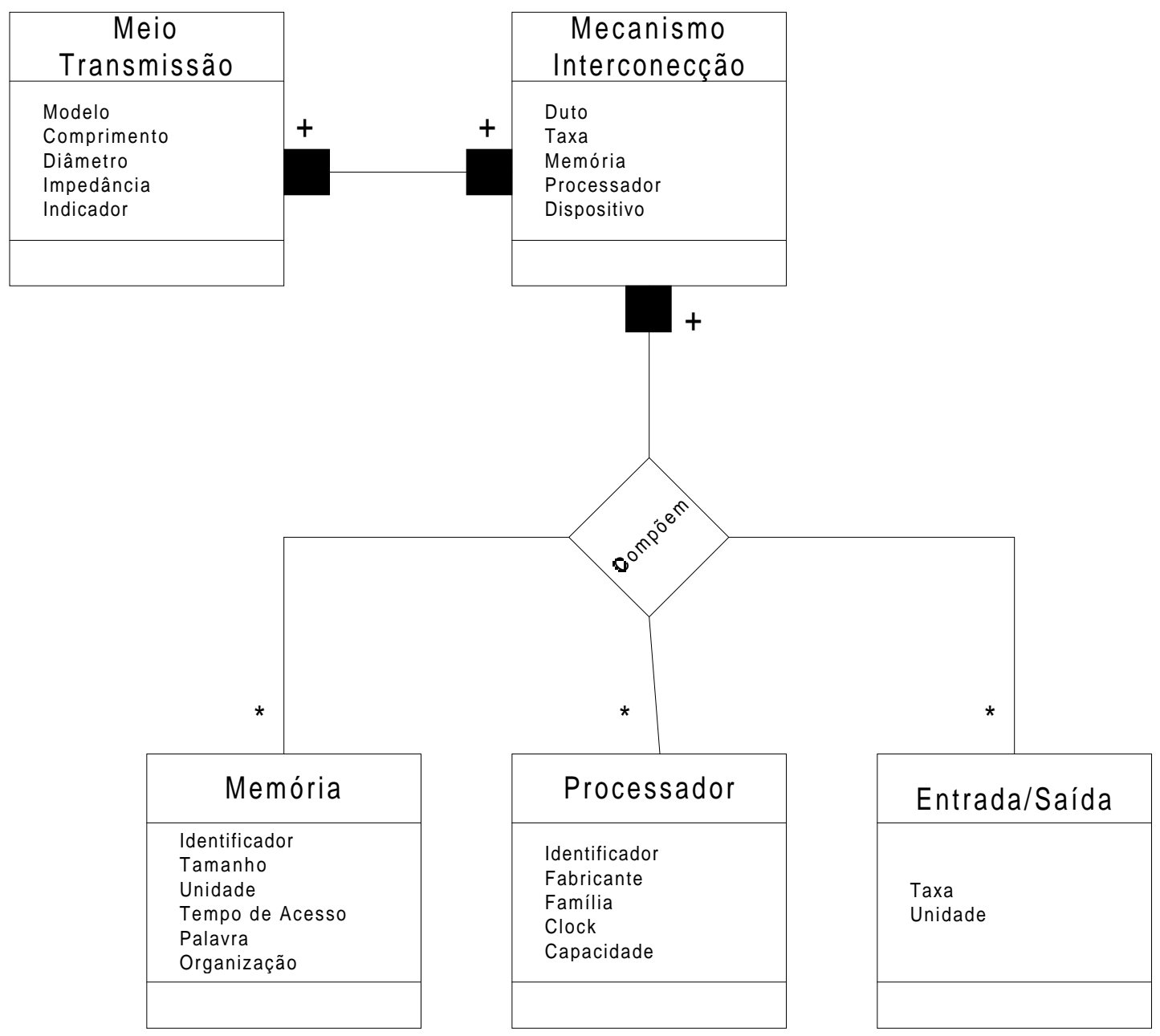

Figura 5-4 - Modelo de Objetos - Componentes de Hardware 


\subsection{A Arquitetura do Software no P.V.M.}

O ambiente P.V.M. permite que os programas sejam desenvolvidos utilizando-se os paradigmas S.P.M.D. e M.P.M.D. (Figura 5-5), sendo necessário que a ferramenta ofereça suporte a esses mecanismos.

O modelo implementado na ferramenta F.A.P.P. baseia-se no mapeamento das tarefas P.V.M., sendo essas a unidade de processamento do P.V.M.. Dessa forma, o usuário define o paradigma e o número de tarefas a serem disparadas. A ferramenta permitirá que o desenvolvimento de programas paralelos seja obtido de uma maneira mais eficiente, utilizandose o hardware existente. Dessa forma, no aspecto mais genérico de desenvolvimento de software, a ferramenta pode ser muito útil para a manutenção do sistema, pois fornece um protótipo organizado e com identificações das localizações das rotinas utilizadas na aplicação.

As tarefas da aplicação são executadas em um conjunto de máquinas que são selecionadas pelo usuário, para que um dado programa P.V.M. possa executar. A aplicação enxergará o ambiente de hardware como uma coleção de elementos de processamento, posicionando cada tarefa no elemento processador apropriado, isso levando em conta o tamanho da tarefa e a característica das máquinas que compõe o hardware, possibilitando, um "pseudoescalonamento" de processos. O P.V.M. possui rotinas para o empacotamento, envio e recebimento de mensagens entre as tarefas. A ferramenta F.A.P..P. permite que sejam especificadas as trocas de mensagens entre as tarefas, indicando quais tarefas são emissoras e quais tarefas são receptoras. 
A ferramenta permite também que sejam especificados os tipos de comunicação, indicando se o receive é bloqueante ou não bloqueante.

Figura 5-5 - Gerador de Protótipo de Aplicações para Ambientes Paralelos Virtuais

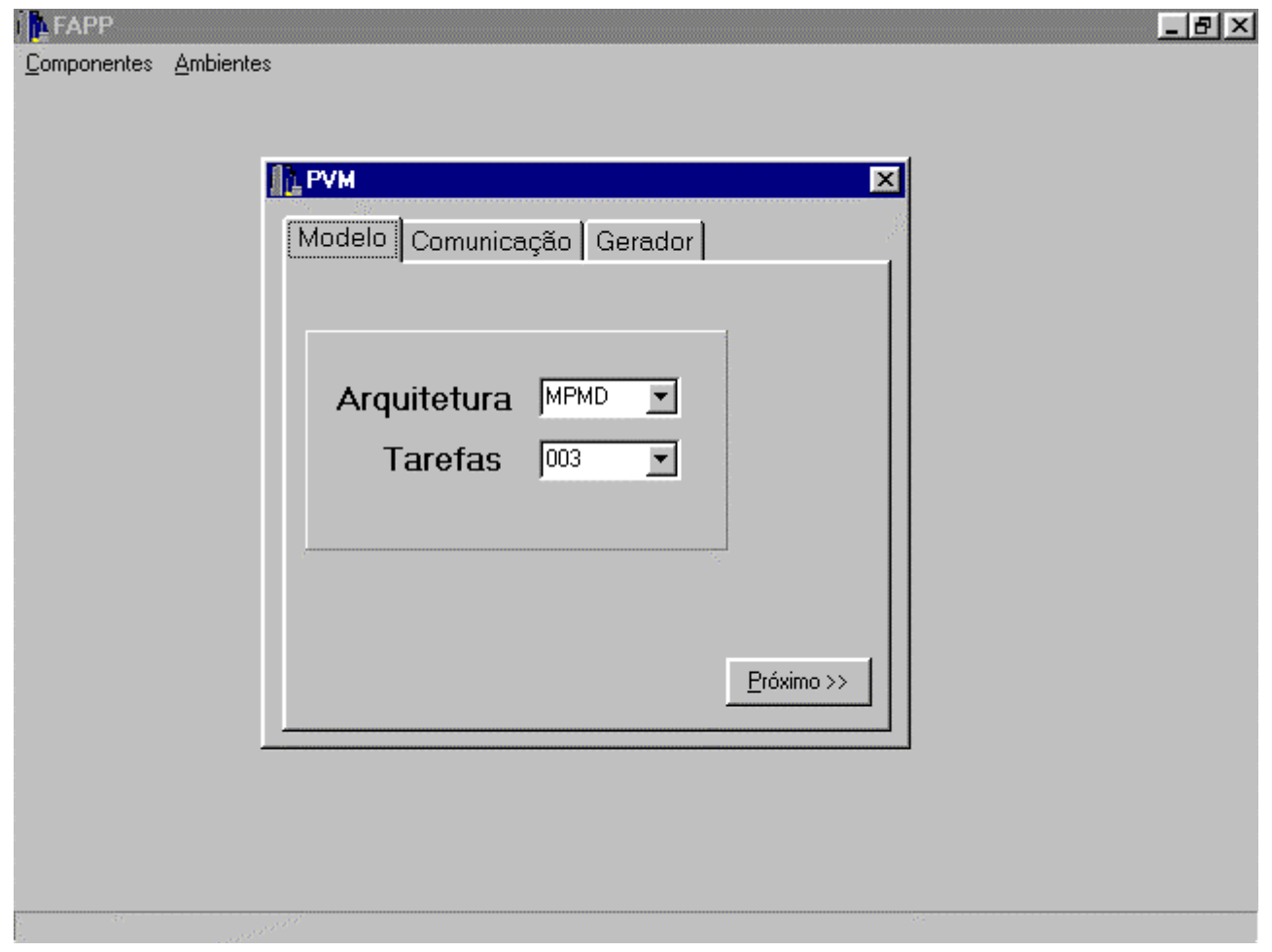

Para que os procedimentos nessa seção possam ser implementados, tem-se o modelo de objetos apresentados na Figura 5-6, que permite o mapeamento das funções que serão utilizadas, juntamente com o hardware compondo o protótipo da aplicação. 


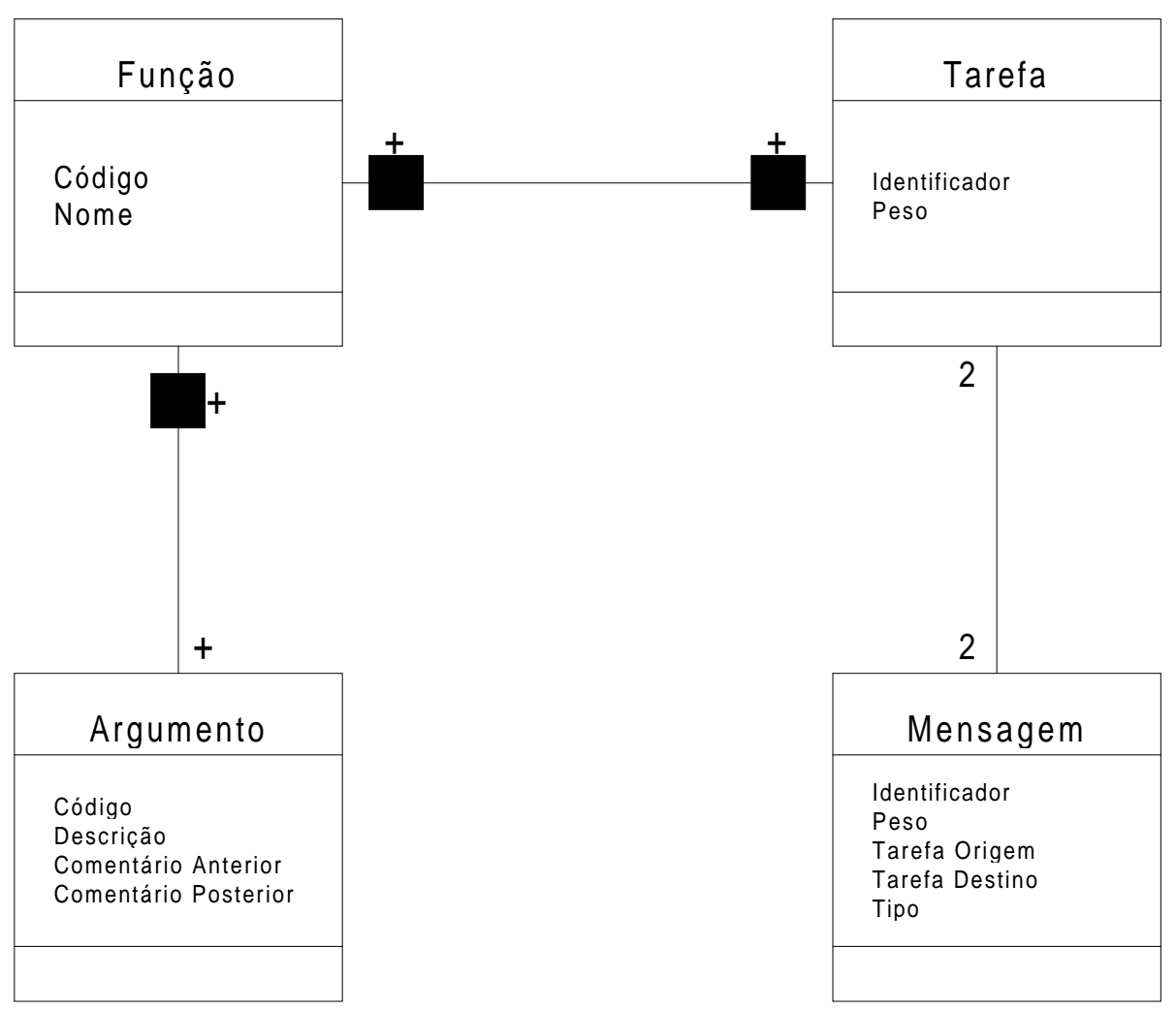

Figura 5-6 - Modelo de Objetos - Componentes de Software

O grafo da Figura 5-7 apresenta um exemplo de aplicação paralela/distribuída a ser implementada. Nesse caso adota-se o paradigma S.P.M.D., com três tarefas filhas sendo geradas. O grafo indica todas as informações necessárias, tais como: o número de tarefas, a comunicação existente entre as tarefas (incluindo o sentido da comunicação), o tipo de comunicação (bloqueante, não bloqueante), entre outras. 


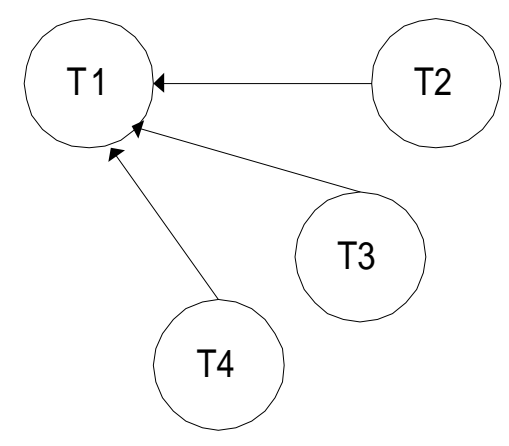

Figura 5-7 - Grafo das tarefas e suas comunicações S.P.M.D.

Para esse exemplo, tem-se a geração do seguinte protótipo para o programa P.V.M. correspondente:

\section{HEADER}

$/ /-$

// USP/ICMC - SC

// FAPP - COMPUTAÇÃO PARALELA - SISTEMAS DISTRIBUÍDOS

// ArquivoM:

$/ /-$

//Inclusão da biblioteca PVM

\#include "pvm3.h"

//Número máximo de tarefas a serem ativadas

\#define MAXNCHILD x

//Define constante que especifica mensagem

\#define MSGTAG 1 //defina o tipo de mensagem a ser enviada (valor defaul=1)

/* 
*/

//Defina o restante de suas constantes

/*

n.........

*/

//Início do programa principal

$\operatorname{main}()$

\{

//Definição das variáveis

int ntask $=\mathrm{a}$;

int mytid;

int tids[ntask];

int tids_escravos[ntask-1];

int myparent;

int $\mathrm{i}$, info;

char *hosts[] = $\{$ "h1","h2,.... $\}$;

//Defina o restante de suas variáveis

/*

$* /$

// criando os pvmds escravos 


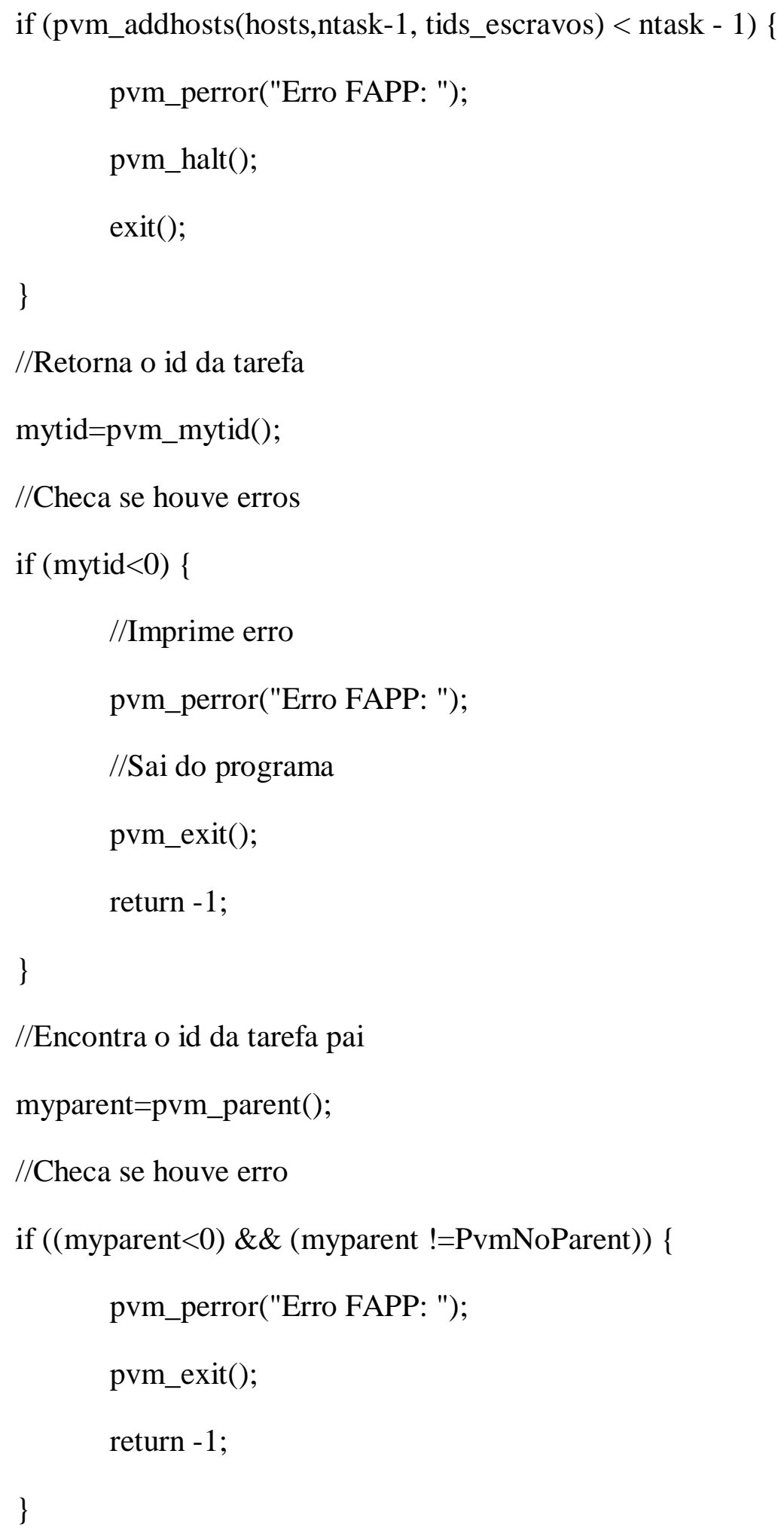


//Se não existir processo pai, então eu sou o processo pai

if $($ myparent $==$ PvmNoParent $)\{$

//Dispara as tarefas filhas

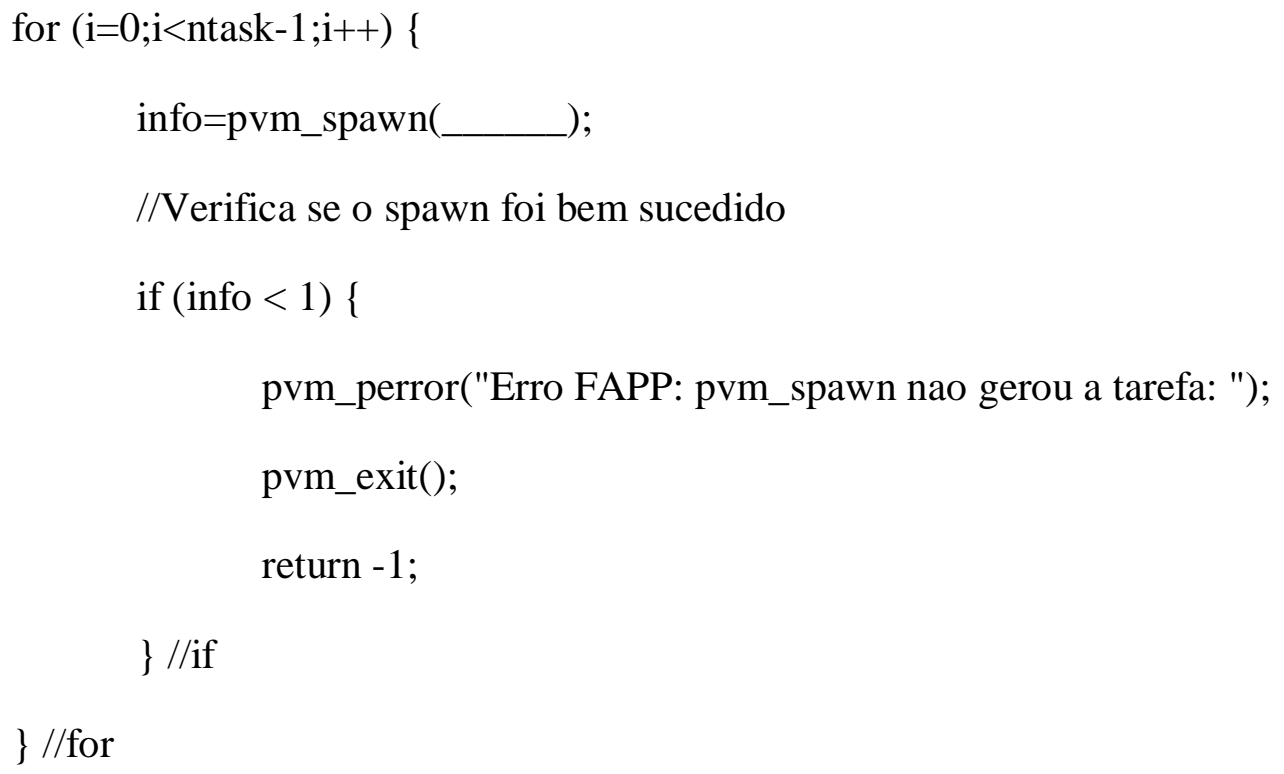

//Rotinas de recebimento de mensagens

//Recebe mensagem

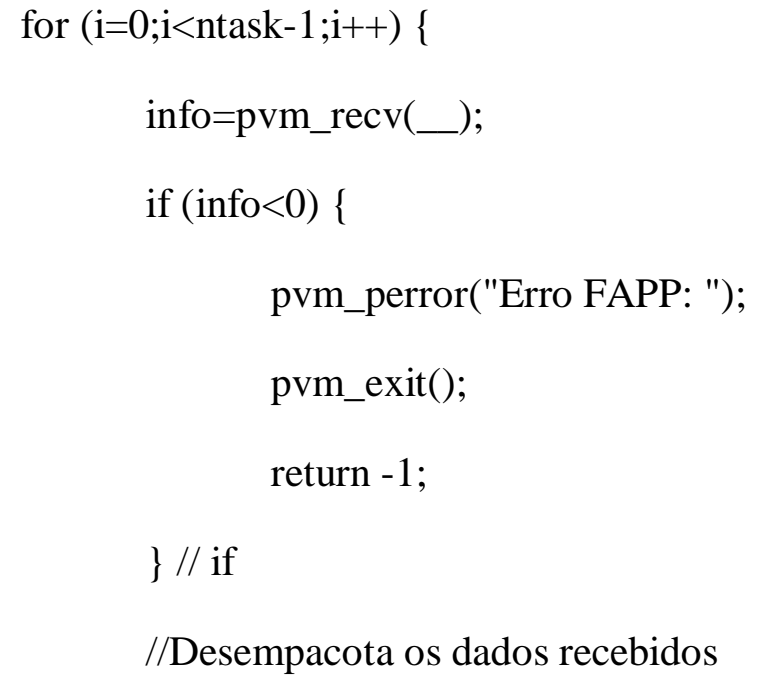




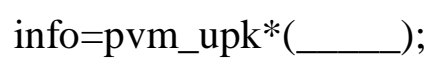

\} // for

//Definas as rotinas a serem executadas

//com os dados desempacotados

/*

$* /$

//Insira a parte do código a ser executada após o retorno das tarefas filhas

/*

$* /$

pvm_exit();

\} else \{

//Insira o código a ser executado pelas tarefas filhas

/*

$* /$

//Defina as rotinas que geram

// os dados a serem enviados

/* 
$* /$

//Rotinas de envio de mensagens

//Inicializa buffer de envio

pvm_initsend(PvmDataDefault);

//Empacota dados

pvm_pk*(_ $)$;

//Envia mensagem

pvm_send(__ $)$;

\}

//Insira aqui funções que devem ser executadas tanto pela tarefa mestre

//quanto pelas filhas

/*

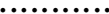

$* /$

pvm_exit();

exit();

\}

// 
Num segundo exemplo (Figura 5-8), o paradigma escolhido é o M.P.M.D., com o número de tarefas igual a dois, ou seja, duas tarefas filhas e uma tarefa pai. Nesse exemplo, as tarefas filhas se comunicam com a tarefa pai e essa por sua vez também se comunica com as tarefas filhas. Tanto nesse caso como no anterior, a primeira tarefa será a tarefa mestre. Nesse segundo exemplo, especificamente, serão gerados dois programas, um definindo a execução da tarefa mestre e outro definindo a tarefa escrava. A tarefa mestre terá seu nome acrescido do sufixo _m e a tarefa escrava do sufixo_s.

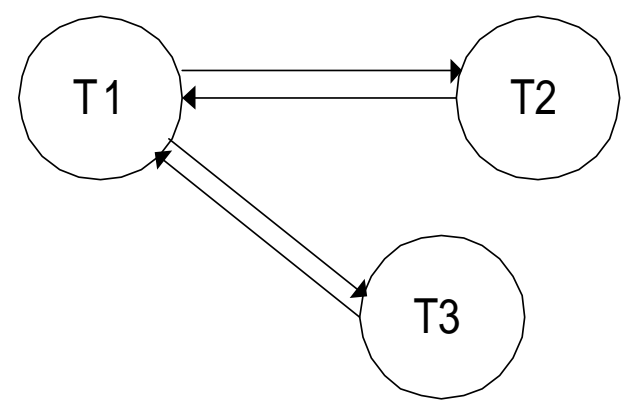

Figura 5-8- Grafo das tarefas e suas comunicações M.P.M.D.

Os protótipos gerados para esse exemplo são apresentados a seguir:

HEADER MESTRE

$/ /-$

// USP/ICMC - SC

// FAPP - COMPUTAÇÃO PARALELA - SISTEMAS DISTRIBUÍDOS

// Código MASTER

// ArquivoM:

$/ /$

//Inclusão da biblioteca PVM

\#include "pvm3.h"

//Número máximo de tarefas ativadas 
\#define MAXCHILD x

//Define constante que especifica a mensagem

\#define MSGTAG 1 //defina o tipo de mensagem a ser enviada (valor default $=1$ )

//Defina o restante de suas constantes

//Início do programa principal

$\operatorname{main}()$

\{

//Definição das variáveis

int mytid;

int $\mathrm{i}$, info;

int ntask=a;

int tids[ntask];

int tids_escravos[ntask-1];

char *hosts[] $=\{$ "h1","h2,.... $\}$;

//Defina o restante de suas variáveis

/*

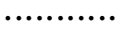

*/

// criando os pvmds escravos

if (pvm_addhosts(hosts,ntask-1, tids_escravos) $<$ ntask - 1) \{

pvm_perror("Erro FAPP: ");

pvm_halt(); 


\section{exit();}

\}

//Defina as rotinas a serem executadas pelo programa mestre antes que sejam

//disparadas as tarefas filhas

/*

$* /$

//Dispara as tarefas filhas

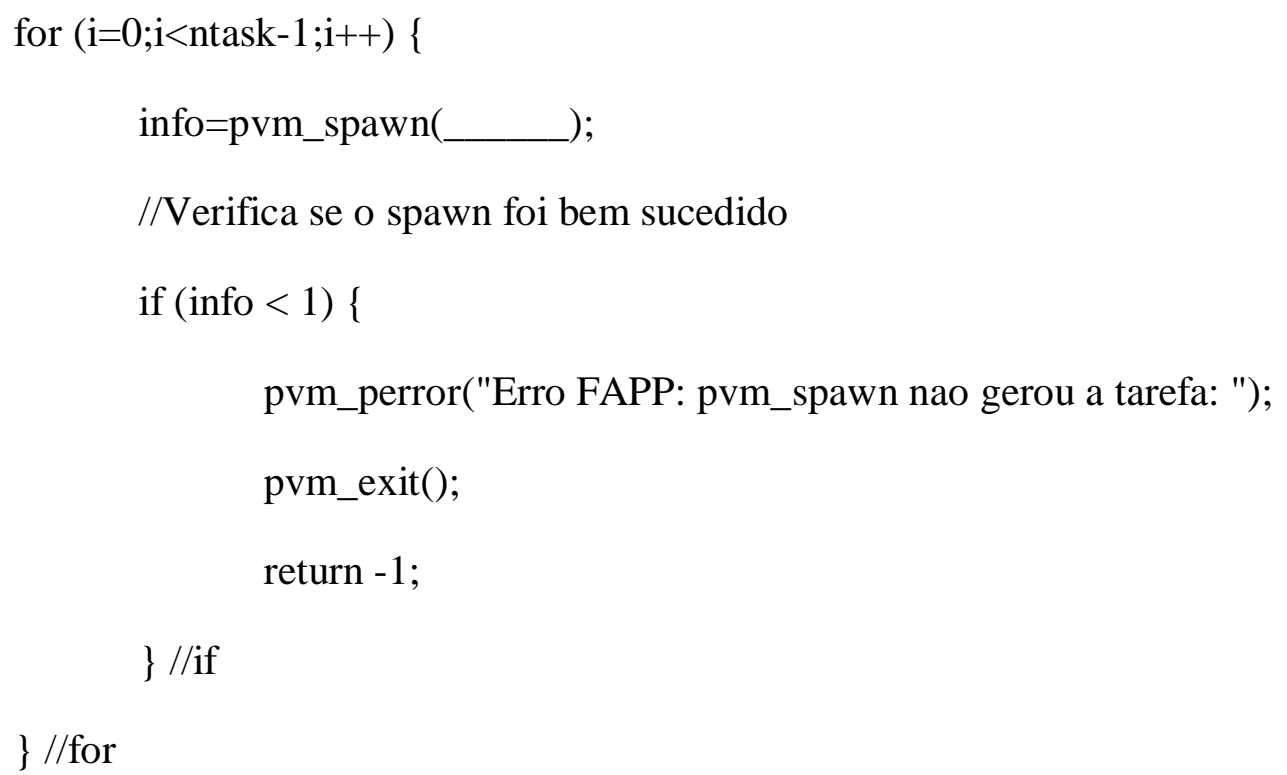

//Checa se spawn foi bem sucedido 
//Defina as rotinas que geram

// os dados a serem enviados

/*

(n.........

*/

//Rotinas de envio de mensagens

//Inicializa buffer de envio

for $(\mathrm{i}=0 ; \mathrm{i}<$ ntask $-1 ; \mathrm{i}++)\{$

pvm_initsend(PvmDataDefault);

//Empacota dados

pvm_pk*(_ $)$;

//Envia mensagem

pvm_send(__ $)$;

\}

//Rotinas de recebimento de mensagens

//Recebe mensagem

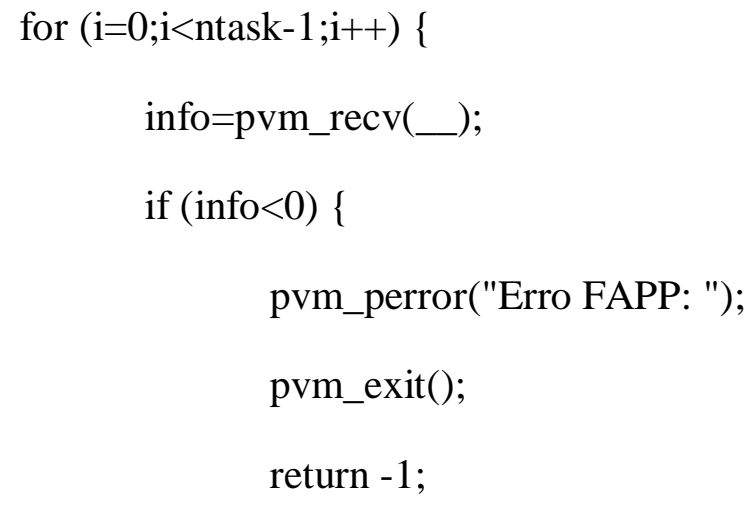


\}// if

//Desempacota os dados recebidos

info=pvm_upk*(__ $)$;

\} // for

//Definas as rotinas a serem executadas

//com os dados desempacotados

/*

$* /$

//Digite as rotinas a serem executadas após a execução das tarefas filhas

/*

$* /$

pvm_exit();

exit();

\}

/I 


\section{HEADER ESCRAVO}

$/ /-$

// USP/ICMC - SC

// FAPP - COMPUTAÇÃO PARALELA - SISTEMAS DISTRIBUÍDOS

// Código SLAVE

// ArquivoS:

$/ /-$

//Inclusão da biblioteca PVM

\#include "pvm3.h"

//Número máximo de tarefas ativadas

\#define MAXCHILD x

//Define constante que especifica a mensagem

\#define MSGTAG 1 // defina o tipo da mensagem $($ valor default = 1)

//Defina o restante de suas constantes

/*

$* /$

//Início do programa escravo

main()

\{

//Definição das variáveis 
int myparent;

int info;

int ntask=a;

int tids[ntask];

//Defina o restante de suas variáveis

/*

$* /$

//Retorna id da tarefa pai

myparent=pvm_parent () ;

//Checa se ocorreu erro

if $(($ myparent $<0) \& \&$ (myparent != PvmNoParent $))\{$

pvm_perror("Erro FAPP: ");

pvm_exit();

return -1 ;

\}

//Defina as rotinas a serem executadas pelas tarefas filhas

/*

$* /$

//Rotinas de recebimento de mensagens 
//Recebe mensagem

info $=$ pvm_recv(_ $)$;

if $($ info $<0)\{$

pvm_perror("Erro FAPP: ");

pvm_exit();

return -1 ;

\}

//Desempacota os dados recebidos

info $=$ pvm_upk $*(\ldots)$;

//Definas as rotinas a serem executadas

//com os dados desempacotados

/*

$* /$

//Defina as rotinas que geram

// os dados a serem enviados

/*

$* /$

//Rotinas de envio de mensagens 
//Inicializa buffer de envio

pvm_initsend(PvmDataDefault);

//Empacota dados

pvm_pk*(_ $)$;

//Envia mensagem

pvm_send(__ $)$;

//Termina a tarefa

pvm_exit();

exit();

\}

$/ /$

Os protótipos apresentados, permitem uma otimização no desenvolvimento de aplicações P.V.M., pois os usuários não precisam conhecer P.V.M. para ainda assim desenvolver uma aplicação. Entretanto, o não conhecimento de P.V.M. não implica em não conhecimento de conceitos de paralelismo, ou seja, o usuário deverá ter conhecimentos de programação paralela pois estará a cargo dele a escrita dos procedimentos a serem executados pela aplicação escolhida por ele.

\subsection{Arquitetura de Hardware do M.P.I.}

Assim como no P.V.M., para que seja desenvolvido um programa M.P.I., faz-se necessária a definição, por parte do programador, dos elementos de processamento que compõem a sua arquitetura, o conjunto de processos a serem executados e o paradigma de programação S.P.M.D ou M.P.M.D.. Da mesma forma que na especificação do P.V.M., a definição do hardware será feita em um arquivo de configuração e de acordo com a especificação da classe Elemento Processador. As classes modeladas para o ambiente P.V.M. poderão e deverão ser utilizadas na composição dos elementos que irão compor o hardware sobre o qual 
será executada a aplicação M.P.I.. O modelo de objetos é o mesmo apresentado na seção anterior para o P.V.M..

\subsection{Arquitetura de Software do M.P.I.}

O M.P.I., do mesmo modo que o P.V.M., permite que sejam desenvolvidos programas utilizando os paradigmas S.P.M.D e M.P.M.D., apesar do paradigma M.P.M.D. ser pouco utilizado. Assim, o usuário define o paradigma e o número de tarefas a serem disparadas.

Os programas M.P.I. consistem de processos autônomos, executando seu próprio código. O modelo de objetos utilizado pelo software do M.P.I. também é o mesmo utilizado pelo modelo de software do P.V.M..

O grafo da Figura 5-9 apresenta um exemplo de aplicação paralela/distribuída a ser implementada. Nesse caso adota-se o paradigma S.P.M.D., com três tarefas filhas sendo geradas. O grafo indica todas as informações necessárias, tais como: o número de tarefas, a comunicação existente entre as tarefas (incluindo o sentido da comunicação), o tipo de comunicação (bloqueante, não bloqueante), entre outras.

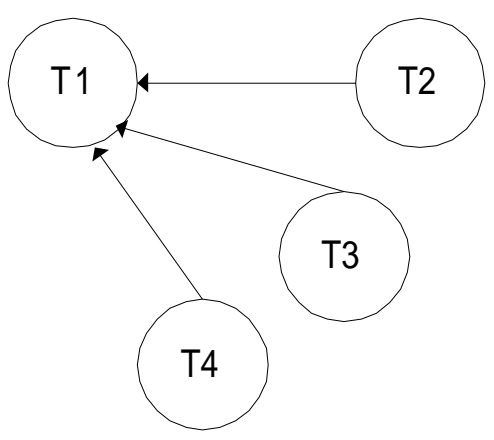

Figura 5-9- Grafo das tarefas e suas comunicações S.P.M.D. (M.P.I.)

Para esse exemplo, tem-se a geração do seguinte protótipo para o programa M.P.I. correspondente:

\section{HEADER}

//Inclusão da biblioteca MPI

\#include "mpi.h" 
//Número máximo de tarefas a serem ativadas

\#define MAXNCHILD x

//Define constante que especifica mensagem

\#define MSGTAG y

//Defina o restante de suas constantes

//Início do programa principal

main(int $\operatorname{argc}, \operatorname{char} * \operatorname{argv}[])$

\{

//Definição das variáveis

int rank ;

int ret;

int size;

int $\mathrm{i}$;

int tag;

int mpi_err;

MPI_status status;

char message [a];

//Defina o restante de suas variáveis 
//Inicializa

mpi_err=mpi_init $(\& \operatorname{argc}, \& \operatorname{argv})$;

//Checa se houve erros

if $($ mpi_err $<0)\{$

//Imprime erro

printf (" ");

//Sai do programa

return;

\}

else \{

//Retorna o id da tarefa

ret=mpi_comm_rank(mpi_comm_world,\&rank);

// Retorna número de processos dentro do grupo

ret=mpi_comm_size (mpi_comm_world, \&size);

$\operatorname{tag}=\mathrm{x}$

// Eu sou o processo pai

if $($ rank=0) \{

//Insira a parte do código a ser executada pela tarefa pai 
//Rotinas de recebimento de mensagens

mpi_recv (_);

\} else \{ // Eu sou tarefa filha

//Insira o código a ser executado pelas tarefas filhas

$$
\begin{aligned}
& \text { //Envia mensagem } \\
& \text { mpi_send (__ }) \text {; } \\
& \text { mpi_finalize(); } \\
& \text { \} }
\end{aligned}
$$

//Insira aqui funções que devem ser executadas tanto pela tarefa mestre

//quanto pelas escravas

mpi_finalize();

\}

Num segundo exemplo (Figura 5-10), o paradigma escolhido é o M.P.M.D., com o número de tarefas igual a duas, ou seja, duas tarefas filhas e uma tarefa pai. Nesse exemplo, as tarefas filhas se comunicam com a tarefa pai e essa por sua vez também se comunica com as tarefas filhas. Tanto nesse caso como no anterior, a primeira tarefa será a tarefa mestre. Nesse segundo exemplo especificamente, serão gerados dois programas, um definindo a execução da tarefa mestre e outro definindo a tarefa escrava (apesar desse paradigma ser pouco utilizado em aplicações M.P.I.). A tarefa mestre terá seu nome acrescido do sufixo _m e a tarefa escrava do sufixo_s. 


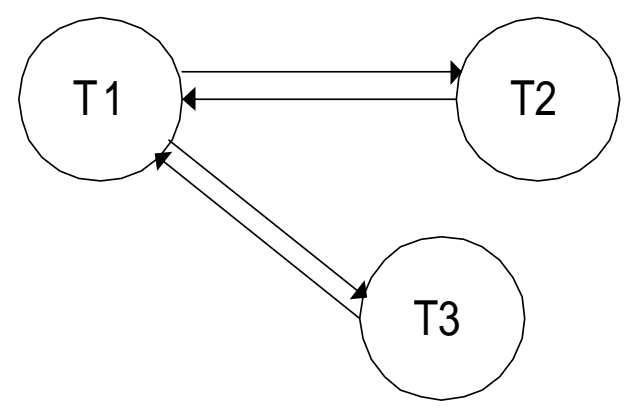

Figura 5-10- Grafo das tarefas e suas comunicações M.P.M.D.

Os protótipos gerados para esse exemplo são apresentados a seguir:

\section{HEADER MESTRE}

//Inclusão da biblioteca MPI

\#include "mpi.h"

//Número máximo de tarefas ativadas

\#define MAXCHILD x

//Define constante que especifica a mensagem

\#define MSGTAG y

//Defina o restante de suas constantes

//Início do programa principal

mail(int $\operatorname{argc}$, char $* \operatorname{argv})$

\{

//Definição das variáveis

int rank ; 
int ret;

int size;

int $\mathrm{i}$;

int tag;

int mpi_err;

MPI_status status;

char message [a];

//Defina o restante de suas variáveis

//Defina as rotinas a serem executadas pelo programa mestre antes que sejam //disparadas as tarefas filhas

//Rotinas de envio de mensagem

//Inicializa buffer de envio

mpi_init(\&argc, \&argv);

//Envia mensagem

mpi_send(__ $)$;

//Recebimento de mensagem

mpi_recv(__ $)$;

//Digite as rotinas a serem executadas após a execução das tarefas filhas 
mpi_finalize(); //Finaliza cada processo

\}

\section{HEADER ESCRAVO}

//Inclusão da biblioteca PVM

\#include "mpi.h"

//Número máximo de tarefas ativadas

\#define MAXCHILD x

//Define constante que especifica a mensagem

\#define MSGTAG y

//Defina o restante de suas constantes

//Início do programa escravo

main(int argc, char *argv)

\{

//Definição das variáveis

int rank ;

int ret;

int size;

int $\mathrm{i}$;

int tag;

int mpi_err; 
MPI_status status;

char message [a];

//Defina o restante de suas variáveis

//Defina as rotinas a serem executadas pelas tarefas filhas

//Rotinas de recebimento das mensagens

mpi_recv(__ $)$;

//Defina as rotinas a serem executadas com os dados recebidos

//Envio de mensagens

//Envia dados

mpi_send(__ $)$;

//Termina a tarefa

mpi_finalize();

\}

Assim como para P.V.M., os protótipos apresentados, permitem uma otimização no desenvolvimento de aplicações M.P.I., pois os usuários não precisam conhecer M.P.I. para ainda assim desenvolver uma aplicação. Entretanto, o não conhecimento de M.P.I. não implica em não conhecimento de conceitos de paralelismo, ou seja, o usuário deverá ter conhecimentos de programação paralela pois estará a cargo dele a escrita dos procedimentos a serem executados pela aplicação escolhida por ele. 


\subsection{Considerações Finais}

A computação paralela em ambientes paralelos virtuais é bastante versátil, permitindo que a busca por alto desempenho possa ser exercitada a partir de plataformas computacionais distribuídas. Isso traz benefícios diversificados, incluindo uma possível queda na relação custo/benefício da computação paralela, uma vez que ambientes distribuídos (por exemplo redes de estações de trabalho ou de computadores pessoais) podem ser utilizados para esse fim.

A escolha de ambientes paralelos virtuais, que correspondem atualmente às plataformas de passagens de mensagens (ou plataformas de portabilidade) executando sobre sistemas computacionais distribuídos, está intimamente ligada à vasta utilização e difusão desses ambientes, nas mais diferentes áreas do conhecimento [BEG94, GEI94].

Estudos gerais foram realizados sobre a Ferramenta de Apoio à Programação Paralela (F.A.P.P.) onde foram identificadas as suas características principais, o embasamento teórico, as metodologias utilizadas e o meta-modelo orientado a objetos proposto por Calônego [CAL97] e utilizado como base para essa ferramenta, para que se pudesse definir e estender esse modelo para comportar ambientes paralelos virtuais.

A extensão desse meta-modelo foi realizada propondo-se um novo modelo de objetos para o software, uma vez que, o modelo proposto por Calônego [CAL97] foi para Occam2 que possui comandos como unidade de paralelismo, e para ambientes virtuais essa unidade passa a ser a tarefa.

Assim, partindo-se do novo modelo de objetos para software, do modelo de objetos para hardware e do meta-modelo proposto inicialmente, torna-se possível a geração de arcabouços de programas em P.V.M. e M.P.I., tornando mais fácil a tarefa do usuário programador, a documentação do sistema, bem como sua manutenção, pois auxiliará tanto usuários experientes, ou seja, aqueles que possuem conhecimento sobre ambientes paralelos virtuais, quanto aqueles que possuem algum conhecimento sobre programação paralela mas que não possuem conhecimento sobre esses ambientes.

O mapeamento do hardware da maneira apresentada pela ferramenta, possibilitará, através da utilização de algoritmos mais apurados a obtenção do melhor escalonamento das tarefas nos processadores existentes e que farão parte da máquina virtual descrita pelo usuário. A existência do cadastro das funções P.V.M. permite ao usuário um help on-line, pois estão especificados os argumentos necessários às funções e também as especificações de quais procedimentos deverão ser executados antes e depois de cada função.

A definição da comunicação existente entre as tarefas constitui uma forma de segurança, evitando que o usuário defina uma rotina de envio sem definir a respectiva rotina de recebimento nas instâncias pais e filhas. Dessa maneira, o procedimento que o usuário deverá seguir é: gerar o código segundo suas especificações e altera-lo de acordo com a aplicação de desejar utilizar. 
O próximo capítulo apresenta a utilização da ferramenta, exemplos da extensão da F.A.P.P., bem como os resultados da ferramenta. 


\section{Utilização e Validação da Ferramenta}

Este capítulo traz exemplos de utilização e de validação da F.A.P.P. estendida para ambientes paralelos virtuais. Serão apresentados dois exemplos, um para P.V.M. utilizando a arquitetura S.P.M.D. e outro utilizando arquitetura M.P.M.D..

\subsection{Considerações iniciais}

A extensão da F.A.P.P. , possibilita a utilização de ambientes paralelos virtuais por um número de usuários maior, através da produção de arcabouços de programas P.V.M. e M.P.I..

Essa ferramenta permite que o hardware a ser utilizado seja descrito, bem como o funcionamento básico do software. Descrevendo-se de forma correta o software e o hardware, torna-se possível a utilização de algoritmos que possam fornecer o melhor escalonamento para as tarefas especificadas diante do hardware descrito.

A implementação natural dessa ferramenta, segundo a proposta original de Calônego [CAL97], dar-se-ia percorrendo-se grafos ou dígrafos, tornando-se necessário para isso a geração dos domínios da linguagem $C$, bem como das funções das bibliotecas P.V.M. e M.P.I.. Neste capítulo, será visto que segundo a modelagem, e para atingir o objetivo inicial, a implementação pode ser mais simples, dando-se através da utilização de bancos de dados e de templates, gerando de maneira mais simples os arcabouços desejados.

Foram utilizados C++ Builder e Paradox [TEL97] [REI97] como ferramentas para construção da extensão da F.A.P.P., o que tornou possível a existência de uma interface gráfica mais amigável e a confecção da ferramenta utilizando-se a análise orientada a objetos, como proposto inicialmente.

Para os testes de validação da ferramenta, foram utilizados PCs conectados através de uma rede padrão ethernet, utilizando o Sistema Operacional Linux e o compilador C da Borland (Borland C++ 4.5), disponíveis no Laboratório de Sistemas Digitais (LaSD). 


\subsection{Validação da Ferramenta}

No contexto do P.V.M.:

Partindo-se do modelo da F.A.P.P. proposto por Calônego [CAL97], poder-se-ia, caso fosse necessária, fazer-se a modelagem da linguagem $\mathrm{C}$ em nível de comandos, assim como a modelagem das funções das bibliotecas P.V.M. e M.P.I.. Se fosse esse o nível de abstração o desejado para o desenvolvimento deste trabalho, seria justificável a criação de algoritmos que montariam um grafo complexo, o qual seria percorrido para gerar uma especificação textual e, a partir desta, gerar o arcabouço dos programas P.V.M. e M.P.I.. A modelagem, no entanto, pode e deve ser em nível mais alto, pois para Occam2, justificava-se a utilização de grafos, já que a unidade de paralelismo era em nível de comandos e a dos ambientes paralelos virtuais aqui apresentados dá-se em nível de tarefas. Uma vez tendo feito essa definição em nível mais alto, justifica-se a geração não em grafos, mas sim com a utilização de bancos de dados e templates, que permitem uma implementação mais clara das especificações definidas pelo usuário.

Para o mapeamento de um grafo seria necessária a criação dos domínios $\mathrm{C}$ e Ambientes Paralelos Virtuais, além de todo o mapeamento da sintaxe desses ambientes e linguagem. Além disso, far-se-ia também necessária a montagem da linguagem do grafo para que pudesse ser especificada as ligações do grafo em um programa P.V.M. ou M.P.I.. Um tipo de aplicação que faz uso de árvores e grafos, mas cujo objetivo é o de proporcionar a transformação de uma linguagem ou especificação para outra são os sistemas de transformação como por exemplo DRACO [CAS98], apresentando como vantagens a reutilização, caso esse que não ocorre com o mapeamento em questão.

Como o intuito deste trabalho é o de proporcionar uma ferramenta que produza arcabouços de programas para ambientes paralelos virtuais, e não partir de uma linguagem para outra, mas sim de uma especificação previamente definida, optou-se pelo uso de bancos de dados e templates, o que evita o mapeamento desnecessário da linguagem de especificação para o grafo e deste para a linguagem de especificação.

Para demonstrar a utilização da ferramenta de forma a validá-la, serão apresentados dois exemplos para P.V.M. sendo um para arquitetura S.P.M.D. e outro para arquitetura M.P.M.D.. A ferramenta possui help on-line e interface gráfica, tornando sua utilização mais fácil.

A primeira aplicação escolhida é um exemplo simples S.P.M.D. em que o processo pai dispara as tarefas filhas enviando um token para essas tarefas e essas retornam o token para a tarefa pai. O segundo exemplo é uma versão paralela do método de ordenação quicksort: essa aplicação foi escolhida por não necessitar de grandes recursos de programação, ser de fácil desenvolvimento, compreensão e depuração. 
Após instalada, o uso da ferramenta dá-se através de dois clicks sobre o ícone da F.A.P.P.. O menu apresenta duas opções, uma para Componentes e outra para Ambientes.
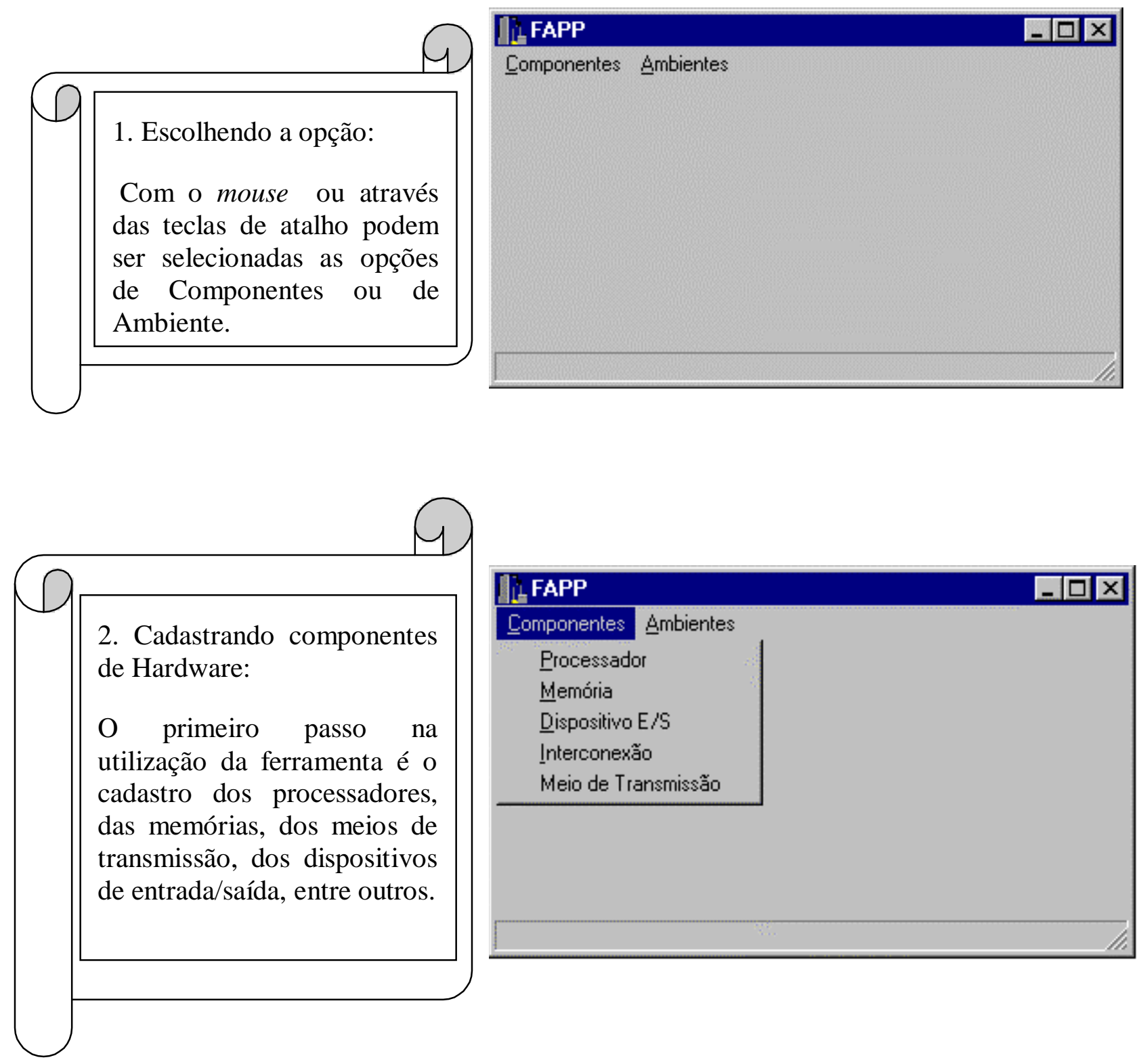


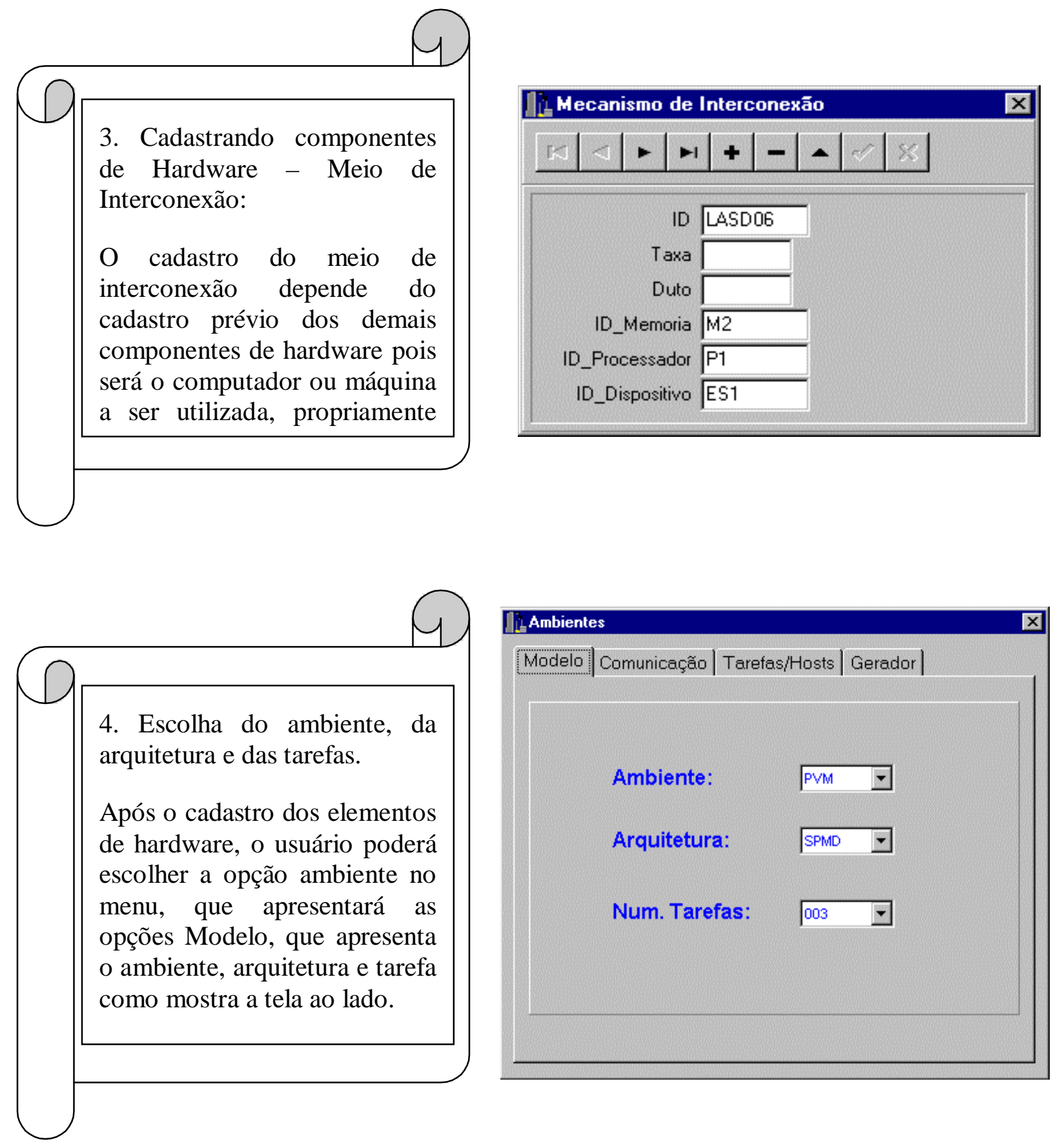



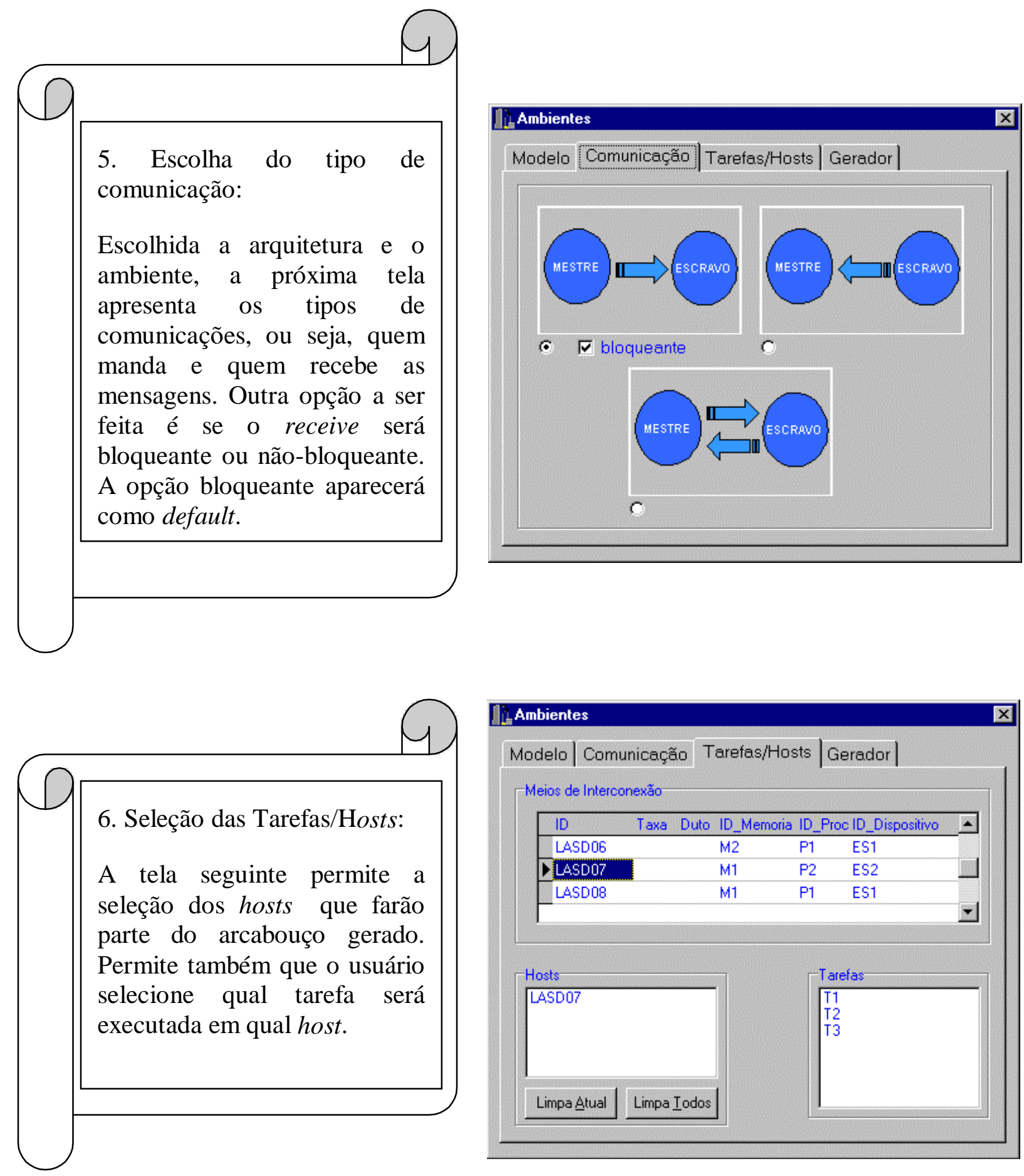


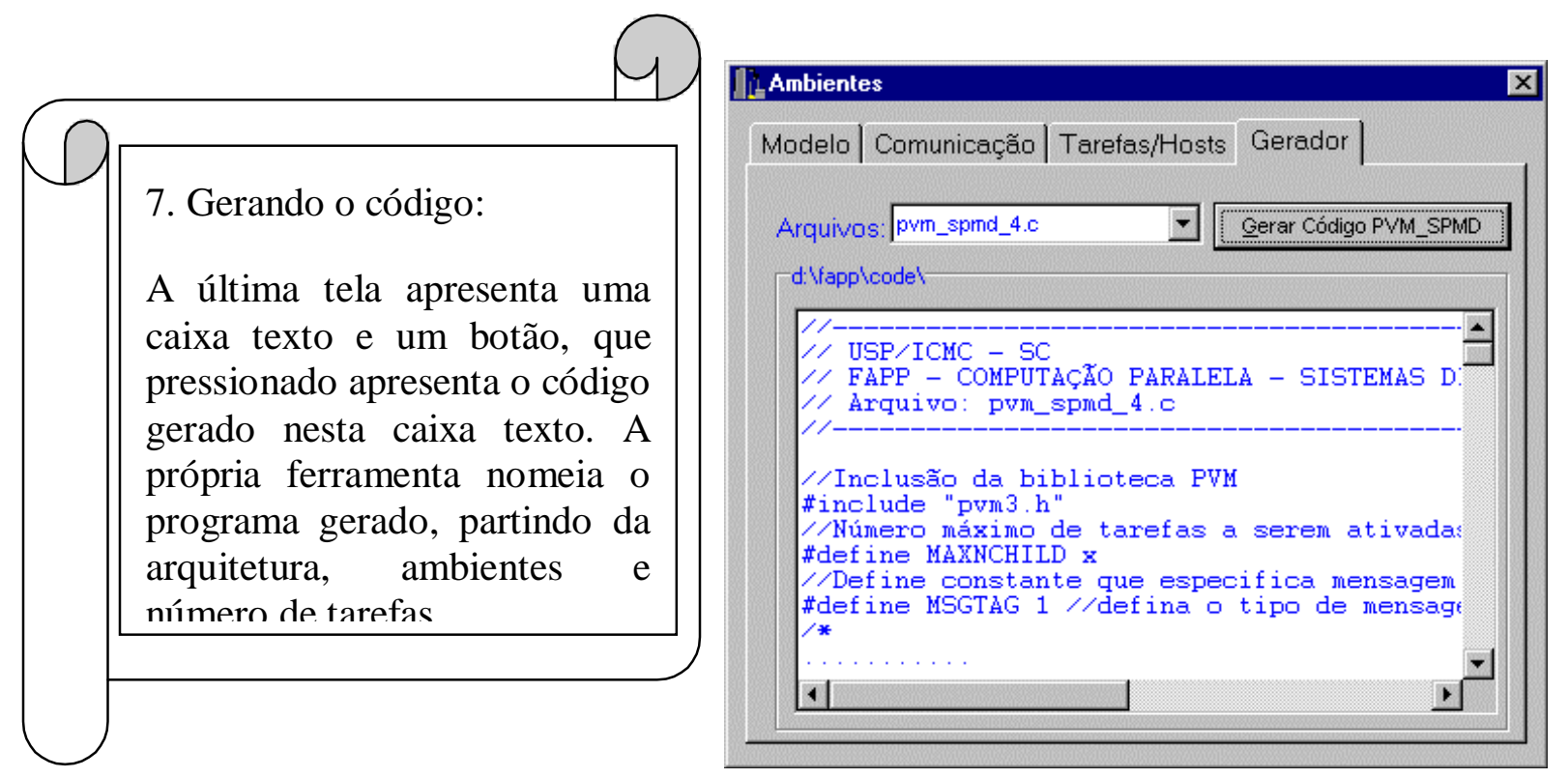

Seguindo os passos apresentados, deseja-se implementar o programa exemplo 1 que é o de passagem de token. Após o cadastramento dos elementos de hardware, escolhendo-se o ambiente P.V.M., S.P.M.D., e o número de tarefas igual a duas $(2-$ a tarefa mestre não é incluída no cálculo, uma vez que para o programa existir faz-se necessária a presença de no mínimo uma tarefa) e, sabendo-se que no problema proposto tanto a tarefa mestre como a tarefa escrava enviam e recebem mensagens (que serão os tokens), escolhe-se como meio de comunicação a opção 3, indicativa de que tanto a tarefa mestre como as tarefas escravas recebem e enviam mensagens. Pelo fato da arquitetura escolhida ter sido a S.P.M.D., um único código é gerado, possuindo tanto as funções que serão executadas pela tarefa pai, quanto as que serão executadas pelas tarefas filhas.

O próximo passo (6) é escolher quais hosts farão parte da máquina paralela virtual. O passo final é o passo sete (7), pois pressionando-se o botão Gerar Código, o código gerado será apresentado no campo texto e automaticamente em um arquivo com o nome constante na tela. Além do código fonte para P.V.M., a ferramenta fornece também um arquivo makefile com o próprio nome do programa e com a extensão make, facilitando ainda mais as operações que devem ser executadas pelo usuário. $\mathrm{O}$ código gerado para esse exemplo é apresentado a seguir. $\mathrm{O}$ código gerado pela ferramenta é apresentado em negrito e o código em caracteres normais são complementos para que o problema proposto possa ser solucionado. 


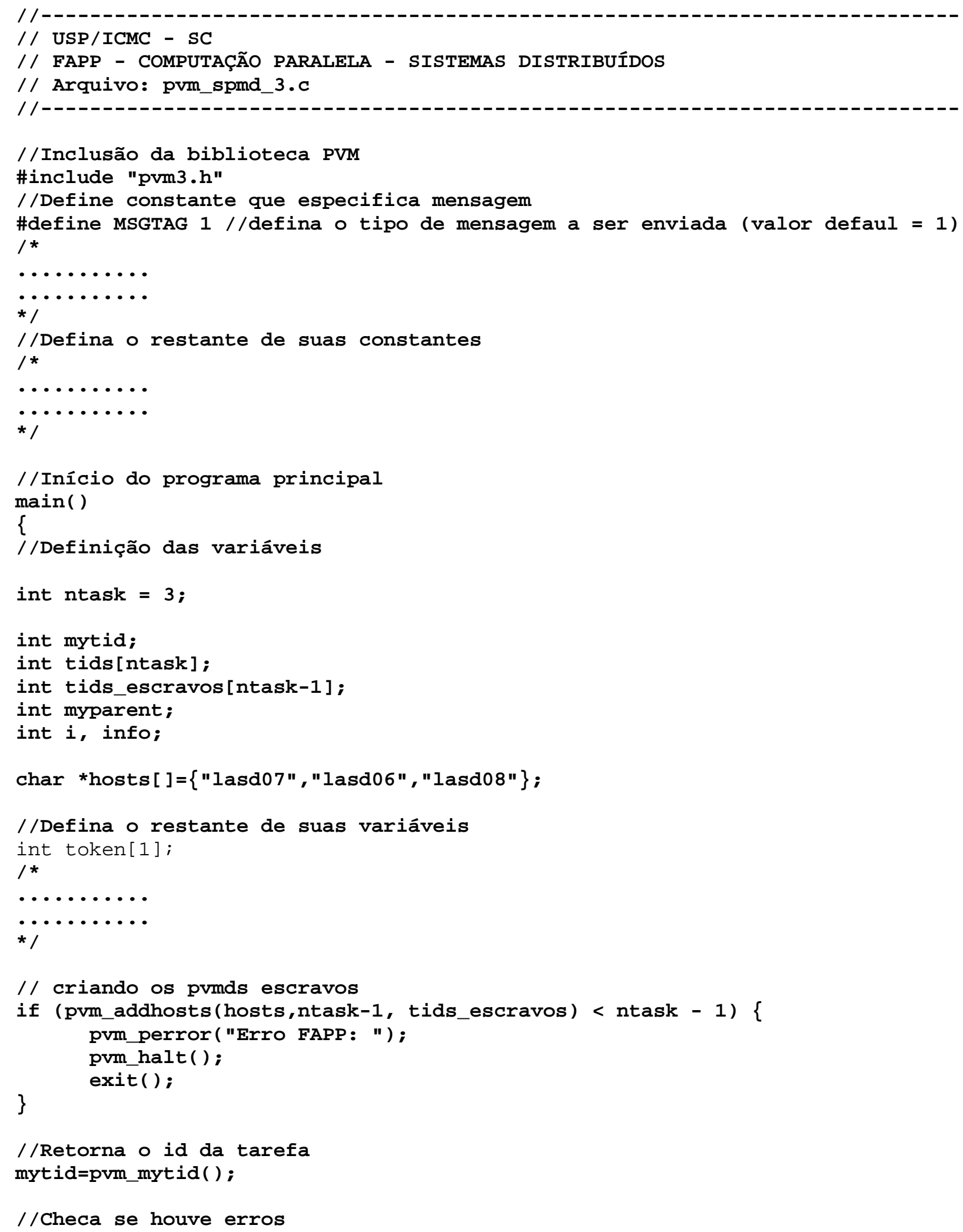




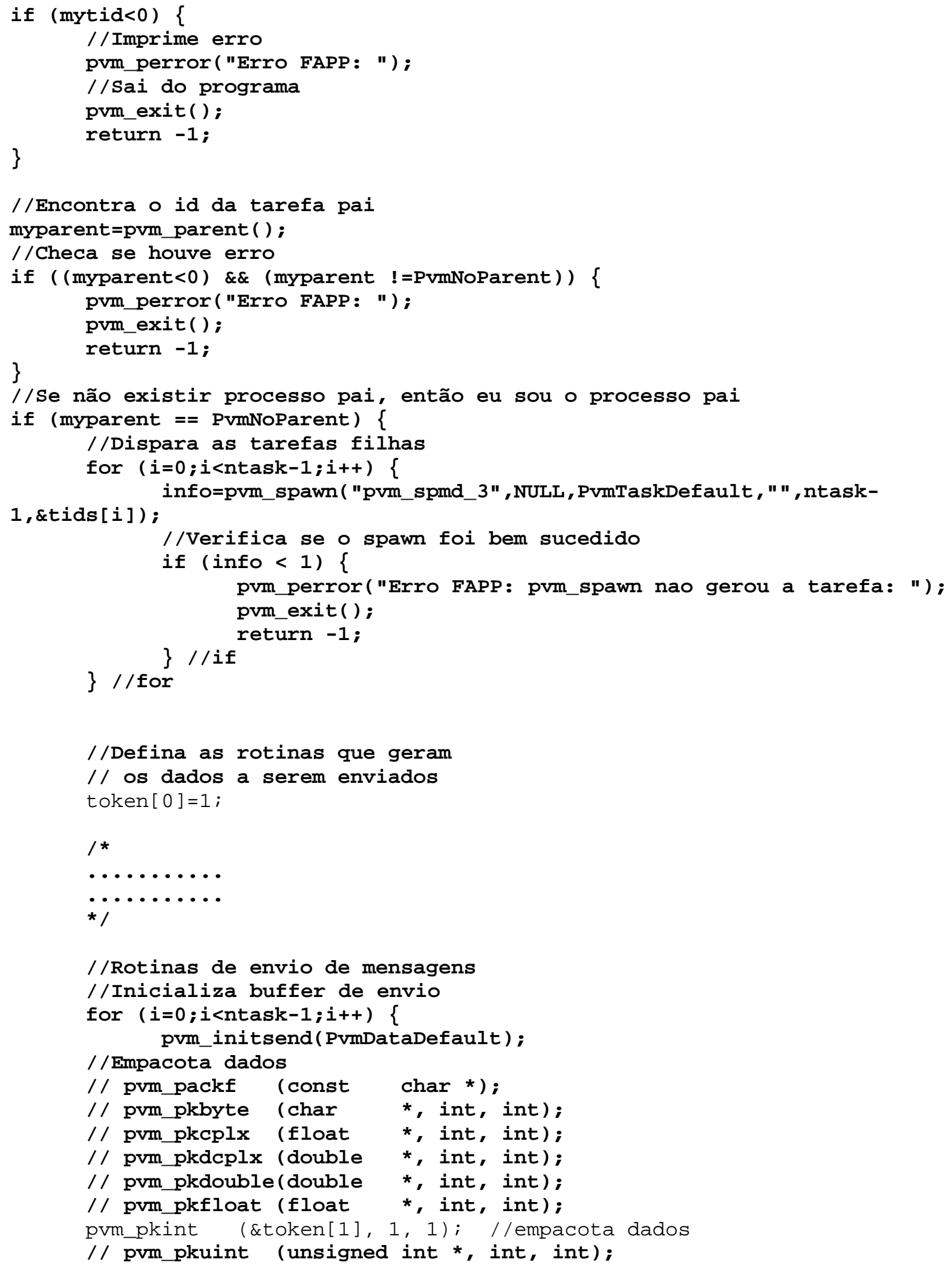


107

// pvm_pkushort (unsigned short *, int, int) ;

// pvm_pkulong (unsigned long *, int, int);

// pvm_pklong (long *, int, int);

// pvm_pkshort (short *, int, int);

// pvm_pkstr (char *);

/ /Envia mensagem pvm_send (tids [i+1], MSGTAG) ;

\}

//Rotinas de recebimento de mensagens //Recebe mensagem

for $(i=0 ; i<n t a s k-1 ; i++)\{$

info=pvm_recv $(-1$, MSGTAG) ;

if $($ info<0) \{ pvm_perror ("Erro FAPP: "); pvm_exit () ; return -1 ;

\} // if

//Desempacota os dados recebidos

// pvm_unpackf (const char *);

// pvm_upkbyte (char *, int, int);

// pvm_upkcplx (float *, int, int);

// pvm_upkdcplx (double *, int, int);

// pvm_upkdouble (double *, int, int) ;

// pvm_upkfloat (float *, int, int);

pvm_upkint (\&token [0], 1, 1); //desempacota dados

// pvm_upklong (long *, int, int);

// pvm_upkshort (short *, int, int);

// pvm_upkstr (char *);

\} // for

printf ("\nMensagens recebidas");

//Definas as rotinas a serem executadas

//com os dados desempacotados

/*

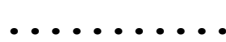

...........

*/

\} else \{

//Insira a parte do código a ser executada após o retorno das tarefas filhas

/*

$\ldots \ldots \ldots$

$\ldots \ldots$

*I

pvm_exit () ;

//Insira o código a ser executado pelas tarefas filhas 


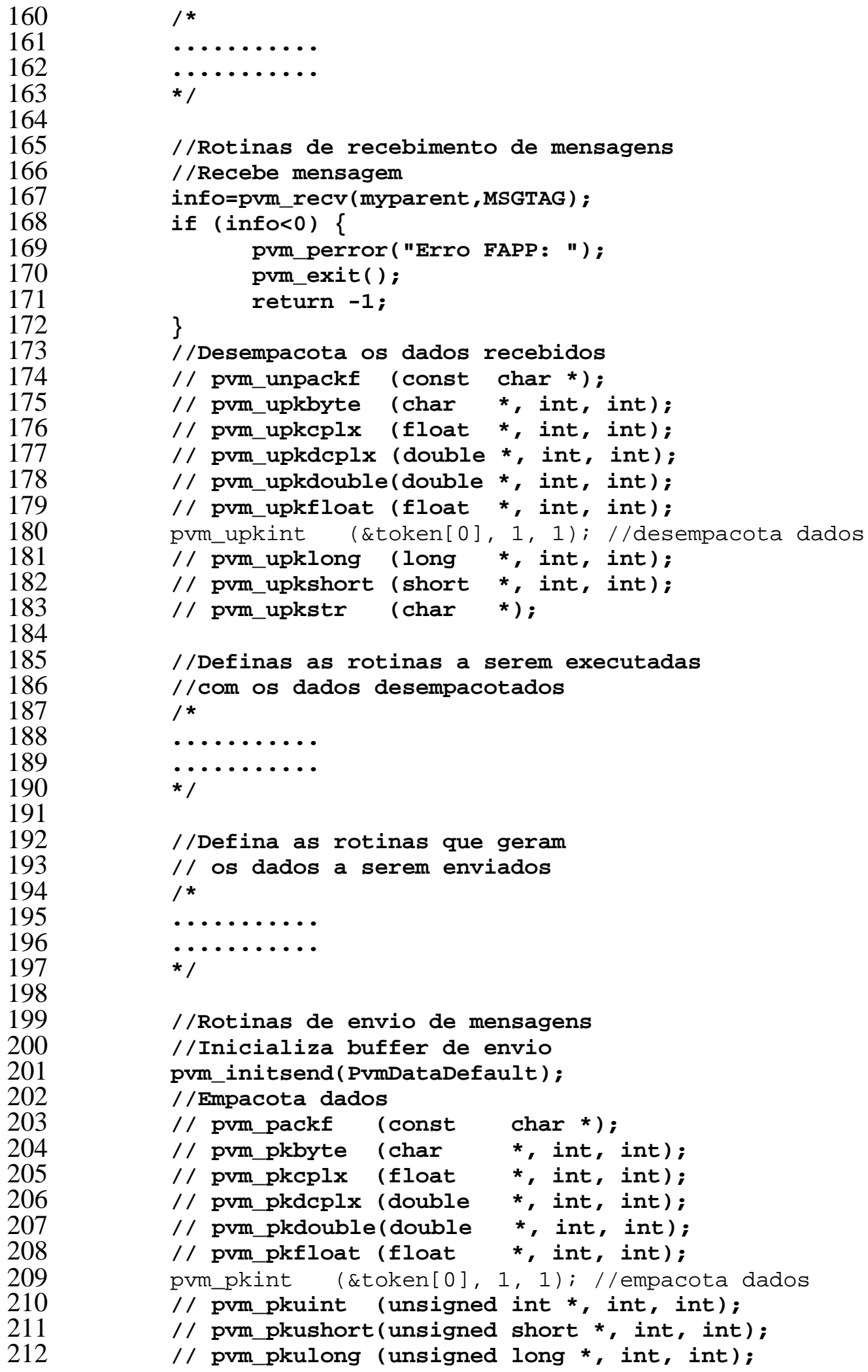




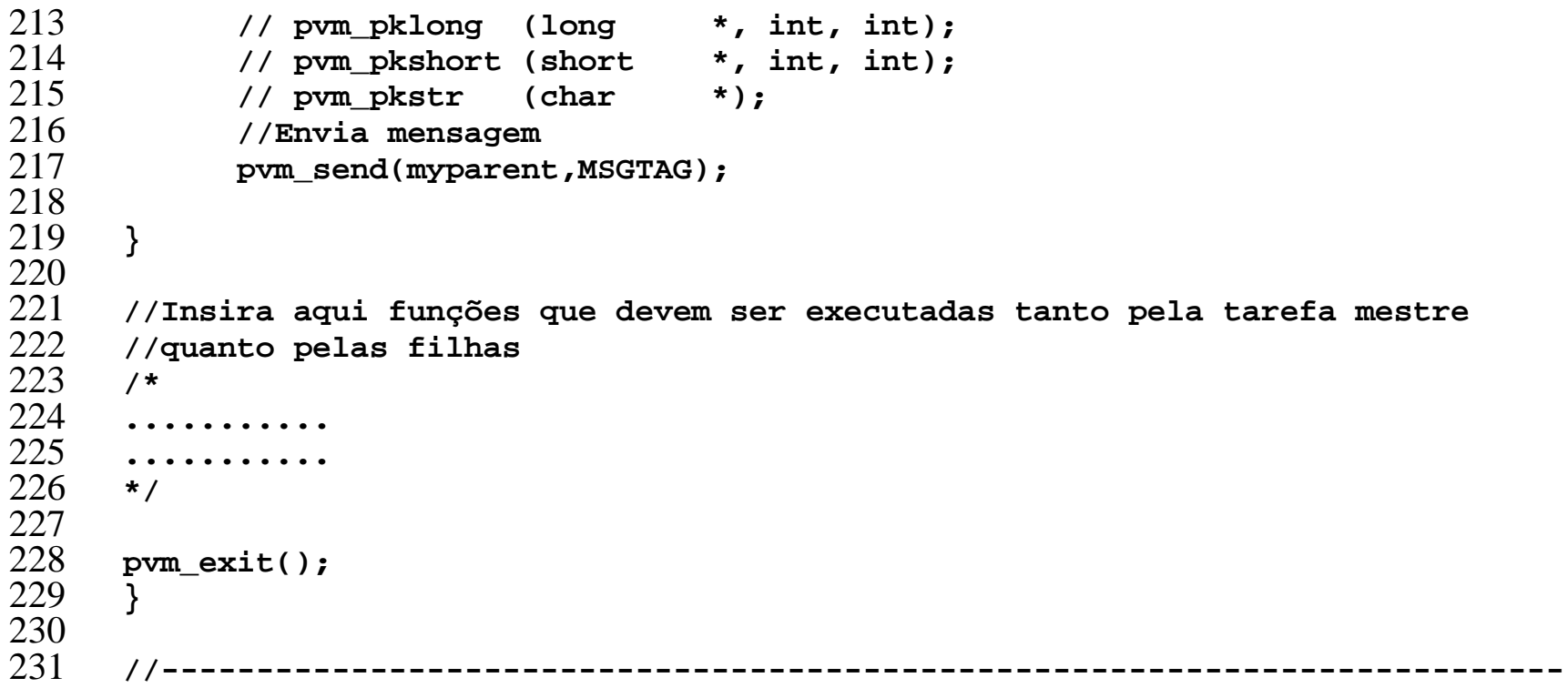


No código apresentado acima, a tarefa simplesmente envia uma mensagem para as tarefas filhas que devolvem essa mensagem para a tarefa pai. A ferramenta solicita no decorrer do código que partes sejam inseridas para que ele possa executar o que o usuário deseja.

Nas linhas iniciais, como por exemplo na linha 8, são feitas as inclusões da biblioteca P.V.M. e algumas definições padrões. Já na linha 44, com a utilização da função add_host, é feito o adicionamento dos hosts, escolhidos pelo usuário, na máquina virtual. Outras funções indispensáveis para a execução de qualquer programa P.V.M. são as apresentadas nas linhas 51, (que retorna o identificador da tarefa), e 63 (que retorna o identificador da tarefa pai). Partindo desses dados, na linha 71 é feita uma seleção, caso o identificador da tarefa identifique que essa tarefa é a tarefa pai, então é executada a função da linha 74, que dispara as tarefas filhas, caso contrário, é executado o código da tarefa filha.

A linha 97 apresenta a rotina de preparação de envio. A ferramenta apresenta a seguir, todas as rotinas de empacotamento, permitindo ao usuário escolher aquela que melhor se adeque a aplicação, de maneira mais rápida e simples (linhas 99 à 111), e logo em seguida é apresentada a função que envia os dados previamente empacotados.

A linha 120 apresenta a rotina de recebimento da mensagem enviada das tarefas filhas. Essas mensagens devem ser desempacotadas para que possam ser utilizadas. Para isso a ferramenta, da mesma maneira que para as rotinas de empacotamento, lista todas as rotinas de desempacotamento (linhas 128 à 137).

Como o problema proposto indicava que tanto a tarefa pai quanto as tarefas filhas devem enviar e receber mensagens, ambos os códigos apresentam as rotinas de envio e recebimento de mensagens. seguir:

O makefile gerado pvm_spmd_3.make compila o programa gerado e é apresentado a

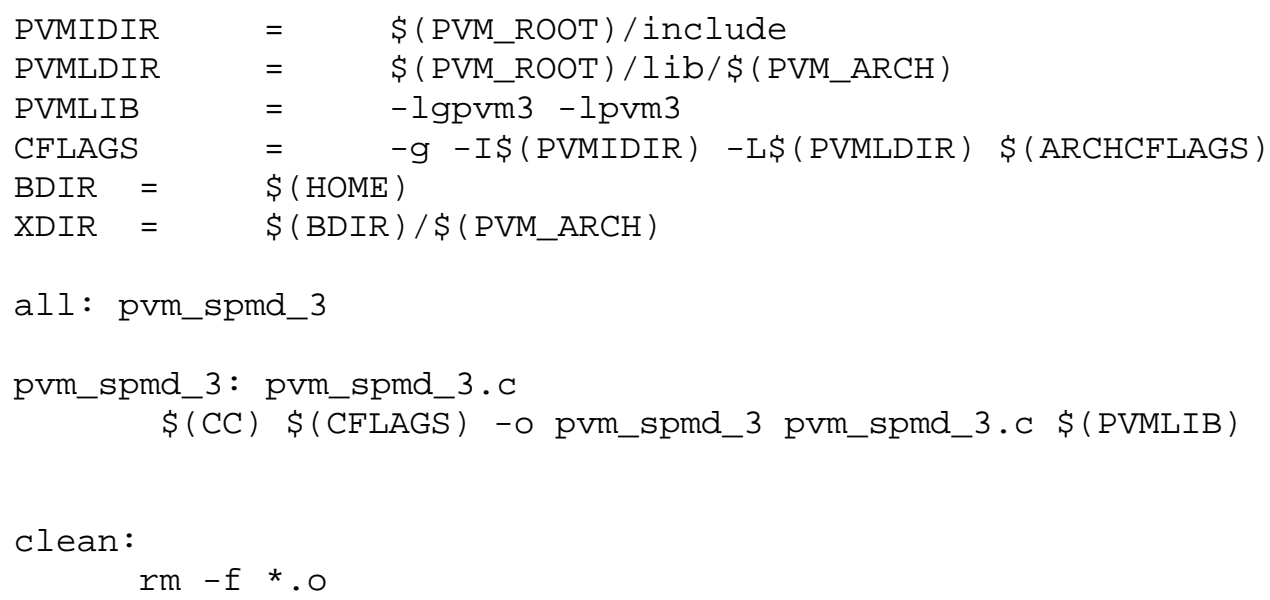


Da mesma forma apresentada para S.P.M.D., os mesmos passos deverão ser seguidos para M.P.M.D.. O problema dois sugere a implementação de um quicksort paralelo. Após o cadastramento dos elementos de hardware, como no problema 1, escolhe-se o como ambiente P.V.M., e M.P.M.D., e o número de tarefas igual a duas $(2$ - a tarefa mestre não é incluída no cálculo, uma vez que para o programa existir faz-se necessária a presença de no mínimo uma tarefa), sabendo-se que no problema proposto tanto a tarefa mestre como a tarefa escrava enviam e recebem mensagens (que serão os tokens), escolhe-se como meio de comunicação a opção 3, indicativa que tanto a tarefa mestre como as tarefas escravas recebem e enviam mensagens. $\mathrm{O}$ próximo passo é escolher quais hosts farão parte da máquina paralela virtual. O passo final é o apresentado no passo sete (7), pois pressionando-se o botão Gerar Código, o código gerado será apresentado no campo texto e automaticamente gerado para um arquivo com o nome constante na tela.

Nesse exemplo, é escolhido M.P.M.D., portanto, dois arquivos serão gerados sendo um o arquivo que conterá as funções executadas pela tarefa pai e outro contendo as executadas pelas tarefas filhas. O nome dos arquivos é dado em função do ambiente, da arquitetura e do número de tarefas escolhido, e nesse caso especificamente são descriminados os códigos da tarefas através dos prefixos_master e_slave.

Como para a arquitetura anteriormente citada, além do código fonte para P.V.M., a ferramenta fornece também um arquivo makefile com o próprio nome do programa e com a extensão make. O código gerado pela ferramenta é apresentado em negrito e o código em caracteres normais são complementos para que o problema proposto possa ser solucionado. 


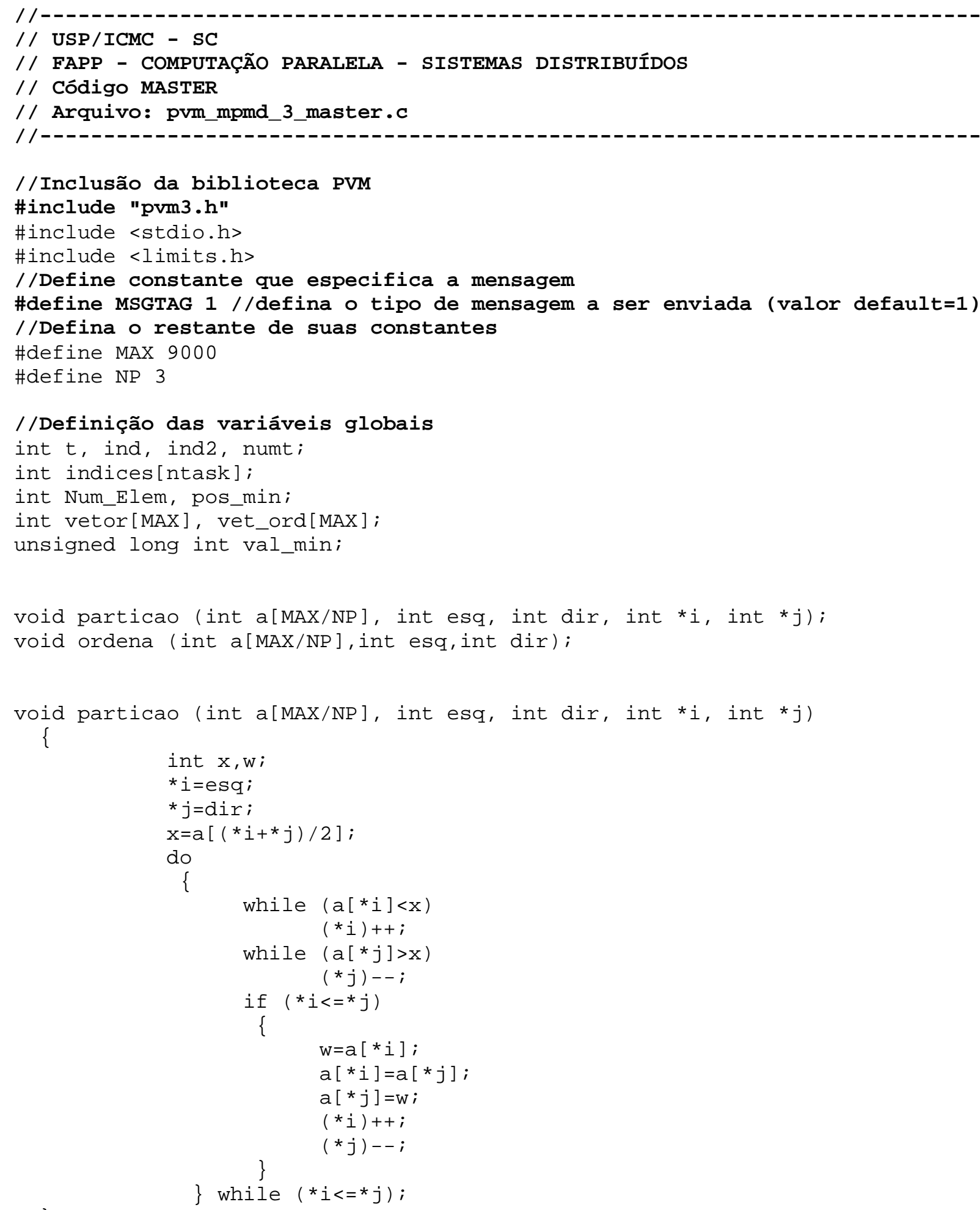




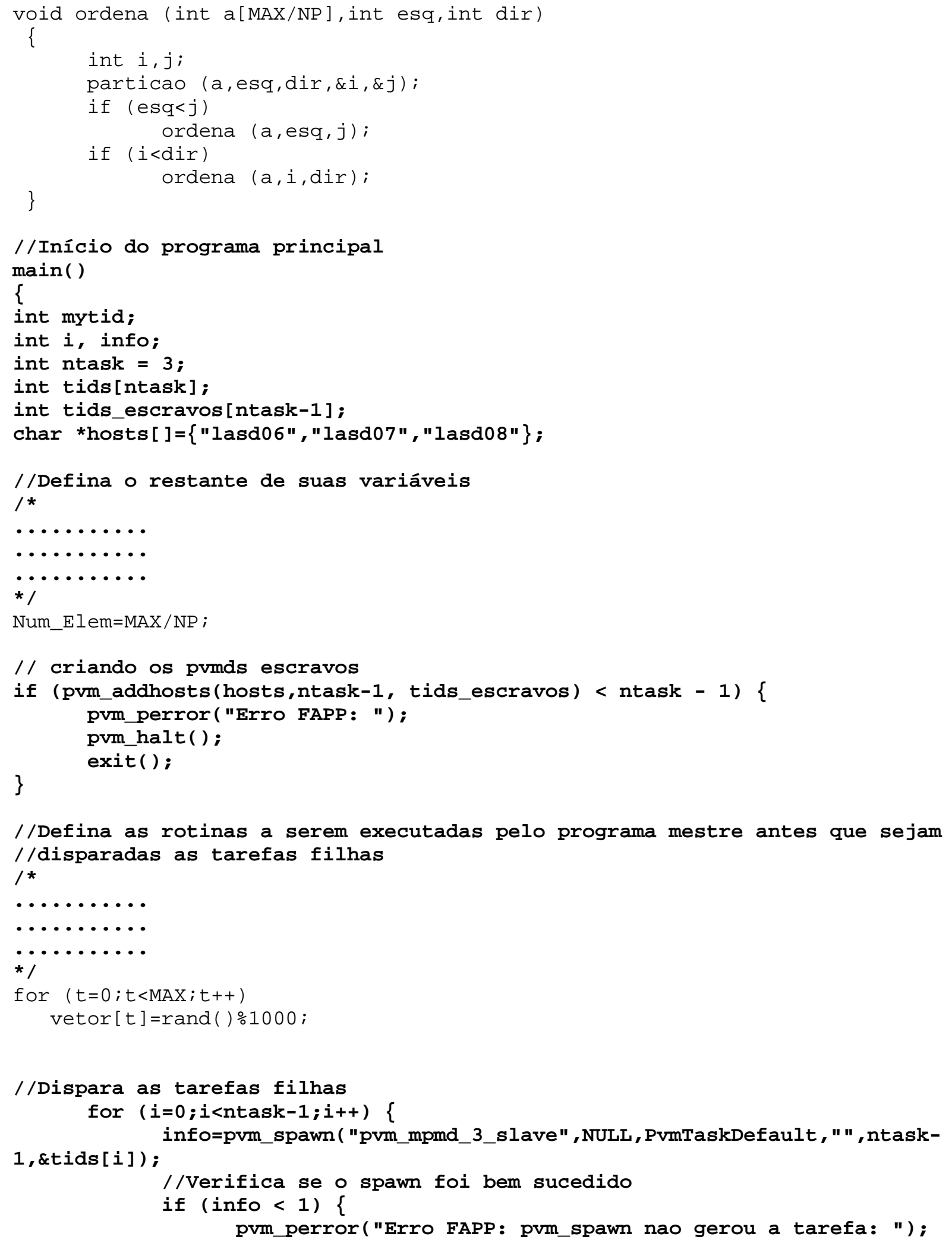


107

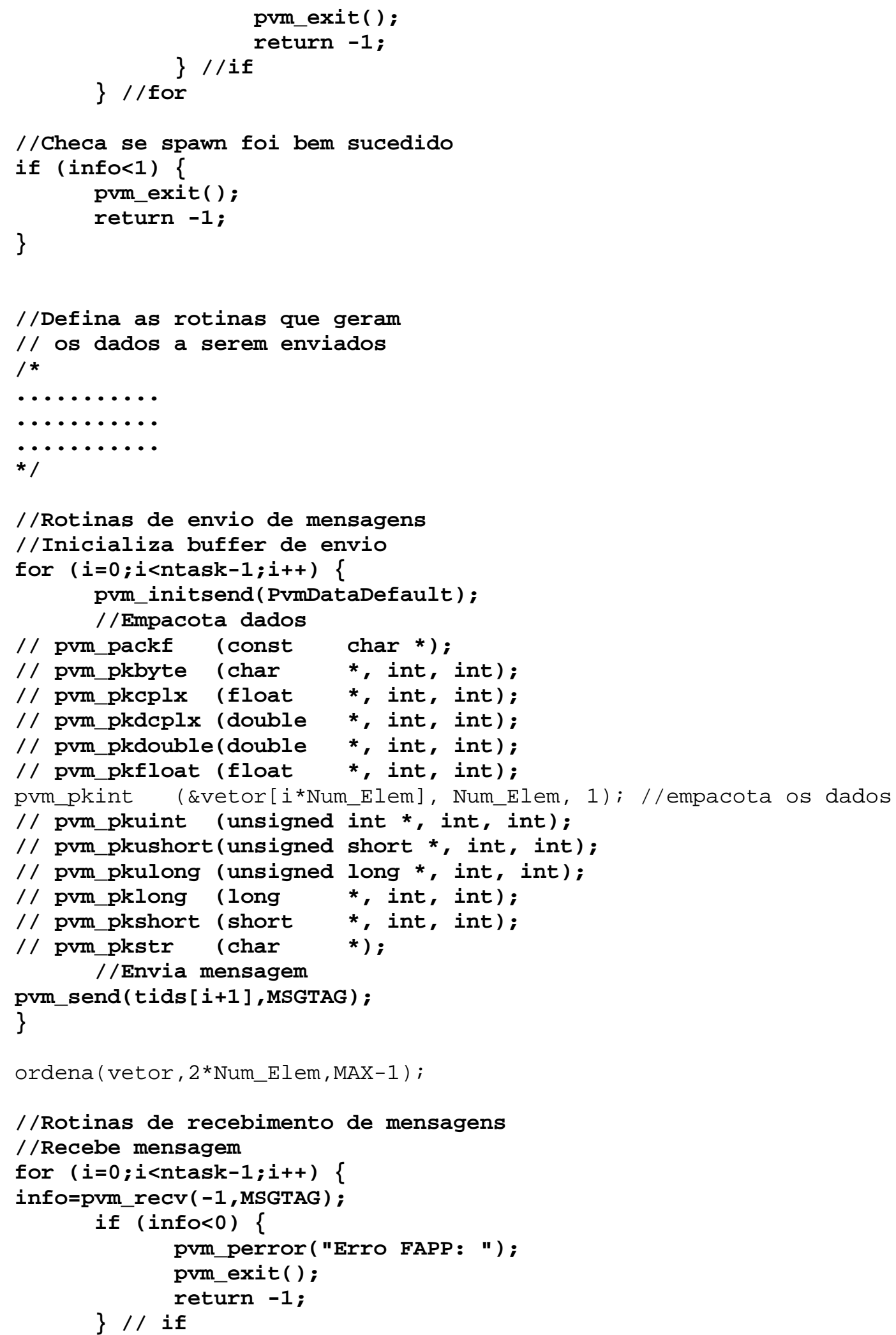


160

161

162

163

164

165

166

167

168

169

170

171

172

173

174

175

176

177

178

179

180

181

182

183

184

185

186

187

188

189

190

191

192

193

194

195

196

197

198

199

200

201

202

203

204

205

206

207

208

209

210

211

212

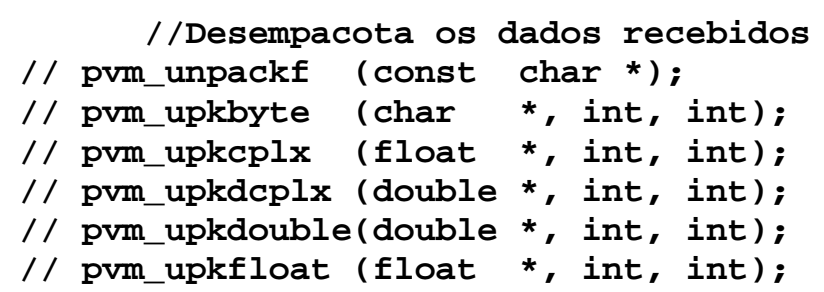


213 pvm_exit();

214

215

\}

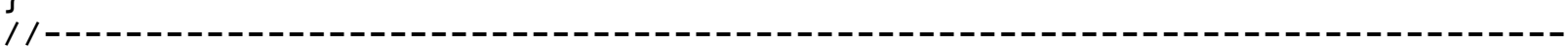




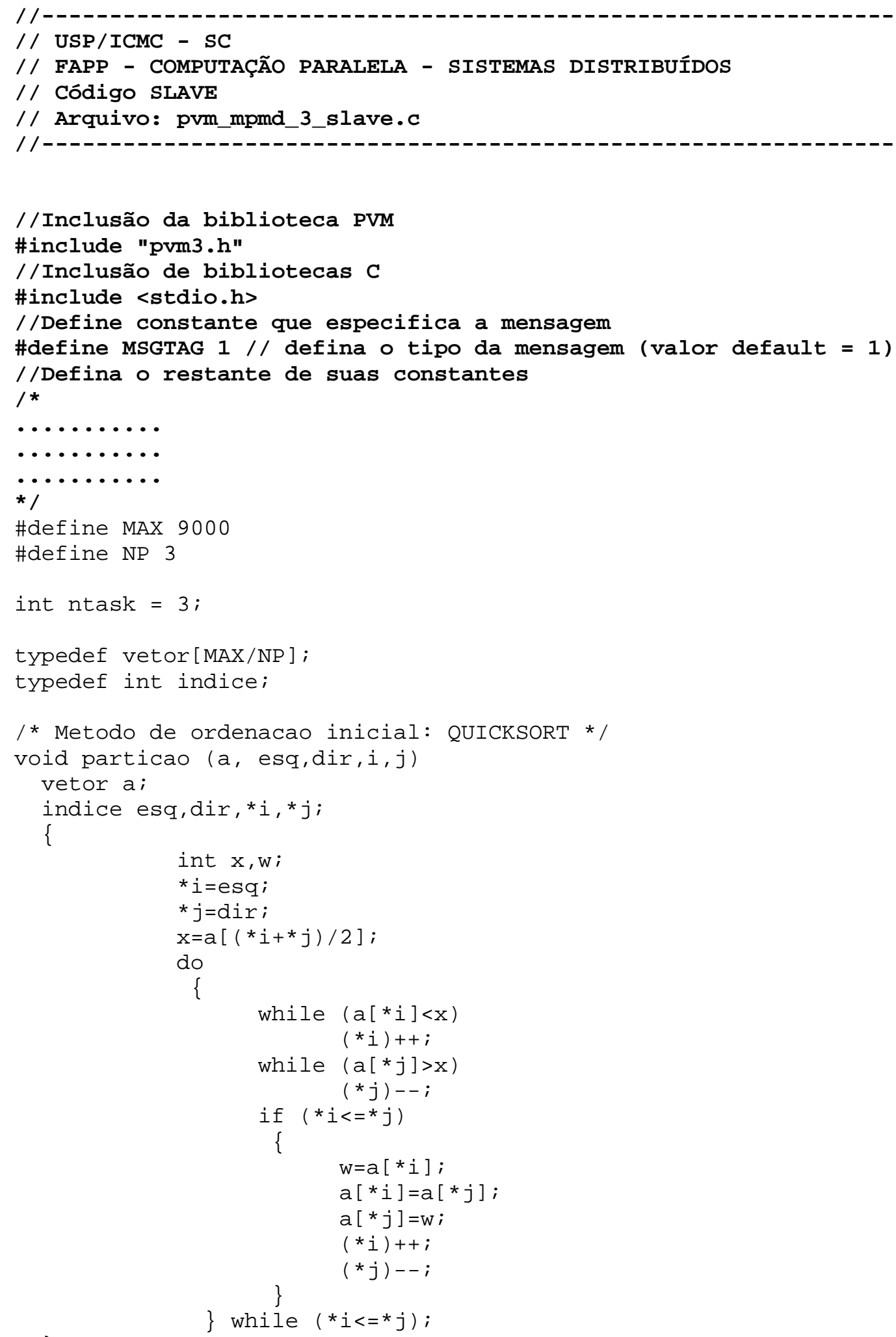




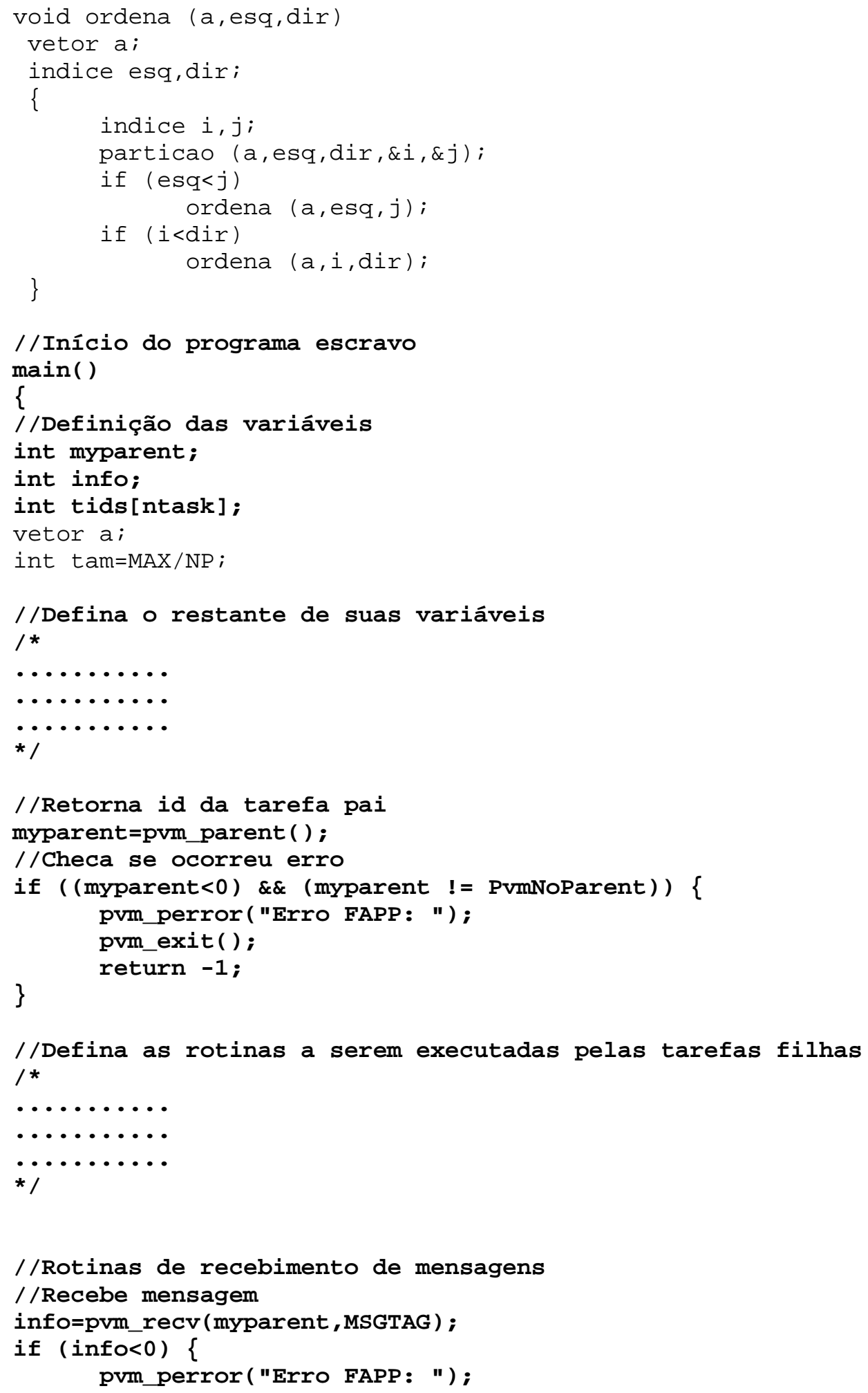




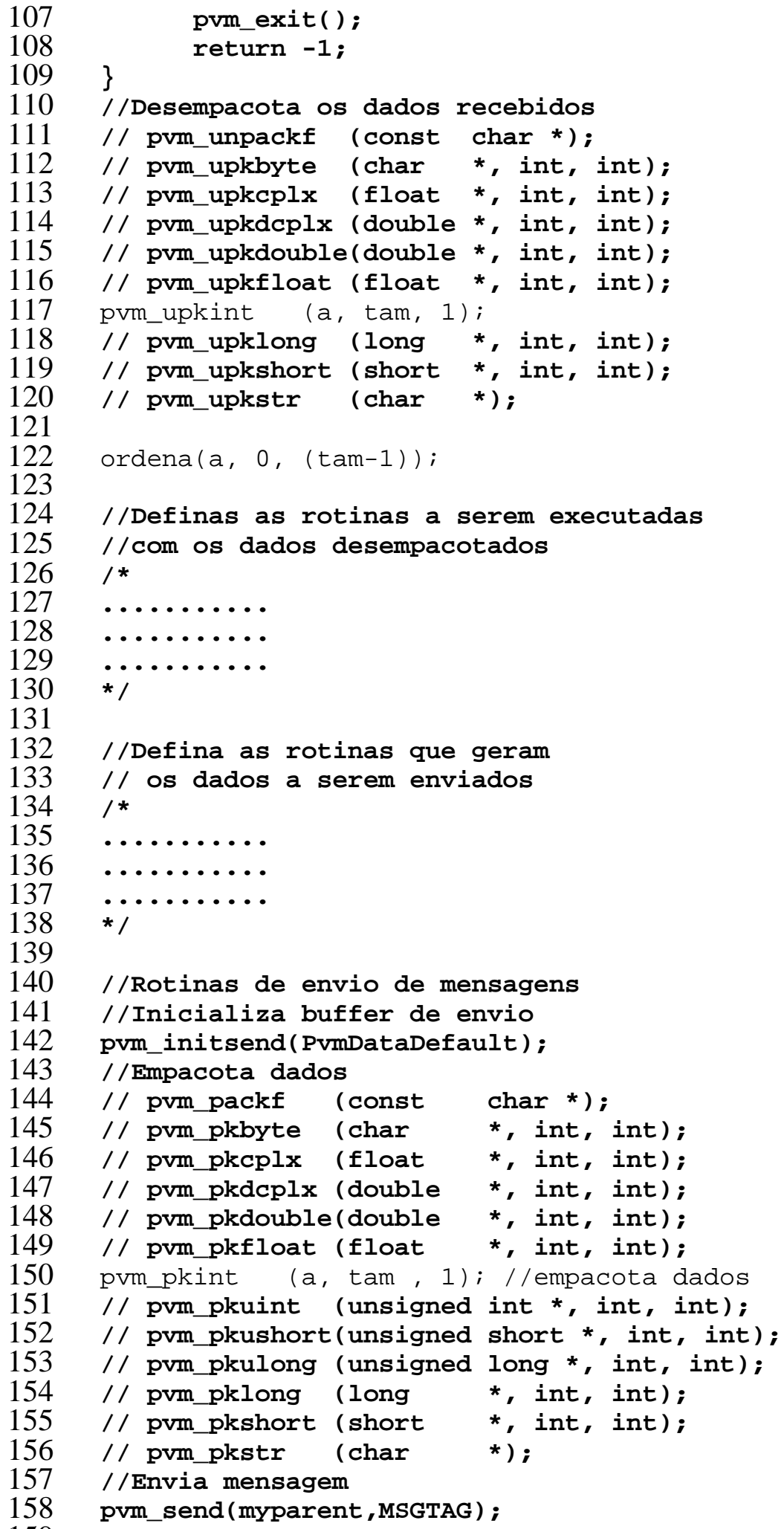


160

161 //Termina a tarefa

162 pvm_exit() ;

163 \} 
No código apresentado acima, a tarefa pai envia partes de um vetor para que as tarefas filhas os ordenem, sendo que a própria tarefa pai fica incumbida de ordenar parte desse vetor. Após a ordenação executada pelas tarefas filhas, essas enviam os vetores ordenados para a tarefa pai que os ordena novamente. A ferramenta solicita no decorrer do código que partes sejam inseridas no código para que ele possa executar o que o usuário deseja.

Da mesma maneira que o problema anterior, nas linhas iniciais são feitas as inclusões da biblioteca P.V.M. e algumas definições padrões, assim, as funções add_host e outras funções indispensáveis para a execução de qualquer programa P.V.M. são apresentadas. As demais linhas que são apresentadas em caracteres normais, são funções que efetuam a ordenação do vetor, sua partição, entre outras.

Como o problema proposto indicava que tanto a tarefa pai quanto as tarefas filhas devem enviar e receber mensagens, ambos os códigos apresentam as rotinas de envio e recebimento de mensagens.

O makefile gerado pvm_mpmd_3.make compila o programa gerado e é apresentado a seguir:

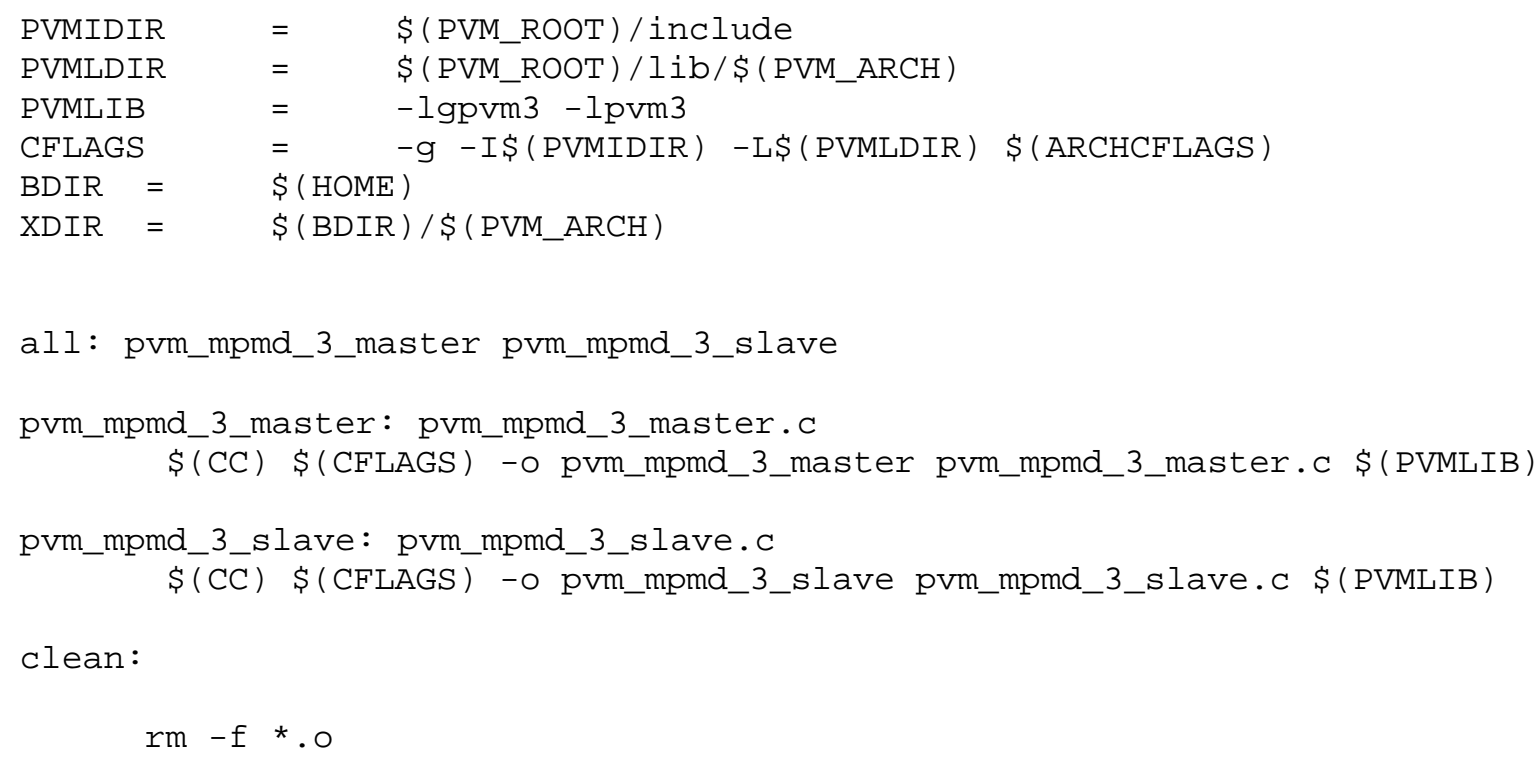

No contexto M.P.I.:

Basicamente, no caso do M.P.I. tem-se a mesma estrutura implementada para o P.V.M., alterando-se apenas o conteúdo do banco de dados e os templates.

No banco de dados tem-se as funções do ambiente paralelo virtual adotados e os templates das aplicações, que no caso do M.P.I. são diferentes das do M.P.I.. 
Trata-se portanto apenas de um trabalho de programação/digitação, onde toda a modelagem necessária já está desenvolvida e foi apresentada no Capítulo 5.

Uma futura implementação para a geração do código para M.P.I. deve seguir os seguintes passos:

- efetuar o cadastramento das funções M.P.I.;

- cadastro dos templates (campo memo) para M.P.I (apresentados no Capítulo $5)$;

- incluir no código fonte métodos que efetuem o tratamento da funções M.P.I..

Com isso o código final M.P.I. poderá ser gerado seguindo-se exatamente os mesmos passos descritos neste capítulo para uma aplicação P.V.M..

\subsection{Considerações Finais}

A utilização de ferramentas que auxiliam a construção de programas, sejam elas para programas seqüenciais ou paralelos, é de grande valia para os usuários desses ambientes, tendo em vista o auxílio não só na confecção de programas menos sujeitos a erros mas também na organização e estruturação desses programas, facilitando assim a manutenção.

Outra grande contribuição dessas ferramentas, é permitir que pessoas sem muito conhecimento de programação tenham oportunidade de utilizar, na prática, algumas linguagens e até ambientes, como é o caso da ferramenta desenvolvida. A utilização prática desperta o interesse das pessoas, pois existe uma interação maior entre homem/máquina, o que não acontece em uma interação homem/livro.

Os exemplos apresentados produzem resultados idênticos quando feita a comparação entre um programa gerado pela ferramenta e produzido por um usuário experiente, pois o que voga são as funções ou rotinas escritas pelos usuários para fazer o que realmente interessa.

Os testes da ferramenta foram feitos para P.V.M. primeiramente. A implementação do ambiente M.P.I. implica somente em trabalho de programação, pois sua modelagem está toda desenvolvida. Essa implementação segue o mesmo padrão do P.V.M., mudando somente as funções, pois agora a biblioteca a ser tratada é outra.

Sendo assim, a produção de arcabouços para ambientes paralelos virtuais torna-se uma solução interessante, permitindo sua difusão de forma mais rápida e fácil, e atingindo assim o objetivo proposto. mestrado.

O próximo capítulo apresenta as conclusões obtidas com a realização desta dissertação de 


\section{Conclusões}

Neste capítulo são apresentadas as conclusões deste trabalho. As contribuições principais e as dificuldades encontradas são discutidas, apresentando-se posteriormente sugestões para trabalhos futuros, que servirão como diretrizes para a continuidade do trabalho aqui iniciado.

\subsection{Considerações Iniciais}

Neste trabalho apresentou-se a extensão da F.A.P.P. para ambientes paralelos virtuais, ferramenta essa que permite a geração automática de arcabouços para esses ambientes. Sua implementação deu-se em ambiente gráfico com helps on-line permitindo maior facilidade de uso.

Discutindo-se os principais aspectos das duas áreas onde este trabalho está inserido, sistemas distribuídos e computação paralela, foram apresentados os motivos iniciais para o surgimento de ambas as áreas e a posterior convergência, permitindo assim, a utilização da "computação paralela distribuída". Isso leva ao interesse da utilização de ambientes paralelos virtuais, pois proporcionam a utilização de computadores pessoais na confecção de uma máquina paralela virtual.

A modelagem da ferramenta foi descrita detalhadamente, destacando-se quais aspectos e características da F.A.P.P. foram utilizados e quais as modificações introduzidas.

Por último, foram apresentados e discutidos exemplos gerados pela ferramenta, permitindo sua validação e principalmente permitindo que algumas questões interessantes possam ser levantadas.

\subsection{Conclusões}

Inúmeras ferramentas de auxílio à programação estão disponíveis na literatura, mas constituem na sua maioria, ferramentas que auxiliam o desenvolvimento de programas seqüenciais. Apenas uma minoria é constituída das que auxiliam o desenvolvimento de programas paralelos. As ferramentas para programas seqüenciais já alcançaram um grau de desenvolvimento que lhes confere um status estável em termos de erro e aceitação. Já as de 
auxílio ao desenvolvimento de programas paralelos são razoavelmente recentes e irão requerer algum tempo para serem consideradas estáveis, pois para o desenvolvimento desses programas faz-se necessária a interferência do usuário na identificação das unidades de paralelismo, na análise da dependência entre os procedimentos, em que nível deve-se dar a comunicação entre esses procedimentos, análise da dependência de dados, loops, entre outras.

O desenvolvimento da ferramenta objeto desta dissertação, dependeu de estudos profundos sobre os ambientes paralelos virtuais, bem como da F.A.P.P., pois foi necessário total conhecimento de ambos para identificar qual o caminho mais prático e ideal para que a implementação pudesse ser concluída com sucesso. $\mathrm{O} \mathrm{C}++$ Builder proporcionou o desenvolvimento gráfico da ferramenta e permitiu a inclusão de help on-line, evitando a constante busca a manuais (muitas vezes não disponíveis). Utilizando-se o banco de dados Paradox (incluído na versão 1.0 do C++ Builder) foi possível a manipulação confiável dos dados.

O C++ Builder e o Paradox mostraram-se adequados para o desenvolvimento da ferramenta, pois oferecem recursos para a geração de interfaces amigáveis e modernas (como botões de navegação, criação de auxílios em tempo de execução, entre outras). Apesar disso, algumas dificuldades foram encontradas e algumas vezes foi necessária a escolha de caminhos alternativos para se chegar ao objetivo desejado.

Observa-se também que nem sempre as soluções mais complicadas são necessariamente as melhores soluções e que muitas vezes as soluções simples, apesar de diversas vezes serem mais difíceis de serem enxergadas, não só solucionam um problema mas o torna prático, viável e operacional.

\subsection{Contribuições Deste Trabalho}

Este trabalho apresenta uma série de contribuições, destacando-se:

- permitir a geração automática de arcabouços para ambientes paralelos virtuais, possibilitando a definição das rotinas de comunicação entre as tarefas;

- permitir que um maior número de possíveis usuários tenha acesso à computação paralela, os quais não possuem conhecimentos profundos de ambientes paralelos virtuais;

- permitir fácil manutenção dos programas, tornando a ferramenta interessante também para os usuários que possuem bom nível de conhecimento de ambientes paralelos virtuais; 
- apresentar resultados práticos da utilização do P.V.M. e do M.P.I., o que torna interessante e atraente a utilização da ferramenta;

- servir como base para novas pesquisas no grupo de Programação Concorrente e Sistemas Distribuídos, dentre as quais o Balanceamento Dinâmico de Cargas em Plataformas Paralelas/Distribuídas utilizando para isso toda a modelagem para hardware existente na ferramenta;

\subsection{Dificuldades Encontradas}

Dentre as dificuldades relacionadas abaixo, o estudo e entendimento da F.A.P.P., foi sem dúvida a maior, pois possui uma enormidade em código fonte. Embora o código apresente uma boa estruturação, a grande falha é a falta de uma documentação mais completa sobre os detalhes de implementação (como, aparentemente, sempre ocorre). Como conseqüência da falta de documentação, levou-se mais tempo para assimilar a informação inserida nas listagens dos programas.

A seguir estão relacionadas algumas dificuldades que merecem ser destacadas:

- todas as informações estudadas necessitaram ser filtradas e adaptadas para o problema considerado;

- o nível de abstração no qual deveria ser desenvolvida a ferramenta, uma vez que a ferramenta é flexível e permite a utilização de vários recursos;

- a delimitação do contexto, ou das fronteiras de atuação.

\subsection{Trabalhos Futuros}

Considerando que esse projeto de mestrado produziu uma ferramenta para geração de arcabouços de programas para ambientes paralelos virtuais, várias melhorias podem ser feitas, tais como:

- inclusão de um módulo para efetuar balanceamento de carga de acordo com as especificações de hardware e de software feitas pelo usuário; 
- partindo-se das especificações dos ambientes, produzir uma linguagem intermediária que proporcione a transformação de um programa em M.P.I. para P.V.M. e vice-versa;

- integração de um módulo que permita a simulação da execução das tarefas descritas pelo usuário, produzindo resultados sobre desempenho e comunicação;

- complementar a modelagem desenvolvida para que possa ser embutida em um ambiente de transformação já consagrados na literatura, o que permite o reuso de código;

- adicionar o ambiente PVM-W95 [SOU96];

- medir a qualidade do software utilizando técnicas de Engenharia de Software.

\subsection{Considerações Finais}

Analisando-se os objetivos e a motivação inicialmente propostos para este trabalho, verifica-se que a extensão da F.A.P.P. apresentou bons resultados, atingindo seu objetivo, visto que:

- permite a criação de arcabouços de programas para ambientes paralelos virtuais, sem que o usuário detenha grandes conhecimentos de programação paralela;

- os inúmeros exemplos gerados e testados no Laboratório de Sistemas Distribuídos e Computação Paralela foram todos corretos; 


\section{Referências Bibliográficas}

[ALM94] ALMASI, G. S., Gottlieb A., Hight Parallel Computing, 2 $2^{\mathrm{a}}$ ed., The Benjamin Cummings Publishing Company, Inc., 1994.

[AND83] ANDREWS, G. R., Schineider, F. B., Concepts and Notations for Concurrent Programming, ACM Computing Survey, v. 15, n. 1, pp. 3-43, 1983.

[APR92] APPlied Parallel Research Plocerville, CA, Forge 90 distributed memory paralleliser: user's guide version 8.0 edition, 1992.

[AXF90] AXFORD, T., Concurrent Programming. Fundamental Techniques for Real-Time and Parallel Software Design, Wiley - Series in Parallel Computing, England, 1990.

[BEG94] BEGUELIN, A., Geist, A., Dongarra, J., Jiang, W., Manchek, R., Sunderam, V., PVM: Parallel Virtual Machine. A User's Guide and Tutorial for NetWork Parallel Computing, The MIT Press, s. 1, 1994.

[BLE94] BLECH, R. A., An overview of parallel processing, Slides, Parallel Computing with PVM Workshop, Nasa Lewis Research Center, http://www.lerc.nasa.gov/Other_Groups/IFMD/2620/tutorialPP.html, 1994.

[BOA79] BOAVENTURA NETTO, P. O., Teoria e Modelos de Grafos, Blücher, s. 1, 1979.

[BUT94] BUTLER, R. M., Lusk, E. L., Monitors, messages and clusters: The P4 parallel programming system, Parallel Computing, v. 20, pp.547-564, 1994.

[CAL94] CALKIN, R., Hempel, R., Hoppe, H. C., Wypior, P., Portable programming with the PARMACS messagepassing library, Parallel Computing, v. 20, p. 615-632, 1994.

[CAL97] CALÔNEGO JR., N., Uma Abordagem Orientada a Objetos de Uma Ferramenta de Auxílio a Programação Paralela, Tese (Doutorado), Instituto de Física e Química da Universidade de São Paulo (USP), Outubro, 1997.

[CAR94] CARMICHAEL, A., Advantages in Object Technology - Object Development Methos, SIGS Books, Inc., 1994.

[CAR95] CARRERA, E., Loques, O., P-Rio: Graphic and Modular Programming on PVM, II EuroPVM Users' Meeting, pp, 89-94, Luon-France, September, 1995.

[CAS98] CASTElO, L. H.; Do Prado, A. F. \& Lopes de Souza, W. Automatic Implementation of Mondel Specifications into Java, European Reuse Workshop'98 - Acessing the Benefits of Reuse, Madrid, Spain, 0406/11/1998, pp.21-23.

[CHA92] CHAPMAN, B. M., Mehrotra, P. and Zima H., Programming in Vienna FORTRAN, Scientific Programming, 1992, pp. 31-50. 
[CHA94] CHAPMAN, B. M., Mehrotra, P. and Zima H., Vienna Fortran Compilation System User Guide Version 1.0, Dep. of Statistics and Computer Science, University of Vienna, Australia, 1994.

[COL96] COLEMAN, D., Arnold, P., Bodoff, S., Dollin, C., Gilchrist, H., Hayes, F., Jeremaes, P., Desenvolvimento Orientado a Objetos: O Método Fusion, Rio de Janeiro, Editora Campus, 1996.

[COU94] COLOURIS, G., Dollimore, J., Kindberg, T., Distributed Systems Concepts and Design, $2^{\mathrm{a}}$ ed., AddisonWesley Publishing Company, s. 1, 1994.

[CRO95] CROSS, M., Ierotheou, C. S., Johnson, S. P., Automatic parallel code generation for message passing on distributed memory systems, Parallel Computing, v. 22 (1996), pp.227-257, Dezembro, 1995.

[DES87] DESROCHERS, G. R., Principles of Parallel and Multiprocessing, Intertext Publications, Inc., McGrawHill Book Company, New York, 1987.

[DON95] DONGARRA, J. J., et al, An introduction to the MPI standard, University of Tennessee Technical Report CS-95-274, http://www.netlib.org/utk/papers/intro-mpi/intro-mpi.html,1995.

[DOS96] DOSS, N., MPI Frequently Asked Questions, http://www.erc.msstate.edu/mpi/mpi-faq.html, 1996.

[DUN90] DUNCAN, R., A Survey of Parallel Computer Architectures, IEEE Computer, pp. 5-16, Fevereiro, 1990.

[FLY72] FLYNN, M. J., Some Computer Organizations and Their Effectiveness, IEEE Transactions on Computers, v. C, n. 21, pp. 948-960, 1972.

[FOS95] FOSTER, I., Designing and Building Parallel Program, Addison-Wesley Publishing Company, s. 1, 1995.

[GEH89] GEHANI, M., McGettrick, A. D., Concurrent Programming, AT\&T Bell Laboratories, Great Britain, 1989.

[GEI94] GEIST, A., Beguelin, A., Dongarra, J., Jiang, W., Manchek, R., Sunderam, V., PVM 3 User's Guide and Reference Manual, Oak National Laboratory, Setembro, 1994.

[GIL81] GILOI, W. K., A Complete Taxonomy of Computer Architecture Based on the Abstract, Proceedings of the IFIP: Workshop on Taxonomy in Computer Archtecture, pp. 19-38, Junho, 1992.

[GRO95] GROPP, W., Skjellum, A., Using MPI: Portable Paralle Programing with the Message Passing Interface, MIT Press, 1995.

[HAY82] HAYNES, L. S., Lau, R. S., Siewiorek, D. P., Mizell, D. W., A Survey of Highly Parallel Computing, IEEE, Janeiro, 1982.

[HOA78] HOARE, C.A.R., Communicating Sequential Processes, Comunications of The ACM, v. 21, n. 8, pp. 666$677,1978$.

[HOA85] HOARE, C. A. R., Communicating Sequential Processes, Prentice Hall, 1985.

[HWA84] HWANG, K., Briggs, F. A., Computer Archiecture and Parallel Processing, McGraw-Hill International Editions, 1984. 
[IER95] IEROTHEOU, C. S., Johnson, S. P., Cross, M, Leggett, P. F., Computer aided parallelisation tools (CAPTools) - conceptual overview and performance on the parallelisation of structured mesh codes, Parallel Computing, v. 22 (1996), Dezembro, 1995.

[INM90] INMOS Limited, Transputer Development System, 2a ed., Prentice Hall, U.K., 1990.

[JAC92] JACOBSON, I., Object-Oriented Software Engineering, Addison-Wesley, 1992.

[JOH96] JOHNSON, S. P., Cross, M., Everett, M. G., Automatic Parallel Code Generation for Message Passing on Distributed Memory Systems, v. 22, pp 227-258, 1996.

[KIR91] KIRNER, C., Arquitetura de Sistemas Avançados de Computação, Anais da Jornada EPUSP/IEEE em Sistemas de Computação de Alto Desempenho, pp. 307-353, 1991.

[MAC96] MACDONALD, N., et al, "Writing message-passing parallel programs with MPI", Course Notes, The University of Edinburgh, http://www.epcc.ed.ac.uk/epcc-tec/package.html, 1996.

[MAL74] MALKEVITCH, J., Meyer, W., Graphs, Models \& Finite Mathematics, 1a ed., Prentice Hall, 1974.

[MAR96] MARTIN, J., Odell, J. J., Análise e Projeto Orientados a Objetos, Makron Books do Brasil, $1^{\text {a }}$ ed., 1996.

[MAT93] MATRONE, A., Linda and PVM: A Comparison between Two Environments for Parallel Programming, Parallel Computing, v. 19, pp. 949-957, 1993.

[MCB94] MCBRYAN, O. A., Na Overview of Message Passing Environments, Parallel Computing, v. 20, pp. 417444, 1994.

[MUL93] MÜLlENDER, S. J., Distributed Systems, 2 ${ }^{\mathrm{a}}$ ed., ACM PRESS Frontier Series, Addison-Wesley Publishing Company, 1993.

[NAV89] NAVAUX, P. O. A., Introdução ao processamento paralelo, RBC - Revista Brasileira de Computação, v. 5, n. 2, pp. 31-43, Outubro, 1989.

[PAP95] PAPAS, C. H., Murray, Borland C++ 4.0, Makron Books do Brasil Ltda, São Paulo, 1995.

[PRE95] PRESSMAN, R. S., Engenharia de Software, $2^{\text {a }}$ Ed., Makron Books do Brasil Ltda, 1995.

[QUI87] QUINN, M. J., Designing Efficient Algorithms for Parallel Computers, McGraw Hill, New York, 1997.

[REI97] REISDORPH, K., Henderson, K., Teach Yourself Borland C++ Builder in 21 Days, Sams Publishing, United States of America, 1997.

[SNI96] SNIR, M., et al, MPI: The Complete Reference, The MIT Press, 1996.

[SNO92] SNOW, C. R., Cambridge Computer Science Text Concurrent Programming, Cambridge University Press, 1992. 
[SOU96] SOUZA, P. S. L., Máquina Paralela Virtual em Ambiente Windows, Dissertação de Mestrado, Instituto de Ciências Matemáticas de São Carlos (ICMSC), Universidade de São Paulo (USP), Maio, 1996.

[SUN94] SUNDERAM, V. S., Geist, A., Dongarra, J., Manchek, R., The PVM concurrent computing system: evolution, experiences and trends, Parallel Computing, v. 20, pp. 531-545, 1994.

[TAN85] TANENBAUM, A. S., van Renesse, R., Distributed Operating Systems, ACM Computing Surveys, v. 17, n. 4, Dezembro, 1985.

[TAN88] TANENBAUM, A. S., Computer Networks, 2a ed., Prentice Hall International Inc., 1988.

[TAN92] TANENBAUM, A. M., Modern Operating Systems, 2a ed., Prentice Hall International Inc, 1992.

[TEL97] TELLES, M., Hight Performance Botland C++ Builder, Coriolis Group Books, United States of America, 1997.

[TOW89] TOWNER, L. E., Ranede J., Case - Concepts and Implementation, IBM Series, McGraw-Hill Book Company, Intertext Publication, New Uork, 1989.

[WAL94] WALKER, D. W., The design of a standard message passing interface for distributed memory concurrent computers, Parallel Computing, v. 20, pp 657-673, 1994.

[ZAL91] ZALUSKA, E. J., Research lines in distributed computing systems and concurrent computation, Anais dos Workshop em Programação Concorrente, Sistemas Distribuídos e Engenharia de Software, pp. 132-155, 1991.

[ZHO93] ZHOU, S., Zheng, X., Wang, J., Delisle, P., Utopia: a Load Sharing Facility for Large, Heterogeneous Distributed Computer, Software-Practice and Experience, v. 23 (12), pp 1305-1336, 1993.

[ZIM92] ZIMA, H. P., Chapman, B. M., Software Tools for Parallel Program Development, Programming Environment for High Level Scientific Problem Solving, Elsevier Science Publishers, IFIP, 1992. 